\title{
OECD Public Governance Policy Papers No. 05
}

\section{Building resilience: New}

strategies for strengthening infrastructure resilience and OECD maintenance 


\section{Building Resilience}

New Strategies for Strengthening Infrastructure Resilience and Maintenance 


\section{Foreword}

Following the COVID-19 shock to economies and societies, many countries are including renewed infrastructure investment as a stimulus measure. Such investments present an opportunity for governments to address short-term infrastructure challenges through maintenance spending while building resilient and sustainable infrastructure for the future.

Tackling the complex challenges and opportunities related to infrastructure resilience and maintenance requires a multidimensional approach, considering a range of factors and stakeholders at the local, regional, national and global level. This approach seeks to get the best out of the asset over its life-cycle , across functions and tasks and the entire infrastructure system/network. As infrastructure is inevitably affected by environmental social and governance (ESG) risks, this approach can identify the trade-offs among objectives, and therefore enable more robust policy choices.

Drawing on examples and case studies, this report provides a framework for optimising existing infrastructure assets and building new resilient infrastructure, including new strategies for ensuring quality and performance over the asset's life-cycle.

The COVID-19 crisis has demonstrated the importance of infrastructure for supply chain resilience, logistics and delivery of essential goods and services. It has underlined the need for countries to make their infrastructure more resilient to future disasters and pandemics, to ensure the continued operation of critical networks such as utilities, transport and telecommunications. Infrastructure resilience plans should include an assessment of infrastructure essential for the functioning of economies and societies, as well as of how infrastructure systems are interlinked and how they contribute to resilient communities and economies.

Beyond ensuring operational resilience, economic stimulus spending -- whether directed to investments in new infrastructure or to the upgrading of existing stock -- should target sustainability and resilience objectives related to the Paris Agreement, the Sustainable Development Goals, and the Sendai Framework, while meeting the G20 Principles for Quality Infrastructure. Given the volume of existing infrastructure assets, maintenance should be an urgent priority for many OECD and G20 countries.

Green infrastructure development ensures that infrastructure itself does not undermine environmental sustainability goals, whilst protecting infrastructure assets and services against environmental impacts and climate change. Climate change adaptation, through, for example, nature-based solutions, can help countries develop infrastructure that is resilient to the risks of rising seas or climate extreme events such as storms or floods or extreme temperatures.

New technologies can help reduce maintenance costs whilst improving operational efficiency and offer alternatives to traditional infrastructure design, construction and maintenance. Technology development has been pivotal in responding to the COVID-19 crisis, enabling infrastructure to become more resilient to future disasters and pandemics. It has allowed continued operations of critical networks such as utilities, transport and telecommunications despite the large-scale disruptions and rapidly changing needs caused by the crisis. 
Through its multidimensional framework, this report supports the development of the G20 Policy Agenda on Infrastructure Maintenance presented by the Italian presidency at the G20 Ministries of Finance and Central Banks meeting in July 2021. 


\section{Acknowledgements}

This report was prepared under the auspices of the OECD Public Governance Directorate (GOV) and the OECD Directorate for Financial and Enterprise Affairs (DAF) with contributions from the OECD Environment Directorate (ENV) and the OECD Centre for Entrepreneurship, SMEs, Regions and Cities (CFE). André Laboul OECD co-ordinator on infrastructure and special advisor to G20 sherpa and G20 deputy finance ministers, facilitated OECD inputs to the G20.

This report was co-ordinated and written by Raffaele Della Croce, Senior Economist at the OECD under the guidance of Edwin Lau, Head of the OECD Infrastructure and Public Procurement Division. Luisa Mimmi and Lawrence Bartolomucci from the Italian Ministry of Finance ensured feedback throughout the development of the report.

Major inputs and comments were provided by Catherine Gamper, Michael Mullan, Jack Radish, Ana Maria Rivadeneira, Lorena Cruz Serrano, Charles Baubion, Francesco Peruzzi, Edwin Lau, Dorothee AllainDupré, Wu Yingyin, Rudiger Ahrend, Anna Pietikainen, Alexis Durand, Miguel Amaral, Barbara Ubaldi, Felipe Gonzalez-Zapata, Mauricio Mejia Galvan, Marco Daglio, Arturo Rivera Perez, Michael Jelenic, David Goessmann, Piret Tonurist, Yumika Yamada, Tim Bishop, Joel Paula and Mamiko Yokoi-Arai. Lauren Thwaites and Elisabetta Pilati prepared the report for publication and dissemination.

This report leverages G20 work undertaken by the Infrastructure Working Group (IWG). This includes initiatives such as the Roadmap to Infrastructure as an Asset Class ("Roadmap") the G20 Principles for Quality Infrastructure Investment ("QII") and the technology-enabled infrastructure (InfraTech) Agenda. The report also benefited from discussions held at the G20 Infrastructure Working Group on $6^{\text {th }}$ of February 2021 under the Italian presidency.

This work draws on several OECD policy research and tools. This includes: the OECD Recommendation on the Governance of Infrastructure, the OECD Recommendation on the Governance of Critical Risks; the OECD work on Climate Resilient Infrastructure and OECD Recommendation on Effective Public Investment Across Levels of Government.

Comments on draft versions of this publication were received from the G20 Infrastructure Working Group, the G20/OECD Task Force on Long-Term Investment, the OECD Senior Infrastructure and PPP Officials Network and the OECD Leading Practitioners of Public Procurement Working Party, under the OECD Public Governance Committee. Comments were received also from the Think Tank 20 Infrastructure and Financing working group supporting the G20 Italian presidency.

The report also builds on the OECD Implementation Handbook on Quality Infrastructure, OECD Compendium of Policy Good Practices for Quality Infrastructure Investment and the OECD Note on COVID-19 and a New Resilient Infrastructure Landscape and the G20/OECD Report on the Collaboration with Institutional Investors and Asset Managers on Infrastructure. 


\section{Table of contents}

Foreword 2

$\begin{array}{ll}\text { Acknowledgements } & 4\end{array}$

Executive summary

New Strategies for Strengthening Infrastructure Resilience and Maintenance 10

1 The context: COVID-19 calls for a new resilient infrastructure landscape 13

Introduction - The urgency of resilient infrastructure 14

1.1. Sustainable and Resilient Infrastructure 15

1.2. Optimising existing infrastructure assets and building infrastructure resilience 16

1.3. Emerging opportunities for resilient infrastructure and maintenance 18

$\begin{array}{ll}\text { 1.4. Major challenges and proposed framework } & 21\end{array}$

References $\quad 25$

2 Infrastructure resilience \& maintenance require an appropriate regulatory and institutional framework 28 Introduction 29

2.1. A systemic approach to resilient and sustainable infrastructure 29

2.2. Ensuring infrastructure performance and resilience over the asset life-cycle 32

2.3. The role of regulation for asset performance and resilience 35

References 38

3 Innovation in maintenance and asset management strategies of existing infrastructure 41

Introduction 42

3.1. Monitoring and evaluation of public investments throughout the delivery, operation and decommissioning 42

3.2. Maximising asset utilisation in operations and maintenance $\quad 44$

3.3. Leveraging Infratech for better asset maintenance 46

3.4. Nature based solutions to strengthen infrastructure resilience 50

3.5. Promoting public sector take-up of Infra-tech and Nature-based solutions 51

References $\quad 54$

4 Building capabilities for resilience and maintenance in strategy and planning $\quad 58$

Introduction 59

4.1. Long-term planning: mainstreaming resiliency and maintenance in infrastructure $\quad 60$

4.2. Integrating resilience \& maintenance at the project level 63 
4.3. Supporting policy makers under uncertainty 65

4.4. Building smart-intelligent infrastructure for resilience and maintenance $\quad 67$

4.5. Engaging citizens and stakeholders for better planning: inclusiveness, public participation, transparency

5 Ensuring funding and financing for maintenance and resilient infrastructure $\quad 74$ Introduction 75

5.1. Maintenance funding and incentives for optimal operations and management 75

5.2. Budgetary treatment of infrastructure spending 78

5.3. Delivery models and life-cycle approach for the private sector 80

5.4. ESG risk disclosure for institutional investor's investment in resilient infrastructure $\quad 81$

5.5. Leveraging capital markets and private sector resources 82

References 83

\section{FIGURES}

$\begin{array}{lr}\text { Figure 1.1. Infratech } & 18\end{array}$

Figure 1.2. Digital Maturity by Industry $\quad 19$

Figure 2.1. Tailing Dams and Climate Change $\quad 31$

Figure 2.2. Components of a fiscal risks management framework $\quad 33$

Figure 3.1. Maintenance policies $\quad 48$

Figure 4.1. Costs generally estimated to assess affordability of new infrastructure projects, 202062

Figure 4.2. Mechanisms to help identify proposals offering the best value for money, $2020 \quad 64$

Figure 4.3. Building Intelligent Infrastructure for Resiliency and Maintenance 67

Figure 5.1. Dimensions of Infrastructure Financing $\quad 80$ 


\section{Executive summary}

\section{The context: COVID-19 calls for a new resilient infrastructure landscape}

As seen during the COVID-19 pandemic, natural hazards and extreme weather events, infrastructure systems such as health, power, water and sanitation, transport, and telecommunications are particularly vulnerable to being damaged or disrupted. This is because they are often organised in complex networks through which even small local shocks can propagate quickly (OECD 2019). Vulnerabilities are amplified by chronic infrastructure challenges such as ageing, poor maintenance and rehabilitation, resulting in inadequate service provisions and cascading effects worsening the impacts of external shocks.

A new holistic and systemic approach to asset management is needed to optimise existing infrastructure assets and make them more resilient. In the current context of constrained finance, ageing facilities and rising demand, countries are looking for strategies to maximise returns on infrastructure investments. A life-cycle approach to infrastructure investment takes into account the potential costs of operation and maintenance from the very inception of the project, notably looking at the cost of new projects, value for money (VfM) assessments and affordability estimates. Indeed, upgrading existing infrastructure assets also provides a solution for existing asset stock making it more effective, longer-lasting and better value for money.

Effective asset management and maintenance are critical for ensuring that assets can withstand external shocks. Enhanced monitoring or modifying operational routines can reduce the risk of failure due to changing environmental and climatic conditions, or other factors undermining infrastructure functioning (e.g. digital threats). Portfolio management techniques can help governments understand and better manage risks. Beyond financial risk management, looking at the overall infrastructure asset portfolio through a government balance sheet approach ensures value for money (i.e. optimisation of return). Over the lifetime of infrastructure assets, the benefits of resilient investments are generally considered higher than the cost of inaction.

\section{Institutional and regulatory framework for infrastructure resilience and maintenance}

Infrastructure projects involve many policy areas, several layers of legislation and regulation, and different levels of government. Subnational governments - state, regional and local - are responsible for 57 percent of public investment in the OECD and 37 percent worldwide (OECD, 2018; OECD/UCLG, 2019), and they have key responsibilities for infrastructure maintenance and resilience at a local level. Establishing clear inter-governmental co-ordination mechanisms and building capacity within subnational institutions are essential for infrastructure resilience. Taking a coherent multi-sectoral approach to risk-related regulations can facilitate compliance and develop the right skills among different levels of public administration.

Economic regulators set tariffs and ensure access to both public and private infrastructure in a number of industries such as water, electricity and gas, telecommunications and transport. Where economic 
regulators are involved in infrastructure industries, they have an ongoing relationship with the operators of regulated infrastructure throughout the infrastructure's life-cycle - from the identification of infrastructure needs, through construction and maintenance to its eventual decommissioning. In addition regulations can prescribe detailed technical regulations and standards or specify contractual outcomes for quality infrastructure and resilience.

Regulation is one of the most effective means for governments direct infrastructure stakeholders to increase infrastructure life-span and optimise costs, assess risk exposure and build resilience. Coherent, efficient and predictable regulatory frameworks incentivise investment in public infrastructure, and ensure the delivery of ongoing improvements in infrastructure performance. Many economic regulators operate as independent bodies within the regulatory framework and can provide technical input to decision-making. Regulations on risk assessment, land use, or infrastructure and operational resilience are indispensable for infrastructure stakeholders to assess the quality of infrastructure, risk exposure and building resilience.

\section{Innovation in maintenance and asset management strategies of existing infrastructure}

To meet increasing demand, rather than expanding capacity through new infrastructure, governments can maximise asset use and quality for users through demand management techniques and "smart infrastructure". Monitoring the whole-of-life performance of an asset is also crucial to optimise life-cycle costs and ensure asset quality. Monitoring asset performance during the operation phase measures the asset's condition, use and functionality, and can help inform operators on maintenance requirements for effective, safe and accessible public services. Without a clear view of the age profile and quality of the asset base, a country is unable to budget appropriately for maintenance funding.

New technologies and data science encompassing earth observation, remote sensing, big data, Internet of things (loT), cloud technologies and machine learning are transforming how infrastructure is operated and maintained. Automation and smartphones reduce maintenance costs, offering alternatives to traditional infrastructure design, construction and maintenance, such as building information modelling and 3D printing, while predictive maintenance can extend the life of the asset while ensuring efficient budget allocation. Information technology systems such as digital twins, used in conjunction with blockchain technology, can facilitate data gathering and analysis, reducing costs and potential fraud. In addition, technology development plays a critical role in responding to the COVID-19 crisis, helping make infrastructure more resilient to future disasters and pandemics by ensuring the continued operations of critical networks such as utilities, transport and telecommunications.

Nature-based solutions (NbS) offer innovative, cost-effective opportunities for supporting infrastructure sustainability and resilience. The concept of $\mathrm{NbS}$ is based on the understanding that natural and managed ecosystems produce a diverse range of benefits on which sustainable infrastructure and resilience depend. $\mathrm{NbS}$ can protect infrastructure assets and services from harmful environmental impacts (including those related to climate change), but also help reduce infrastructures' negative impacts on the environment. NbS interventions range from minimal to significant changes to ecosystem services. Minimal measures can protect or conserve ecosystem functions (e.g. forest maintenance measures), whereas significant measures can include the restoration of entire ecosystems (e.g. planting mangrove forests). NbS can also be integrated with infrastructure design and maintenance as a complementary measure, such as the creation of permeable surfaces to reduce direct losses and damages from flooding, or to reduce the impacts of extreme heat. NbS can increase the effectiveness and operable life of grey infrastructure. 


\section{Building capabilities for resilience and maintenance in planning and strategy}

Existing decision-making frameworks are not always well adapted to accommodating a diverse (and at times competing) set of objectives. For example, operations and maintenance needs might end up being neglected if political incentives are skewed towards displaying tangible results to a certain section of society. This can result in inefficient investments that fail to respond adequately to the needs of the population.

At a macro level, developing a long-term strategic vision for infrastructure helps governments identify and address infrastructure service needs in a timely and coherent manner. The full cost of the infrastructure asset's life-cycle (including maintenance and upgrade costs) should be taken into account during the budgeting, project appraisal and selection processes, ensuring that the projects that are ultimately selected encompass these costs and benefits. At a micro level, resilience and maintenance criteria need to be taken into account for project design, budgeting, selection and prioritisation, including downstream costs. Climate resilience needs to be integrated into the design pipeline of projects to ensure that they are consistent with national plans and future climate change scenarios.

Ensuring that infrastructure systems can cope with highly uncertain future operating conditions requires a dynamic approach to infrastructure planning and decision-making that can accommodate uncertainty This allows for both a greater degree of flexibility, and adjustments over time to reflect changing conditions or new information. Intelligent monitoring and modelling technologies - new processes and analytics - can improve investment planning and extend asset life. Public participation and digitalisation allow decision makers to proactively inform, consult and engage with stakeholders at all stages of the policy-making cycle.

\section{Ensuring funding and mobilising investment}

Given current constraints and future stimulus impact on public budgets, alternative and diversified funding sources are needed with budgetary treatment playing a key role in planning and securing stable funding for infrastructure. Public interventions should also focus on creating incentive schemes to better mobilise private financing. Different delivery models (feed-in-tariffs, premium tariffs, quotas, tenders) and quality of support schemes define the role of the private sector in providing maintenance and operations services. The public sector needs to put more emphasis on a life-cycle approach in order to attract long-term backing such as institutional investors with an interest in maintaining the value of their assets over time. Ultimately this will drive down the overall costs of projects, including operations, maintenance and eventual replacement, building up appropriate capital reserves.

Delivering systemic change for sustainable and resilient infrastructure requires gaining community support and the social licence to operate infrastructure assets. A new narrative on infrastructure investment has to reconcile the nature of infrastructure as a service with the development of infrastructure as an asset class, including relevant information for infrastructure investors on the sustainability and resilience of assets in terms of the long-term horizon and of environmental, social and governance (ESG) impacts. To reflect this narrative, alternative models and products need to be developed involving all stakeholders through new forms of collaboration between private, public sectors and communities. The financial sector, by applying long-term thinking, has the potential to be a driver of change for the future. 


\section{New Strategies for Strengthening Infrastructure Resilience and Maintenance}

Economic recovery packages in the aftermath of the COVID-19 pandemic represent a once-in-ageneration opportunity to build more resilient and sustainable infrastructure. To capture this opportunity, governments need to urgently address four bottlenecks to ensure that today's investments meet the challenges of tomorrow: 1) governance approaches that fail to take into account costs and risks over the whole life of infrastructure investments; 2) poor take-up of innovative solutions for building resilience; 3 ) insufficient information and capacity to plan and make decisions; and 4) funding for infrastructure maintenance that is both insufficient and insufficiently targeted.

\section{Institutional and regulatory framework for infrastructure resilience and}

\section{maintenance}

- Governments can better ensure value for money over the life-cycle of an asset, improve resilience and limit fiscal risks by adopting an integrated set of responsibilities and functions designed to identify, report and take action on infrastructure risks and challenges.

- Coherent, efficient and predictable regulatory frameworks incentivise investment in public infrastructure and ensure the delivery of ongoing improvements in infrastructure performance.

- Economic regulators can give confidence to the market in regulated sectors such as water or energy and contribute to resilient and quality infrastructure. Life-cycle costs and asset quality can be optimised through sustainable tariff settings, supporting market efficiency, quality, reliability and affordability of services.

- Asset and maintenance standards allow to hold contractors accountable for project and professional specifications - including resilience aspect- and can be embedded in contractual provisions improving maintenance delivery. Standards should be updated regularly to adapt to a changing climate and environment.

\section{Scaling-up innovations in infrastructure maintenance and asset management}

- Governments should ensure appropriate monitoring during the operational phase including regular observation and recording of the performance data of an asset. An asset's value and depreciation should be reviewed regularly during operations, while managing the end of infrastructure contracts through audit and ex post value for money evaluations.

- Beyond expanding infrastructure capacity, governments can also meet increasing demand by maximising asset utilisation and by adopting innovative solutions to enhance quality and resilience. But scaling up to achieve benefits will require building digital maturity, strengthening the agility of regulatory approaches, and modernising decision-making and performance processes within government.

- Automation, sensors and user feedback tools, e.g. smartphones and smart infrastructure, can improve feedback and provide cheaper, more real-time monitoring, extending the life of the asset by improving targeted maintenance and demand management. This requires a move from one-size-fits all approaches such as scheduled maintenance to intervention strategies based on risk and data management.

- Once collected, infrastructure data can feed data-driven solutions, such as digital twins and predictive maintenance, to better model maintenance needs and risks and to provide a more 
holistic approach through the infrastructure life-cycle. This supports an efficient allocation of the available budget, but requires standardised data and agile regulatory and budgetary decision-making.

- Less invasive maintenance interventions and new materials support resilience and sustainability, but require testing and evaluation to inform new standards and regulations.

- Nature-based solutions ( $\mathrm{NbS}$ ) are an innovative way to build resilience, but require strategic government leadership to co-ordinate and engage stakeholders.

\section{Building capabilities for resilience and maintenance in planning and strategy}

- Multiple stakeholders and long lifespan require integrated and dynamic infrastructure governance to cope with highly uncertain future operating conditions:

- At a macro level, a long-term strategic vision for infrastructure, serves to ensure policy coordination and aligns incentives for investment in maintenance and resilient infrastructure.

- At a micro level, project design, selection and prioritisation should integrate resilience criteria, including the costs of maintaining and upgrading/adapting infrastructure across its life-cycle.

- Public budgets form the intersection of these two levels, prioritising capital investments, and linking them with downstream operations and maintenance (O\&M) costs. The full cost of the infrastructure asset's life-cycle (including maintenance and upgrade costs) should be taken into account by countries during the budgeting, project appraisal and selection processes, ensuring that the projects that are ultimately selected take into account these costs and benefits. Countries should develop an integrated national infrastructure plan, prioritising all projects according to the highest cost-benefit ratio based on economic, environmental and social factors. Such a framework should cover all aspects of a sound asset management system, ranging from asset management policy and strategy to key enablers and opportunities such as natural based solutions and technological innovations.

- Existing multi-stakeholder processes such as national climate adaptation planning and critical infrastructure programmes can help identify entry points for mainstreaming and promote crosssectoral co-ordination for maintenance and infrastructure.

- Regulatory frameworks, and decision-making and accountability processes requires a dynamic approach to infrastructure planning and decision-making, with a focus on data, outcomes, asset quality, real-time monitoring and risk management, in order to benefit from new ICT tools and innovations such as digital platforms.

- Utilising futures and foresight methods, anticipatory innovation aims to build a concrete value chain from imagining future scenarios to concrete innovation pathways.

- Stakeholder engagement enables governments to understand community needs and to communicate how infrastructure improvements benefit users both in terms of immediate infrastructure services as well as long-term value to tax-payers.

\section{Ensuring funding and mobilising investment to maximise services to the Community}

- Framing infrastructure as a service to communities, rather than simply as an investment, helps to maintain focus on quality and resilience over the life of an asset and the appropriate funding and delivery options that follow suite: 
- The choice of funding models for operations and maintenance (O\&M), e.g. maintenance funds versus annual appropriations, affects governments' ability to maintain asset value over its life-cycle.

- Public sector funding is particularly crucial in accelerating action in difficult to reach areas like adaptation and resilience.

- The choice of delivery models, e.g. feed-in-tariffs, premium tariffs, quotas, tenders, and quality of support schemes should take into account the related incentives for the private sector to provide maintenance and operations services (PPPs, asset recycling, risk allocation).

- Budgetary and contractual arrangements for infrastructure investment and maintenance should focus on creating incentives to attract alternative and diversified funding sources to secure stable funding for infrastructure.

- Incorporating a life-cycle approach will help attract long-term investors such as institutional investors with an interest in maintaining the value of their assets over time, driving down the overall costs of projects and building up appropriate capital reserves.

- New forms of collaboration between the private sector, national and subnational governments and communities have the potential to be a driver of change for the future, e.g. drawing on long-term asset management experience from the financial sector.

- Resilience \& maintenance considerations should be integrated into current recovery packages as resilience and maintenance measures will have an immediate stimulus impact and investments will set the priorities and direction for additional investment in more green and sustainable infrastructure. 


\title{
The context: COVID-19 calls for a new resilient infrastructure landscape
}

\begin{abstract}
Economic recovery packages in the aftermath of the COVID-19 pandemic represent a once-in-a-generation opportunity to build more resilient and sustainable infrastructure. To capture this opportunity, governments need to urgently address current bottlenecks to ensure that today's investments meet the challenges of tomorrow.

This chapter introduces a new holistic and systemic approach to asset management needed to optimise existing infrastructure assets and make them more resilient. This approach is seeking to get the best out of the asset over its life-cycle, across functions and tasks and the entire infrastructure system/network. As infrastructure will be affected by environment social and governance (ESG) risks, this approach allows for the identification of the trade-offs between objectives, and the enabling of more robust policy choices.
\end{abstract}




\section{Introduction - The urgency of resilient infrastructure}

Recent events have highlighted the strains on and fragility of our infrastructure. As seen in the COVID-19 pandemic crisis, natural hazards and extreme weather events, infrastructure systems such as health, power, water and sanitation, transport, and telecommunications are particularly vulnerable, as they are often organised in networks through which even small local shocks can propagate quickly (OECD 2019a). Disruptions to infrastructure amplify chronic infrastructure challenges such as underfunding, poor maintenance and mismanagement, resulting in poor water quality and sanitation systems, faulty transport networks and unreliable electricity grids.

As governments reconsider their priorities and infrastructure needs, they face new major challenges (OECD 2021c and d). Infrastructure investment is subject to increasing levels of complexity as it is being called upon to meet multiple objectives and deliver multiple benefits in the short and long-term, in a context of increasing interconnectedness and interdependence of infrastructure systems across geographies, sectors and levels of government. Climate change poses a number of threats to economic development, with rising sea levels and increased risk of drought in some areas, in connection with extreme wildfires, shifting rainfall patterns and greater prevalence of temperature extremes (IPPC 2021) ${ }^{1}$.

Ultimately COVID-19 has added to the deep uncertainty over which infrastructure investment must take place, resulting from uncertainty in projecting the future impacts of climate change and broader environmentally harmful impacts of socio-economic expansion, resulting in biodiversity loss, ecosystem degradation - including reaching tipping points beyond which it is difficult to predict ecosystem responses, accelerating technological change, and demographic changes.

A new holistic and comprehensive approach to asset management is needed to optimise existing infrastructure assets and make them more resilient building back better. Current decisions on infrastructure part of recovery packages will determine countries' capacity to reach their climate objectives for the near (2030) and long term (2050 and beyond) OECD (2021d forthcoming) ${ }^{2}$.

\footnotetext{
${ }^{1}$ Many changes in the climate system become larger in direct relation to increasing global warming. For example, every additional $0.5^{\circ} \mathrm{C}$ of global warming causes clearly discernible increases in the intensity and frequency of hot extremes, including heatwaves (very likely), and heavy precipitation (high confidence) IPPC (2021)

2 Recent OECD work prepared for the G20 Italian presidency has been looking at design of green recovery packages, establishing effective evaluation frameworks and monitoring, aligning recovery packages with climate objectives, and strengthening innovation and R\&D. See OECD (2021d forthcoming) "Aligning short-term recovery measures with longer-term climate and environmental objectives", prepared at the request of Italy for the G20 meetings of the Energy Transition Working Group and Climate Sustainability Working Group under the 2021 Italian Presidency.
} 


\subsection{Sustainable and Resilient Infrastructure}

The purpose of infrastructure is to provide a service to the society. The OECD defines infrastructure as the system of public works in a country, state or region, including roads, utility lines and public building - in essence the tangible backbone of essential goods and services underpinning an economy.

Investment in sustainable and quality infrastructure, implemented through appropriate delivery mechanisms, and managed efficiently over the life-cycle , contributes to economic development, and enables the achievement of environmental, social and governance (ESG) objectives and the Sustainable Development Goals (SDGs). SDGs related to resilient and sustainable infrastructure focus on promoting sustainable industrialisation and foster innovation empowering communities and inclusiveness ${ }^{3}$.

Sustainable infrastructure includes built or natural systems that provide a range of services in a manner that ensures economic, financial, social, environmental, and institutional sustainability both in line with the Sustainable Development Goals and over the entire infrastructure lifecycle - from strategic planning to decommissioning \& repurposing. Among infrastructure resources and services can be included energy, water, transportation, communications and flood protection.

Resilience is a key part of sustainable and quality infrastructure. It applies to both "normal" usage of the infrastructure facilities which need to be resilient to time, usage, obsolescence, environmental impacts (including slow onset impacts related to climate change), etc., as well as "abnormal" pressures such as those stemming from natural hazards (e.g., earthquakes, tsunami, floods, storms etc., some of which may be exacerbated by climate change impacts) or large health crisis (e.g., epidemics or pandemics), as well as other human-induced threats such as terrorism, industrial accidents, etc. The system-wide impacts caused by COVID-19 and the key role played by infrastructure in sustaining economic and social activity have heightened the need to consider infrastructure resilience at a broader level.

Transformative Resilience. The OECD defines resilience as "the capacity of systems to absorb a disturbance, recover from disruptions and adapt to changing conditions while retaining essentially the same function as prior to the disruptive shock" (OECD, 2019a). Beyond simple adaptation, the COVID-19 emergency offers an opportunity for transformative resilience (Giovannini, Benzcur \& others 2020) and planning antifragile systems (Taleb N. 2012 and .Blečić I., Cecchini A. 2019)

Infrastructure cannot be resilient if it is poorly maintained. Developed under the Japanese G20 Presidency, the G20 Principles for Quality Infrastructure Investments highlight the importance of 'raising economic efficiency in view of life-cycle cost'. Delivering infrastructure that is efficient on a life-cycle basis, includes effective operation, monitoring and maintenance, essential for ensuring that economic efficiency is maintained during the operational phase of projects. Inadequate maintenance, in particular, can result in a rapid deterioration of asset quality, require costly rehabilitation, and interruption of essential services. In particular, repair and maintenance of existing assets are important in developing countries that face severe financing constraints for building new assets, coupled with capacity and technological challenges

\footnotetext{
3 SDG Goal 9 is: to "Build resilient infrastructure to promote sustainable industrialisation and foster innovation". Investment in transport, irrigation, energy, communications, and water and sanitation infrastructure is essential to empower communities in developing and developed countries. Resilient infrastructure links with Goal 11: Making cities and human settlements inclusive, safe, resilient and sustainable. Climate-resilient infrastructure can also support efforts to achieve the Sendai Framework for Disaster Risk Reduction. The importance of resilience is also emphasised by relevant OECD guidance in this area, including the OECD Recommendation on the Governance of Critical Risks (OECD, 2014), and the OECD Framework on the Governance of Infrastructure (OECD, 2017).
} 
for carrying out maintenance. Effective maintenance is all the more important for reducing downtime and extending the lifetime of assets ${ }^{4}$.

\subsection{Optimising existing infrastructure assets and building infrastructure resilience}

Progress in delivering infrastructure has been relatively slow, despite the high priority for economies and societies and international and regional initiatives currently undertaken (G20, 2020, Serebrisky et al., 2015). Ensuring affordable and reliable access to basic services remains a major challenge in lower and middle-income countries, while advanced economies are struggling with underinvestment in their ageing infrastructure (OECD 2017).

Under-investment in infrastructure has been chronic in advanced economies over the past decades resulting in an ageing and poorly maintained infrastructure stock. In advanced G20 economies, public investment fell from 5 percent of GDP in the late 1960s to 3 percent in the mid-2000s (OECD 2017). In the United States, for instance, the National Association of Manufacturers rates transport-related land-based infrastructure as mediocre to poor, with US bridges on average 42 years old, and 1 in 9 structurally deficient. The American Society of Civil Engineers (2017) estimates cumulative spending needs of more than USD 10 tn through to 2040 to maintain, repair, or rebuild existing infrastructure.

In developing countries, infrastructure needs are driven by the growing population, economic growth, urbanisation and industrialisation. Recent estimates shows that the emerging markets will invest an average of USD $2.2 \mathrm{tn}$, or 3.9 percent of GDP, annually in infrastructure to 2040, close to double the aggregate spend in advanced markets over the same period (Swiss Re 2020). The World Bank report, Beyond the Gap, finds that with the right policies, investments of 4.5 percent of GDP will enable LMICs to achieve the infrastructure-related SDGs and stay on track to limit climate change to $2^{\circ} \mathrm{C}$.

As infrastructure needs far exceed the resources available to countries, policy intervention should focus on spending current resources better, increasing the efficiency of capital spending. Improving infrastructure governance to produce better outcomes from existing assets is among the critical ways to close the global infrastructure gap (OECD 2017). Although figures are difficult to calculate, it is clear that the public sector dominates infrastructure spending, according to the World Bank, accounting for 87-91 percent of infrastructure investments- albeit with wide variation across regions (World Bank 2020).

\subsubsection{Asset Management life-cycle and portfolio approach to infrastructure investment}

In the current context of constrained finance, ageing facilities and rising demand, optimising existing infrastructure assets allows to upgrade the existing asset stock making it more effective, cheaper and longer-lasting. A life-cycle approach to infrastructure investment takes into account the potential costs of operation and maintenance from the very inception of the project, notably looking at the cost of new projects' value for money (VfM) assessments and affordability estimates which should include life-cycle costs (OECD 2021c)An asset management life-cycle approach is key to the development and use of public assets, optimising balance sheets to maximise returns, managing risks better and ensuring that assets can withstand disruptions.

Portfolio management techniques can help governments understand and better manage risks. Given that governments undertake multiple infrastructure investments at any one time, in aggregate the activity

\footnotetext{
4 The OECD Compendium of Policy Good Practices for Quality Infrastructure Investment (2020) offers comprehensive policy guidance for policymakers and practitioners in both developed and developing countries on how best to ensure quality infrastructure investment at every stage of a project. The Implementation Handbook complements the Compendium by providing forward-looking solutions, accompanied by concrete examples and case studies.
} 
represents an investment portfolio that can be assessed and managed based on a range of criteria, including implementation risk. New Zealand, for example, makes use of risk profiles for each investment project to determine which projects would benefit from monitoring assurance (OECD, 2020b).

Beyond risk management, looking at the overall infrastructure asset portfolio through a government balance sheet approach ensures value for money (i.e. optimisation of return). According to the IMF (2018), improved management of financial asset holdings and of nonfinancial public corporations could yield a revenue gain of 3 percent of GDP per year - equivalent to corporate income tax revenue in advanced economies. This is also relevant for emerging markets with Africa's maritime ports, for example, operating at a productivity that is only 30 percent of the international norm (WEF, 2014).

Proper asset management extends beyond operational and financial goals (internalised costs and benefits), but also explicitly considers environmental and social dimensions (externalised costs and benefits).

Asset management and maintenance are critical for ensuring that assets can withstand extreme events. Enhanced monitoring of existing assets or modifying operational routines can reduce the risk of failure as climate conditions change or other vulnerabilities emerge (e.g. digital threats). This can include changing the timing or frequency of maintenance to account for changing patterns of energy demand and supply, investment in early warning systems or purchasing insurance to address financial consequences of climate variability (OECD 2018).

\subsubsection{Building resilience can be cost effective but there are trade-offs: role of the private sector}

The benefits of infrastructure resilience and maintenance spending can be higher than the cost of inaction, and building resilience is in general cost-effective. Rozenberg and Fay (2019) find that, without good maintenance, infrastructure capital costs could increase 50 percent in the transport sector and more than 60 percent in the water sector. Kornejew, Rentschler, and Hallegatte (2019) find that every additional USD 1 spent on road maintenance inn OECD countries saves on average USD 1.50 in new investments, making better maintenance a very cost-effective option.

At the same time, in the short term, projects will not necessarily yield all of these benefits, and there will often be trade-offs to be made between resilience and other policy objectives. Many of the techniques for increasing the reliability of service provision may also increase costs for example, adding redundancy, or designing assets to account for a wider range of potential climates and adapt them to those changes through retrofitting $(\mathrm{ITF}, 2018)^{5}$. As well as the possibility of higher costs, there may be other trade-offs to make, for example, installing hard coastal defences have the potential to disrupt ecosystems or increase the rate of erosion of other properties (OECD 2018).

Traditionally, infrastructure investment has been dominated by the public sector. However, shifting market trends and growing demand for infrastructure across developed and emerging markets have resulted in increased private sector participation. Recent decades have seen a shift towards greater involvement of the private sector in the delivery and operations of infrastructure in favour of the traditional procurement model. Efficiency improvements have been a key component of the rationale for privatisation in an attempt to reduce the budgetary burden caused by inefficiencies of state-owned enterprises.

As governments seek greater levels of private finance in infrastructure and in particular pension fund investment, efforts are underway to develop new models and financial instruments for infrastructure

\footnotetext{
${ }^{5}$ Additional costs for adapting infrastructure (new construction or rehabilitation) depends on the risk, type of asset, and location. For example, increasing a road's resilience to flooding by improving the drainage system only costs a few percent more, while increasing the level of a railway line may increase costs by up to 50 percent (Miyamoto 2019; and Evans and others 2021 forthcoming)
} 
procurement and create infrastructure as an asset class. Innovative partnerships have been launched to invest in low carbon infrastructure, and financing models are emerging for energy efficiency and renewable energy projects.

Diversifying the types of financial stakeholders and sources of finance for such investment through new financing and funding structures and innovative financial tools, can help align public and private sector interest in infrastructure provision and management, while optimising the capital structure and reducing the cost of capital for the public sector.

\subsection{Emerging opportunities for resilient infrastructure and maintenance ${ }^{6}$}

\subsubsection{Infrastructure technology (InfraTech) as an enabler for resilient infrastructure}

New technologies and data science encompassing earth observation, remote sensing, big data, Internet of things (IoT), cloud technologies and machine learning, are transforming how infrastructure is operated and maintained. Using blockchain throughout the project life-cycle , particularly in conjunction with Digital Twins, could significantly reduce the time and cost of infrastructure projects, and reduce fraud (OECD 2019c). Building Information Modelling can vastly improve design, while 3D printing is disrupting construction (WEF, 2021).

Infrastructure technology, or InfraTech, can be described as the integration of material, machine and digital technologies across the infrastructure life-cycle - from development to delivery and operations. Innovations can be cross-cutting, impacting all infrastructure sectors (Artificial intelligence (Al), machine learning (ML), robotics, the Internet of Things (IOT) 3-D printing, and batteries), as well as sector- specific ones (such as autonomous vehicles, electric vehicles, smart grids and new biological water filtration techniques). According to the World Bank (2020) there are six main broad technology categories relevant to infrastructure, as shown below:

\section{Figure 1.1. Infratech}

\begin{tabular}{|c|c|c|c|c|c|}
\hline $\begin{array}{l}\text { Connectivity \& } \\
\text { Communications }\end{array}$ & $\begin{array}{l}\text { Analytics \& } \\
\text { Computation }\end{array}$ & $\begin{array}{l}\text { Cloud \& } \\
\text { Data Storage }\end{array}$ & $\begin{array}{l}\text { Devices \& } \\
\text { Automation }\end{array}$ & $\begin{array}{l}\text { Platforms \& } \\
\text { Interfaces }\end{array}$ & $\begin{array}{l}\text { Materials, Energy } \\
\text { \& Construction }\end{array}$ \\
\hline $\begin{array}{l}\text { Wired or wireless } \\
\text { technologies that } \\
\text { connect people or } \\
\text { devices and enable } \\
\text { data transfer. }\end{array}$ & $\begin{array}{l}\text { Advanced analysis that } \\
\text { uses machine learning } \\
\text { to process large } \\
\text { amounts of } \\
\text { unstructured data. }\end{array}$ & $\begin{array}{l}\text { Tech solutions that } \\
\text { enables efficient mass } \\
\text { movement and storage } \\
\text { of large data sources. }\end{array}$ & $\begin{array}{l}\text { Physical interfaces and } \\
\text { components that } \\
\text { perform specific tasks } \\
\text { or enhance } \\
\text { automation. }\end{array}$ & $\begin{array}{l}\text { Complex systems } \\
\text { combining multiple } \\
\text { technologies or have } \\
\text { whole of system } \\
\text { design thinking. }\end{array}$ & $\begin{array}{l}\text { Applied science and } \\
\text { engineering directly } \\
\text { related to efficiency or } \\
\text { quality for OPS and } \\
\text { construction. }\end{array}$ \\
\hline $\begin{array}{l}\text { - } 5 \text { G Mobile } \\
\text { - } 6 \mathrm{G} \text { Mobile } \\
\text { - LEO Satellite } \\
\text { - Wireless } \\
\text { - Industrial IOT } \\
\text { - Sensors / IOT } \\
\text { - GIS / GPS }\end{array}$ & $\begin{array}{l}\text { - Big Data } \\
\text { - Data \& Analytics } \\
\text { - AI Augmentation } \\
\text { - Auto Cognitive } \\
\text { - Edge Computing }\end{array}$ & $\begin{array}{l}\text { - Cloud } \\
\text { - HD Video } \\
\text { - } \text { BIM }\end{array}$ & $\begin{array}{l}\text { - Robotics } \\
\text { - UAVs (e.g. } \\
\text { Drones) } \\
\text { - Batteries } \\
\text { - Wearables } \\
\text { - Biometrics }\end{array}$ & $\begin{array}{l}\text { - Autonomous Cars } \\
\text { - Fintech and DLT } \\
\text { (e.g. Blockchain) } \\
\text { - AR/VR } \\
\text { - Digital Twin }\end{array}$ & $\begin{array}{l}\text { - 3D Printing } \\
\text { - 4D Printing } \\
\text { - Nano-materials } \\
\text { - Modular } \\
\text { Construction }\end{array}$ \\
\hline
\end{tabular}

Source: World Bank. 2020.

\footnotetext{
${ }^{6}$ The 2020 G20 Presidency mandated the Infrastructure Working Group (IWG) to develop an Agenda to accelerate the adoption and application of technology-enabled infrastructure (InfraTech). This Agenda supports the existing IWG initiatives, the Roadmap to Infrastructure as an Asset Class ("Roadmap"), and the G20 Principles for Quality Infrastructure Investment ("QII"). Three Reference Notes were produced supporting the Agenda: Value Drivers of InfraTech; InfraTech Stock Take of Use Cases; and InfraTech Policy Toolkit.
} 
InfraTech also improves resilience by enabling faster and more targeted response to disruptive shocks or shifts in supply and demand, including the current COVID-19 pandemic. The response to the crisis demonstrates the value of InfraTech in using data effectively to track the outbreak and intervene quickly. For example, a digital twin for infrastructure can be continuously updated with big data from multiple sources, enabling improved testing of what-if scenarios, analysis of the interdependency of multiple systems and simulation of risks and vulnerabilities—all toward the development of the asset's resilience.

Furthermore, InfraTech have a huge potential to improve infrastructure maintenance and reduce related costs. Smart sensors and drones with data analytics and digital twins, can help assess infrastructure assets and target maintenance operations accordingly, driving operations efficiency. Blockchain technology can also be useful to trace maintenance operations across multiple stakeholders and improve transparency and trust (see Chapter 3).

\section{Better and wider application, however, is needed}

If smart technologies are available and tested, they are not necessarily implemented. Several surveys show that companies for asset management still depend on traditional statistical modelling such as visual inspection, vibration monitoring, and thermal imaging, and use MS Excel as a main analysis tool. This is evidenced, in part, by the fact that, to date, only 5 percent of enterprises in infrastructure sectors have started implementing digital twins and less than 1 percent of assets have one (Jalan A., (2018) and Mulders $M$ and Haarman M (2017)).

Patterns of technological adoption vary according to industry. Research undertaken by the Global Infrastructure Hub, has shown that the uptake of digital technologies is relatively low in infrastructure compared with other sectors across the entire infrastructure project life-cycle, including the operations and maintenance phase $(\mathrm{GIH}, 2020)$. There are in fact several practical challenges hampering the adoption of digital solutions in infrastructure. They include challenges in continuous data collection and management, integration into legacy systems, the investment required for acquiring and installing and ultimately a lack of vision on going digital and its prospective benefits to the organisation from top management.

\section{Figure 1.2. Digital Maturity by Industry}

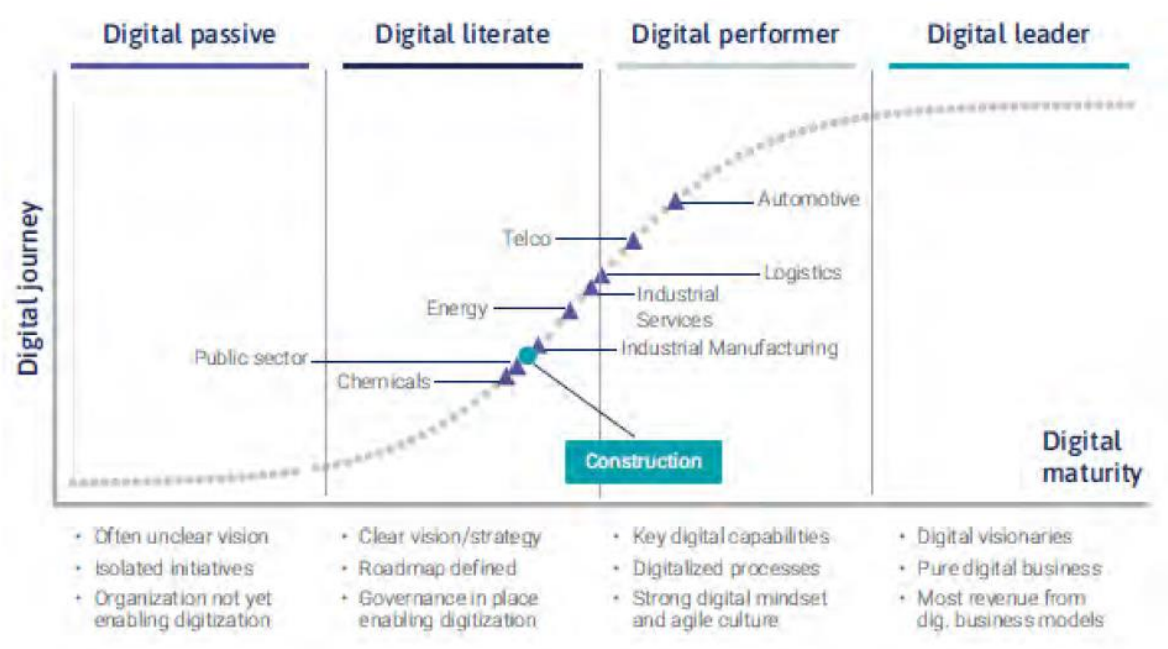

Source: GIH 2020. 
There are also concerns about privacy, the environment, safety and security. Some technologies pose economic or social risks as jobs or sectors are disrupted. Certain technologies may also have unintended environmental risks, due to a heavy reliance on energy or rare materials. Open and inter-operable interfaces and industry standards to enable data interchange imply challenges on data privacy and security. Policymakers must put into place appropriate risk management frameworks to manage or mitigate these risks.

\subsubsection{Nature-based solutions are an opportunity to build resilience, improve ecosystem functions and generate co-benefits for human well-being}

As the COVID-19 crisis draws our attention to the interconnections between healthy ecosystems and healthy communities, it becomes ever more important to understand how Nature-based solutions (NbS) can be fostered, replicated and scaled up where they can help build infrastructure that is resilient and sustainable. $\mathrm{NbS}$ are measures that "protect, sustainably manage or restore nature, with the goal of maintaining or enhancing ecosystem services to address a variety of social, environmental and economic challenges" (OECD, 2021e). The concept of NbS is fundamentally based on the understanding that natural and managed ecosystems produce a diverse range of services on which human wellbeing depends. For example, floodplains and wetlands can protect communities from floods through increasing water retention (an ecosystem service), while simultaneously providing additional co-benefits, such as recreational value and an increase in biodiversity. Similarly, forestry or other interventions aiming to plant trees or restore soils can increase carbon sequestration, protect against extreme temperatures, landslides, sandstorms or desertification, and provide other ecosystem services to neighbouring communities (OECD, 2020). The potential of $\mathrm{NbS}$ is particularly marked in developing countries that do not have extensive networks of infrastructure to rebuild or restore. Accordingly, developing countries can immediately incorporate $\mathrm{NbS}$ approaches in their investments, which - given the size of their infrastructure need - are projected to be substantial over the next decades.

$\mathrm{NbS}$ encompass a wide range of actions, such as the protection and management of the natural environment, the incorporation of green infrastructure in urban areas or the application of ecosystem-based principles to agricultural systems (Eggermont et al., 2015). Interventions range from minimal or no interventions, including protection and conservation, and monitoring strategies; to management approaches to restore entire ecosystems and optimise the generation of chosen ecosystem services, such as planning agricultural landscapes to minimise drought. But $\mathrm{NbS}$ can equally be integrated into infrastructure design and maintenance, where it can contribute to lowering the environmental impact of infrastructure assets and operations or enhance the resilience and sustainable of infrastructure itself. For example, the integration of green roofs or permeable surface around infrastructure assets can reduce energy consumption as well improve resilience against extreme heat and precipitation.

To fully exploit the potential of $\mathrm{NbS}$, countries need to align their infrastructure policies and planning with national (and international) climate policies, related objectives as part of the SDGs or other environmental commitments, such as part of the Convention on Biological Diversity ${ }^{7}$. NbS have a tremendous potential to reduce vulnerability and exposure to disruptive shocks, including but not exclusive to the impacts of climate change, but can also play a key role in rendering infrastructure assets and services greener and more sustainable.

The use of $\mathrm{NbS}$ is often a key alternative to be considered for adaptation investments along better maintenance and structural measures (Agrawala and Fankhauser 2008, OECD 2018)). Structural

\footnotetext{
7 The EU has developed a green infrastructure plan as part of its EU 2020 Biodiversity Strategy. The Strategy's target 2 requires that 'by 2020, ecosystems and their services are maintained and enhanced by establishing green infrastructure and restoring at least $15 \%$ of degraded ecosystems'
} 
adaptation measures "climate proof" infrastructure, reducing the exposure or vulnerability of an infrastructure asset or network, whether from the outset or as part of a retrofitting process. Such investment can take the form of engineering work with clearly identifiable additional costs, such as building a bridge higher than would otherwise be the case or building to higher design standards ${ }^{8}$. Interventions to develop more resilient assets include using alternative materials, digging deeper foundations, elevating assets, building flood protection around the asset, or adding redundant components, changing the composition of road surfaces so that they do not deform in high temperatures, building seawalls or using permeable paving surfaces to reduce run-off during heavy rainfalls.

Similar to broader infrastructure investments, NbS require significant maintenance to make sure they can deliver their resilience benefits over time (OECD, 2021e) and face several challenges, limiting implementation (See Chapter 3).

\subsection{Major challenges and proposed framework}

A range of barriers can prevent new and existing infrastructure from being built and operated in a resilient manner. Risks of shocks and stresses are not fully encoded into public and private investment decisions at all levels. Issues affect both developing and developed countries, although the type of problem does vary.There are three broad causes of the shortage of high-quality and sustainable infrastructure:

\subsubsection{Governance challenges}

Poor governance - defined as the policies, frameworks, norms, processes and tools, used by public bodies to plan, make decisions, implement and monitor the entire life-cycle of public infrastructure (OECD, 2020a and 2020b) - is the principal reason why infrastructure projects fail to meet their timeframe, budget and service delivery and broader objectives. Infrastructure projects with deficient governance often result in cost overruns, delays, underperformance and underutilisation, as well as be at greater risk of poor investment choices, fraud and corruption. This may result in in expensive "white elephants" and bridgesto-nowhere - major investment projects with negative social returns. Good public infrastructure may deteriorate quickly when maintenance is inadequate.

Losses and waste in public investment are often systemic. On average, more than one-third of the resources spent on creating and maintaining public infrastructure are lost because of inefficiencies (IMF 2020). The IMF (2018) found weaknesses in infrastructure governance to be widespread across the public investment cycle, but more prominent in the allocation and implementation stages of public investment, particularly during project appraisal and project selection. Weak inter-agency co-ordination processes, political considerations, corruption and poor budget management are major causes for inefficiency (Rajaram, A. and others 2014).

Neglect of infrastructure governance risks policy misalignments amongst the multiple stakeholders for infrastructure resilience: infrastructure design, investment, construction, ownership, operations or regulation all involve multiple stakeholders. Regulatory decisions and policy frameworks, such as those governing procurement, can inadvertently distort incentives, and discourage the use of innovative alternatives such as ecosystem- and nature-based solutions.

\footnotetext{
${ }^{8}$ For example Brisbane is one of Australia's largest airports in terms of land area and is based on a low-lying coastal site. The consideration of potential climate change impacts (sea level rises, flooding events) led to the resilient design approach in relation to runway height (LTTIA 2020).
} 
Making use of new opportunities for building infrastructure resilience, such as Infratech and investment in $\mathrm{NbS}$, also brings with it a host of governance challenges. While fundamentally under the domain of digital or environment ministries, scaling-up such solutions and mainstreaming them across infrastructure sectors, requires effective governance mechanisms and co-ordination across government jurisdictions.

\subsubsection{Information and capacity}

Infrastructure services often are subject to mismanagement issues due to imperfect information, coordination problems and market failures. Public transport inefficiencies may include sub-optimal supply, inadequacy, high infrastructure maintenance costs, longer commuting, environmental impacts and energy consumption. Similarly, the water service sector needs to deal with billing accuracy, data access and security, over-consumption and lack of quality. About half of electricity costs from major electricity suppliers go towards managing and maintaining infrastructure that delivers power from generators to customers' premises.

Management operation inefficiencies translate to higher costs and loss of asset value. Decision-making is often hampered by poor asset management processes and frameworks, and sub-standard systems, tools and data. Many countries lack a life-cycle view of infrastructure in design, build, and maintenance with few governments managing their wealth using balance sheets. The human factor is often overlooked in the infrastructures maintenance strategies limited to the physical structure. It is key to develop human resilience, i.e. adaptation skills to unknown situations, by informing and training all the actors involved in the infrastructure maintenance process (Evans, C., Godart, B., Kovarik 2021 Forthcoming)

Lack of data is often seen as a major bottleneck for proper asset management. Information on the state of assets may not be readily available, particularly in low-income countries, and the measurement of maintenance needs is difficult, because of lack of standard methodologies, neglect of monitoring, or because the slow effects of asset depreciation may not be immediately visible, while the consequences may be immediate and disastrous.

Awareness and information on risks may not be readily available, or with sufficient geographic resolution for infrastructure planning and investment. Climate change is complex and additional capacity may be needed to support decision-making under uncertainty (OECD, 2018).

There are inherent difficulties and uncertainties in modelling how critical risks, especially those exacerbated by the impacts of a changing climate, and other factors affecting infrastructure sustainability. Infrastructure planning, investment and operation need to take account of uncertainties and build flexibility, redundancy, back-up systems etc. to be prepared for a range of possible future scenarios. The diversity and complexity of critical risks, the increased interdependences and interconnectedness, the fast pace of innovation that fundamentally transforms infrastructure sectors, as well as ageing infrastructure, are among the challenges with which critical infrastructure resilience policies have to contend.

\subsubsection{Insufficient funding}

Lack of reliable and stable funding due to short time horizons, political priorities and pressured public budgets are major barriers to maintenance spending and building resilient infrastructure.

There is a mismatch over time between infrastructure assets and the need for their operation or maintenance. In public budgeting routine maintenance and capital maintenance are often not integrated into a medium-term perspective, and therefore fail to match the multiyear requirements of operations and maintenance $(\mathrm{O} \& \mathrm{M})$ programmes. In addition, the benefits of increased resilience for infrastructure (e.g. climate resilience) often occur beyond the time horizons considered by decision makers, while costs of investing in resilience are incurred in the shorter term. Private investment decisions rarely account for these risks, often because they are heavily discounted to favour short-term profit. 
Budget funding for maintenance is subject to budgetary pressures in favour of priorities such as health when fiscal space is limited. Overall public funding for infrastructure, and in particular dedicated funds for maintenance, is inadequate. Potential infrastructure benefits, such as the value of nature-based infrastructure, may not result in direct revenue for the investor or operator and is therefore difficult to monetise.

Political dynamics may undermine sound decision-making with regards to infrastructure maintenance. Prioritisation of public investment needs is particularly subject to political capture and the electoral cycle may prompt governments to opt for new project as opportunities for ribbon cutting (i.e. political/constituent recognition) rather than maintaining existing assets. Also maintenance costs cannot always be easily recovered from user charges: the requisite price increases tend to provoke stakeholder opposition, and payment evasion.

\subsubsection{A new proposed framework for optimizing existing assets and building resilient infrastructure}

A new holistic and comprehensive approach to asset management is needed to optimise existing infrastructure assets and make them more resilient. This approach is seeking to get the best out of the asset over its life-cycle, across functions and tasks and the entire infrastructure system/network. As infrastructure will be affected by environment social and governance (ESG) risks, this approach allows for the identification of the trade-offs between objectives, and the enabling of more robust policy choices.

Infrastructure cannot be resilient if it is poorly maintained. Governments should aim to make the most of existing assets. Asset management should minimise the total cost of owning and operating fixed capital assets (while providing the desired level of service) but also provide the greatest possible life-cycle revenues, user benefits and, hence, aggregate socio-economic returns (WEF 2014).

Infrastructure investment is a means, not an end and requires a new systemic approach. In order for infrastructure investment to generate long-term benefits to society in terms of inclusive economic growth and improvements to wellbeing, it should contribute to key policy priorities, such as supporting the lowcarbon transition, protecting biodiversity, making societies more resilient, addressing disparities across regions and cities, and promoting sustainable development. In particular the system-wide impacts caused by COVID-19 and the key role played by infrastructure in sustaining economic and social activity have heightened the need to consider infrastructure resilience and impacts on communities at a broader level.

Transitioning to low carbon infrastructure. Investments in low-emission infrastructure will require an unprecedented transformation of our infrastructure system. Most existing energy and transport infrastructure was designed and built for a world of cheap and abundant fossil fuels, contributing to economic growth in many regions but also to GHG emissions. As a result, around 70 percent of GHG emissions are locked into existing infrastructure such as power plants, buildings, and transport. Choices made on infrastructure systems in the next decade will be critical for achieving net zero objectives and halting the dramatic loss in biodiversity.

Resilient infrastructure as an economic opportunity. Resilience is key for absorbing the impacts of adverse shocks, but also creates a unique opportunity for countries to ensure resilience against future risks as part of their recovery efforts. Private investors as well increasingly recognise the business case for sustainability and require assets to meet ESG criteria to manage risks, respond to regulatory requirements and initiatives such as the EU Taxonomy for sustainable activities.

Inclusive infrastructure to provide a service to the Community. While serving as a key means to achieve sustainable development, infrastructure, in both its construction and operation, needs to consider changing community expectations, the increasing power of civil society and social connectivity, as well as potential new legal requirements, all of which add to the complexity of delivering infrastructure projects 
effectively. Strong community opposition can result in project delays cost overruns and cancellations ${ }^{9}$. A lack of an inclusive approach to project planning, design, and delivery is seriously detrimental for companies, investors, and national governments ${ }^{10}$.

Delivering infrastructure that is efficient on a life-cycle basis depends, in a first instance, on sound regulatory and planning frameworks that ensure that the right projects get built with relevant resilience requirements integrated and implemented. Rigorous project appraisal that privileges economic efficiency criteria along with environmental and social sustainability throughout the project life-cycle (planning, investment, operation and maintenance, and disposal) should underpin project selection. Furthermore, effective operation, monitoring and maintenance is essential for ensuring that economic efficiency is maintained during the operational phase of projects.

Getting such infrastructure investments not only right, but also resilient requires revisiting the overarching governance models for infrastructure delivery. The OECD has adopted a Recommendation on the Governance of Infrastructure (2020), which provides countries with practical guidance for efficient, transparent and responsive decision-making processes in infrastructure investment, in a way that is cost effective, affordable with respect to life-cycle costs and trusted by users and citizens. This Recommendation stresses the need to integrate resilience upfront in the design of these investments, in order not only to protect these investments against hazards or threats, but also to maintain their function running at times of disasters, especially when they provide critical services. The OECD Recommendation on the Governance of Critical Risks (OECD, 2014) proposes a fundamental shift in risk governance towards a whole of society effort. It proposes actions that governments can take at all levels of government, in collaboration with the private sector and with each other, to better assess, prevent, respond to and recover from the effects of extreme events, as well as take measures to build resilience to rebound from unanticipated events.

\begin{abstract}
New technologies allow for the reduction of maintenance costs while enabling the improvement of operational efficiency and offering alternatives to traditional infrastructure design, construction and maintenance. Technology development plays a critical role in responding to the COVID-19 crisis enabling infrastructure to become more resilient to future disasters and pandemics and ensuring the continued operations of critical networks such as utilities, transport and telecommunications despite the large-scale disruptions and changing needs caused by the crisis. At the same time, digitalisation comes along with new vulnerabilities, to security threats for instance, which require further thinking around resilience and maintenance.
\end{abstract}

Nature as a key asset for infrastructure sustainability. Green infrastructure development ensures that infrastructure itself does not undermine environmental sustainability goals, while also ensuring that infrastructure assets and services are better protected against the unavoidable impacts of environmental degradation and climate change. Climate change adaptation, including through nature-based solutions, can help countries develop climate-resilient infrastructure that reduces vulnerability and exposure to climate-related risks such as sea level risks or climate extreme events such as storms or floods (OECD, 2018). The COVID-19 crisis has highlighted the interconnections between healthy ecosystems and healthy communities. Fostering, replicating and scaling-up Nature-based solutions (NbS) where they provide a

\footnotetext{
${ }^{9}$ The Inter-American Development Bank (2017) analysed 200 projects across six sectors in Latin America and the Caribbean that were strongly opposed by local communities and found that 36 out of the 200 projects were cancelled; 162 faced delays; and 116 faced cost overruns.

10 The OECD Recommendation on the Governance of Infrastructure (2020) presents 10 dimensions for the governance of public infrastructure that relate to how governments plan, prioritise, fund, budget, deliver, operate and monitor infrastructure assets, providing a whole of government approach that covers the entire life-cycle of infrastructure projects and putting special emphasis on regional, social, gender, resilience and environmental perspectives.
} 
physically effective and cost-efficient alternative or complement to grey infrastructure solutions is a key opportunity for strengthening infrastructure sustainability.

Leveraging innovation to realise resilient infrastructure investments will require appropriate infrastructure governance. To smoothly integrate new technologies into the overall infrastructure system and ensure citizens' acceptance, governments must have good visibility of the rapidly developing concepts. To maximise benefits and minimise risks, existing rules will need to be reviewed and new rules set to engage citizens and businesses in decision making, including about potential trade-offs for resilient and green infrastructure.; to ensure that cost and benefit assessments better account of the full costs of both grey and green infrastructure measures (such as the value of ecosystem services to protect against climate risks; the long-term liability and environmental costs of grey infrastructure, etc.); to identify and address regulatory and other barriers to successful delivery of infrastructure.

\section{References}

Agrawala and Fankhauser (2008), Economic aspects of adaptation to climate change: Costs, benefits and policy instruments.

ASCE (2017), American Society of Civil Engineers.

Blečić I., Cecchini A. (2019) Antifragile planning, Planning theory Journal

Blimpo, M., and M. Cosgrove-Davies (2018), Electricity Uptake for Economic Transformation in SubSaharan Africa. Washington, DC: World Bank.

Browder, G. Ozment, S. \& others (2019), "Integrating Green and Gray: Creating Next Generation Infrastructure". Washington, DC: World Bank and World Resources Institute. (c) World Bank and World Resources Institute [https://openknowledge.worldbank.org/handle/10986/31430]. License: CC BY 4.0.

Eggermont H. \& others (2015), Nature-based Solutions: New Influence for Environmental Management and Research in Europe, GAIA - Ecological Perspectives on Science and Society 24(4): $243-248$.

Evans, C., Halimatussadiah A., Kovarik, J.B. and others (2021 forthcoming) Maintaining Resilient Infrastructure Systems, T20 Policy Brief, Italy.

Evans, C., Godart, B., Kovarik, J.B., Mendoza, J.F. and Palhol, F. (2020). Evaluating Resilient Infrastructure Systems, T20 Policy Brief, Saudi Arabia.

Evans, C., Godart, B., Kovarik, J.B., Mendoza, J.F. and Palhol, F. (2019) Building Resilient Infrastructure Systems T20 Policy Brief, Japan.

Fisch-Romito, V., and C. Guivarch. (2019), "Investment Needs for Transport Infrastructures along Low Carbon Pathways. World Bank, Washington, DC.

G20 (2021) Policy Agenda on Infrastructure Maintenance - Annex - Infrastructure Maintenance Case Studies.

G20/OECD (2020), G20/OECD Report on the Collaboration with Institutional Investors and Asset Managers on Infrastructure: Investor Proposals and the Way Forward, [http://www.oecd.org/daf/fin/private pensions/Collaboration-with-Institutional-Investors-and-Asset-Managers-on-Infrastructure.pdf].

G20 (2019), Principles for Quality Infrastructure Investment.

G20 (2018), Roadmap to Infrastructure as an Asset Class.

Garcia S. and Whittaker T. (2019), ESG Reporting and Financial Performance: the Case of Infrastructure, EDHEC Infrastructure. 
Gallego-Lopez, C., and Essex, J. (2016a), Understanding Risk and Resilient Infrastructure Investment. Evidence on Demand, UK. 33 pp.

Gallego-Lopez, C., and Essex, J., (2016b), Designing for Infrastructure Resilience. Evidence on Demand, UK. 26 pp.

GIH (2020), InfraTech Stock Take of Use Cases, Global Infrastructure Hub, G20 Infrastructure Working Group Reference Note July 2020.

Giovannini, E., Benczur, P., Campolongo, F., Cariboni, J. and Manca, A. (2020), Time for transformative resilience: the COVID-19 emergency, EUR 30179 EN, Publications Office of the European Union, Luxembourg, 2020, ISBN 978-92-76-18113-2 (online), doi:10.2760/062495 (online), JRC120489.

Hutton G., Varughese M. C. (2016), "The Costs of Meeting the 2030 Sustainable Development Goal Targets on Drinking Water, Sanitation, and Hygiene.

IADB (2017), Lessons from Four Decades of Infrastructure Project-Related Conflicts in Latin America and the Caribbean, [https://publications.iadb.org/handle/11319/8502\#sthash.M7vhXdeL.dpuf].

IMF (2020), Well Spent, International Monetary Fund, Washington, DC.

IMF (2018), Fiscal Monitor: Managing Public Wealth. Washington, DC.

IPCC (2021) Summary for Policymakers. In: Climate Change 2021: The Physical Science Basis. Contribution of Working Group I to the Sixth Assessment Report of the Intergovernmental Panel on Climate Change, Cambridge University Press.

ITF (2018), "The Bn Dollar Question: How Much Will It Cost to Decarbonise Cities' Transport Systems?" International Transport Forum, Paris, France.

Jalan A., (2018), "The future of IloT predictive maintenance".

Kornejew, Rentschler, and Hallegatte (2019), Underutilized Potential : The Business Costs of Unreliable Infrastructure in Developing Countries. Policy Research Working Paper;No. 8899. World Bank, Washington, DC. @ World Bank. [https://openknowledge.worldbank.org/handle/10986/31919] License: CC BY 3.0 IGO.

LTIIA (2020) ESG Handbook 2020

Miyamoto (2019). Overview of Engineering Options for Increasing Infrastructure Resilience. Project Report. World Bank.

Mulders M and Haarman M (2017), Predictive maintenance 4.0 predict the unpredictable.

MDB (2016), "Joint Report on Multilateral Development Bank Climate Finance" [www.ebrd.com/2016-jointreport-on-mdbs-climate-finance.pdf].

OECD (2021a), Recommendation of the Council on the Governance of Infrastructure, OECD/LEGAL/0460, [https://legalinstruments.oecd.org/en/instruments/OECD-LEGAL-0460].

OECD (2021b), Recommendation of the Council on Public Procurement, OECD/LEGAL/0411, [https://legalinstruments.oecd.org/en/instruments/OECD-LEGAL-0411].

OECD (2021c ), Implementation Handbook for Quality Infrastructure Investment.

OECD (2021d), Aligning short-term recovery measures with longer-term climate and environmental objectives.

OECD (2021e), Scaling up Nature-based Solutions to Tackle Water-related Climate Risks: Insights from Mexico and the United Kingdom, OECD Publishing, Paris, [https://doi.org/10.1787/736638c8-en]. 
OECD (2020a), Public Procurement and Infrastructure Governance: Initial policy responses to the Coronavirus (COVID-19) crisis, [https://read.oecd-ilibrary.org/view/?ref=135 135391eb6wiwbrmn\&title=Public-Procurement-And-Infrastructure-Governance].

OECD (2020b), Compendium of Policy Good Practices for Quality Infrastructure Investment.

OECD (2020c), ESG and Institutional Investment in Infrastructure" published as part of the 2020 Business and Finance Outlook (BFO).

OECD (2020d), COVID-19 and a New Resilient Infrastructure Landscape.

OECD (2019a), Good Governance for Critical Infrastructure Resilience, OECD Reviews of Risk Management Policies, OECD Publishing, Paris, [https://doi.org/10.1787/02f0e5a0-en].

OECD/IMF (2019b), Reference Note on the Governance of Quality Infrastructure Investment.

OECD (2019c), "Blockchain technologies as a digital enabler for sustainable infrastructure", OECD Environment Policy Papers, No. 16, OECD Publishing, Paris, https://doi.org/10.1787/0ec26947-en.

OECD (2018), Climate Resilient Infrastructure, OECD Environment Policy Paper Nb 14.

OECD (2017a), Getting Infrastructure Right: A framework for better governance, OCED Publishing, Paris, [https://doi.org/10.1787/9789264272453-en].

OECD (2017b), Recommendation on the Governance of Critical Risks.

Rajaram, A.; Minh Le, T \& others (2014), The Power of Public Investment Management: Transforming Resources into Assets for Growth. Directions in Development--Public Sector Governance; World Bank Group, Washington, DC. (C) World Bank. [https://openknowledge.worldbank.org/handle/10986/20393] License: CC BY 3.0 IGO.

Rozenberg, J.; Fay, M. (2019), Beyond the Gap: How Countries Can Afford the Infrastructure They Need while Protecting the Planet. Sustainable Infrastructure; Washington, DC: World Bank. () World Bank.

Serebrisky, T. \& others (2015), Financing Infrastructure in Latin America and the Caribbean: How, How Much and by Whom? Washington DC: Inter-American Development Bank.

Swiss Re (2020), "Power up: investing in infrastructure to drive sustainable growth in emerging markets", sigma No 3/2020, May 2020.

Taleb, NN (2012) Antifragile: Things That Gain from Disorder. 1st edn. New York: Random House. Google Scholar

Vallejo and Mullan (2017), Climate-resilient infrastructure: getting the policies right.

WEF (2021), 4 big infrastructure trends to build a sustainable world.

WEF (2014), Strategic Infrastructure, Steps to Operate and Maintain Infrastructure Efficiently and Effectively.

World Bank, (2020), "World Bank. 2020. Infratech Value Drivers. World Bank, Washington, DC. @ World Bank. [https://openknowledge.worldbank.org/handle/10986/34320] License: CC BY 3.0 IGO.

World Bank (2019), Lifeline: the resilient infrastructure opportunity, World Bank, Washington, DC. 


\section{Infrastructure resilience \&} maintenance require an appropriate regulatory and institutional framework

Adopting an integrated set of responsibilities and functions designed to identify, report and take action on risks and challenges facing an infrastructure project during its implementation can help maintain focus on sustainability and resilience and clarify different roles. Regulations on risk assessment, land use, service continuity, maintenance or other aspects of infrastructure and operational resilience are indispensable in directing infrastructure stakeholders toward assessing the quality of infrastructure, risk exposure and building resilience.

This chapter covers the importance of a systemic and unified approach to sustainable and resilient infrastructure, focusing on the necessary institutional and regulatory framework. 


\section{Introduction ${ }^{11}$}

Incorporating sustainability and resilience considerations in infrastructure planning and delivery enables governments to limit their exposure to fiscal risks over the life of an infrastructure asset and to ensure value for money. A more unified approach to sustainability and resilience would further help inform infrastructure quality and policy options to better take into account climate change and exposure to shocks.

The challenge for infrastructure projects is that they often involve many policy areas, multiple layers of legislation and regulation, and different levels of government. Adopting an integrated set of responsibilities and functions designed to identify, report and take action on risks and challenges facing an infrastructure project during its implementation can help maintain focus on sustainability and resilience and clarify responsibilities.

Economic regulators set tariffs and ensure access to both public and private infrastructure in a number of industries such as water, electricity and gas, telecommunications and transport. Where economic regulators are involved in infrastructure industries, they have an ongoing relationship with the operators of regulated infrastructure throughout the infrastructure's life-cycle - from the identification of infrastructure needs, through construction and maintenance to its eventual decommissioning. Regulations can either prescribe detailed technical regulations and standards for quality infrastructure and resilience, or specify contractual outcomes linked to the duration of service disruption or minimum service requirements (OECD, 2021a and 2021b).

Many economic regulators operate as independent bodies within the overall infrastructure governance framework and can provide technical input to decision-making. Regulations on risk assessment, land use, service continuity, maintenance or other aspects of infrastructure and operational resilience are indispensable in directing infrastructure stakeholders toward assessing the quality of infrastructure, risk exposure and building resilience.

\subsection{A systemic approach to resilient and sustainable infrastructure}

The concept of sustainability rose to prominence in the late 1980s, when the construction industry began to look at environmental, economic, and social aspects for office buildings over their life-cycle s. Resilience, on the other hand, is usually connected to the occurrence of extreme events during the lifecycle of structures and infrastructures. The two approaches combine structural analyses with social and economic aspects; they both rely on techniques for the life-cycle analysis and decision making, including structural design, materials used and maintenance plans ${ }^{12}$.

\footnotetext{
11 This chapter draws from the OECD Recommendations on the Governance of Infrastructure, the Governance of Critical Risks, and Effective Public Investment Across Levels of Government; as well as OECD work on Climate Resilient Infrastructure. It builds on the OECD Implementation Handbook on Quality Infrastructure, in particular Chapter 2: Effective governance as a foundation for implementing quality infrastructure in a COVID-19 context and Chapter 4: Subnational governance and investment in infrastructure.

${ }^{12}$ Sustainability is defined by the American Society of Civil Engineers (ASCE), as "a set of environmental, economic, and social conditions - the "Triple Bottom Line"- in which all of the system has the capacity and opportunity to maintain and improve its quality of life indefinitely, without degrading the quantity, quality or the availability of natural, economic, and social resources" (ASCE 2017). Resilience is usually related to the structural integrity of systems and physical infrastructure during their life cycle. The UN definition for resilience is: "the ability of a system, community or society exposed to hazards to resist, absorb, accommodate to and recover from the effects of a hazard in a timely and efficient manner, including through the preservation and restoration of its essential basic structures and functions" (UNISDR,
} 
Climate change has highlighted the close relationship between sustainability and resilience. From a policy standpoint, climate change mitigation efforts serve to reduce the risk of climate change - increasing sustainability - , whereas climate change adaptation to improve resilience reduces the impacts of climate change for infrastructure. As pointed by Colker R., (2019) communities cannot be resilient without taking into account sustainability considerations on resources like water, air and energy.

While environmental risk reviews and public sector review assessments of major infrastructure project are widely used, academic research and analysis supporting these methodologies are in an early stage and disconnected from practice - engineers and the industry -, often focusing on new projects or a particular infrastructure sector/subsector (Bocchini, et al., 2014). The majority of researchers focus on sustainability and resilience assessments separately without considering the relationship that exists between them (Chittoori, B. \& others 2018; Basu et al. 2015; Haeri 2016; Lee 2016).

A unified approach offers a more accurate description of a system's overall quality. Risk theory can help unify resilience and sustainability approaches. Infrastructure projects that integrate comprehensive, riskbased due diligence can help balance interests of the people, society and planet ${ }^{13}$. Researchers have shown limitations of not having a unified approach when looking at sustainability resilience and risk of a tailing dam under various earthquake magnitudes. On the one hand, the sustainability analysis neglects the potential for an earthquake and the impact on a tailings dam, while on the other hand, discrete risk analysis neglects the economic and environmental impacts from constructing a highly resilient, robust dam (Chittoori, B. \& others (2018) Bocchini, et al., (2014) (See Box 2.1).

2009). The engineering concept of resiliency is based on specific criteria outlined by four pillars of resiliency: robustness, resourcefulness, rapidity, and redundancy (Bruneau and Reinhorn 2006).

${ }^{13}$ The OECD Due Diligence Guidance for Responsible Business Conduct provides practical recommendations, more information available at https://mneguidelines.oecd.org/duediligence/. 


\section{Box 2.1.Sustainability and resiliency for dams}

Dams demonstrate the interconnection of sustainability and resilient concepts, as these large infrastructures cannot be sustainable if they are not resilient enough to stay in operation over their lifecycle . In 2020, the Japanese government issued guidelines and policies for enhancing flood control functions of existing dams and for enhanced flood disaster management. These guidelines are being applied to all major dams in Japan and across sectors under an integrated river management system. This work capitalises on advanced rainfall/flood forecasting systems to inform decision-making processes associated with the management of dam reservoirs and to ensure that water draw-down processes reduce flood risks on downstream communities. Moreover, it leverages the dam inflow prediction system developed by the International Centre for Water Hazard and Risk Management under the auspices of UNESCO (ICHARM) (G20, 2021).

For example, the large dimension and long-lasting life of a tailing dam in the mining sector can have major impacts on local environment, society, and economy ${ }^{14}$. Over the life of the asset, several risks, including climate change, can severely impact the functioning of the asset. For this reason as pointed out by Chittoori, B. \& others (2018), it is key to understand environmental and economic impacts under regular (sustainability analysis) and extreme (resiliency analysis) conditions in a risk framed analysis (i.e. with probabilities of occurrence).

\section{Figure 2.1. Tailing Dams and Climate Change}

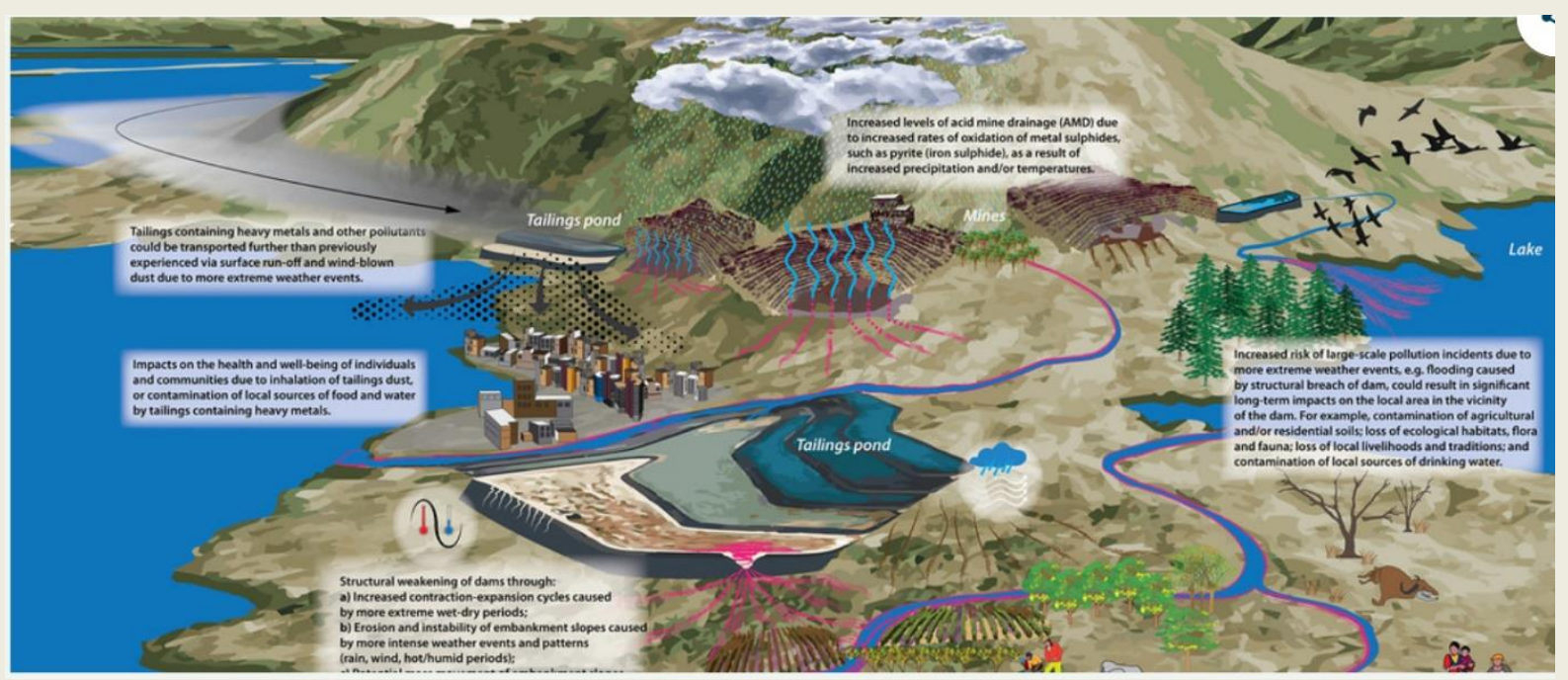

Source: UNEP 2017.

\footnotetext{
${ }^{14}$ A tailings dam is typically an earth-fill embankment dam used to store by-products of mining operations. Tailings dams rank among the largest engineered structures on earth (Source: Wikipedia).
} 


\subsection{Ensuring infrastructure performance and resilience over the asset life-cycle}

Making sure assets performs throughout their life depends on governments' institutional framework and capacity. Most institutions are responsible for the development and delivery of infrastructure, not for operations and maintenance, and the responsibility to ensure adequate performance of infrastructure normally rests with the agency in charge of the project's implementation (OECD, 2017). Poor co-ordination among sectors, levels of government and central agencies (such as central budget authorities, supreme audit institutions and regulatory authorities) can result in major fiscal risks. The lack of accountability over the provision of infrastructure services and risk responsibility - ownership - may lead to the inability to reach predefined service delivery targets, irregular maintenance and under-investment in resilience, exposing governments to much higher outlays in the event of external shocks (OECD, 2021b, and 2021a).

\subsubsection{Roles and responsibilities for asset performance}

A strong institutional framework is necessary for the delivery of strategic infrastructure on time and within the budget. Central units or institutions such as the Central Budget Authority, Supreme Audit Institution, PPP units and regulatory authorities should play their various roles throughout the project cycle. Although the preparation and construction phases inevitably require the majority of resources, responsibility for the assessment and monitoring of projects over the following decade or more of its lifespan needs to be clearly allocated.

Monitoring the implementation of an infrastructure asset is a function often performed by the government agency responsible for implementation, combined with oversight by at least one other government organisation, such as a ministry of finance or the relevant sectorial ministry (OECD, 2021a , and 2021b,). Maintenance capabilities of infrastructure agencies or ministries include collecting relevant data and benchmarks, acquiring the appropriate ICT systems and other tools, and using them in conjunction as a way to improve decision-making (See chapter 3).

The government of Singapore has increasingly recognised the need for an integrated, system-level approach. Under the Singapore Green Plan 2030 (SGP30), the aim is to establish sustainable towns and districts, push for the adoption of cleaner energy vehicles, and green infrastructure and buildings. Supporting this plan is the Singapore's Smart Nation vision launched in 2014 aiming to use data analytics, networks, and information and communication technologies providing opportunities to improve services by utility providers, support energy efficiency, facilitate the adoption of renewable sources. To this end, various Singapore government agencies have worked together to implement several system-level solutions, including the Punggol Digital District, Solar Nova, and Marina Bay's underground District Cooling (G20, 2021).

A strong institutional framework is needed also to monitor and manage fiscal risks related to infrastructure ${ }^{15}$. Countries can reduce fiscal risk by regularly reviewing the amortised cost and depreciation of infrastructure assets reported in the government balance sheet, to make sure that these assets receive appropriate maintenance and avoid any unforeseen reconstruction or replacement costs. The OECD Recommendation on the Governance of Infrastructure invites countries to develop a robust transparent and accountable capital budgeting framework, identifying, measuring, regularly updating and reporting infrastructure annual and multi-annual expenditure in relation to both development of new infrastructure, and maintenance, renovation, adaptation to changing needs and decommissioning of existing assets. As outlined in the OECD Recommendation of the Council on Budgetary Governance, the management of fiscal risk entails a number of components (Figure 2.2), including the collection and

15 Fiscal risks is the term used for describing sources of potential large deviations from the fiscal forecast. They are defined as "the probability of significant differences between actual and expected fiscal performance" OECD (2020c). 
analysis of information on a wide variety of risks, a prevention and mitigation strategy (OECD, 2021a, forthcoming, and 2021b, forthcoming).

\section{Figure 2.2. Components of a fiscal risks management framework}

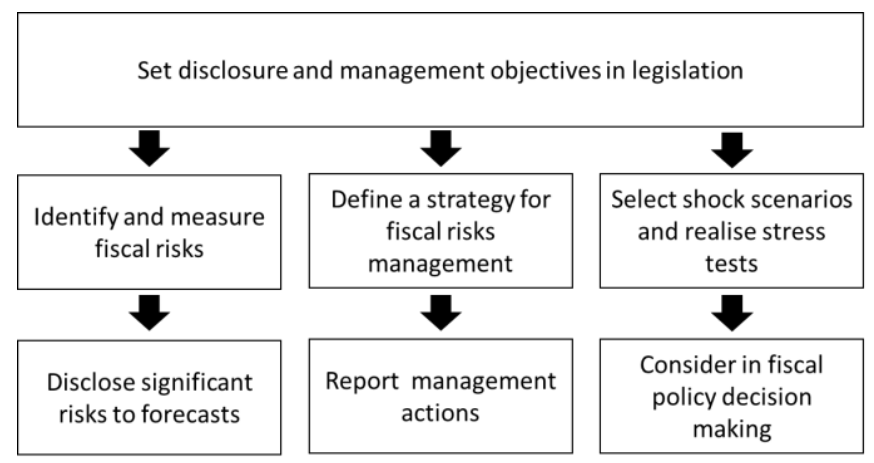

Source: OECD (2020) and OECD (2021a)

\subsubsection{Clarify roles and responsibilities for resilient infrastructure}

A strong institutional structure is key also for resilient infrastructure. In order to ensure that infrastructure is resilient against a wide range of threats, the OECD Recommendation on the Governance of Infrastructure highlights the importance of monitoring implementation and progress in attaining resilience objectives, and defining an accountability framework for critical infrastructure operators. Interdependencies of infrastructure assets and operations needs to be considered across sectors (e.g. electricity, transport, digital) as well as across countries so as to ensure that systemic risks are addressed effectively through resilience measures undertaken at the level of functions, with a focus on the most critical point of failures (OECD, 2019c). For example in Japan, work to develop guidelines and policies for enhancing flood control functions of existing dams and for enhanced flood disaster management was coordinated by Cabinet Secretary of GOJ with involvement of the Ministry of Land, Infrastructure, Transportation and Tourism (MLIT), Ministry of Economy, Trade and Industry (METI), Ministry of Health, Labor and Welfare (MHLW), Ministry of Agriculture, Forestry and Fisheries (MAFF), Japan Meteorological Agency (JMA), and Agency for Natural Resources and Energy (ANRE) (G20, 2021).

With an ageing infrastructure stock and being a disaster-prone country, in 2013 the Japanese government established the Inter-Ministerial Co-ordination Committee to develop a national strategy for the infrastructure's life extension to enhance safety and resilience controlling long-term public expenditures and fostering business in the maintenance sector. The committee was chaired by the Cabinet Office and led primarily by the Ministry of Land, Infrastructure, Transport and Tourism (MLIT) in terms of planning and implementation. Line ministries and municipalities were required to create maintenance plans, specification of maintenance measures (i.e. repair, rehabilitation, or reconstruction), investment plans, and implementation schedules. As of October 2020, the majority of eligible entities had created the individual Facility Plans: 1,824 entities (92percent) for bridges, 712 entities (100percent) for tunnels, and 64 entities (99percent) for dams (G20, 2021).

Lack of accountability and "ownership" of risk is a major challenge. Lack of clarity over responsibility for and management of an asset risk, i.e., determining who is accountable and liable for damages to third parties, will lead to a significant underinvestment in resilience (OECD/The World Bank, 2019, Fisher and Gamper, 2017, OECD, 2019).

In addition, governance mechanisms and risk management should acknowledge the often shared nature of ownership and operation between public and private stakeholders and the need to cover the entire infrastructure life-cycle (OECD, 2021a, and 2021b). Resilience investments are driven by an operator 
incentive structure to maintain business continuity to keep revenues coming, while a lack of competition and monopolistic market conditions can discourage service providers, such as energy sector utilities and system operators.

A good practice for co-ordinating policy objectives and balancing relevant trade-offs across several functions in government is to establish a national policy on critical infrastructure resilience that brings together risk management central bodies, sectoral ministries and agencies overseeing infrastructure delivery, as well as economic regulators (Box 2.2). A national strategy can clarify roles and responsibilities for resilience, as well as reconstruction and rehabilitation costs and clarify incentive structures.

\section{Box 2.2. Strategic Framework for energy supply resilience in Finland}

In Finland, the resilience of the energy production, transmission and distribution networks is a key priority due to the risks that the infrastructure system is exposed to that can result in potentially severe impacts. As a response to these threats, Finland has developed a strategic framework for Security of Supply, with a clear vision for resilience and definition of the country's critical infrastructure services.

Through the strategic framework, Finland has been able to harmonise national preparedness guidelines, outline clear roles and responsibilities across departments and subnational governments, as well as strengthen the role of regulators in ensuring well-functioning markets and sound regulation for critical infrastructure resilience. The strategy also establishes principles of co-operation and partnership with the private sector and international parties, especially since the voluntary co-operation between industry and sectoral government authorities has been fundamental in fostering trust and build consensus on resilience objectives.

Source: (OECD, 2019c; OECD, 2021a, ; OECD, 2021b,).

\subsubsection{Ensure co-ordination at all levels of government}

A multi-level governance approach is needed for infrastructure across sectors. The OECD Recommendations on the Governance of Infrastructure, and on Effective Public Investment across Levels of Government invite countries to design and implement investment strategies tailored to the place the investments aim to serve. Infrastructure governance encompasses all levels of governments, with local levels - regions and cities - having major responsibilities (OECD, 2019a and 2019b). This is particularly relevant for local impact and maintenance responsibilities, with authorities often affected by budget constraints (see also Chapter 5).

Over the past decades, the responsibilities of subnational governments with respect to infrastructure have increased in a majority of OECD countries - both federal and unitary. On average, subnational governments are in charge of 57 percent of public investment in the OECD (OECD, 2018), and almost 40 percent around the world (OECD/UCLG, 2019). Subnational governments have also major responsibilities in managing investments that support climate mitigation and adaptation efforts (G20/OECD, 2020). Across the OECD, they are responsible for 55 percent of environment and climaterelated public investment spending and 64 percent of environment and climate-related public investment (OECD, 2019a). In particular, community-driven approaches to infrastructure operation and maintenance have attracted increasing attention in developing regions. This approach lets rural communities set priorities for rehabilitation and maintenance and gradually decentralised the management, endowing provincial municipalities with authority and budget responsibility. (World Bank, 2014)

Since a large part of infrastructure investment is conducted at the subnational level, there should be robust co-ordination mechanisms for infrastructure policy within and across levels of government. Effective 
investment requires policies and practices across all levels of government to co-ordinate investment, strengthen capabilities, promote policy learnings, and ensure proper framework conditions for public investment (OECD, 2019a and 2019b). The COVID-19 crisis has differentiated impact across regions and cities within countries. All levels of government have to work together for an effective recovery (OECD, 2021e). In Japan, the national and subnational governments are closely linked in an expanding portfolio of national and subnational "National Resilience Plans" (NRPs). These plans aim to ensure that important infrastructure systems such electricity, airports, ICT, railroads, and flood protection can perform their functions in the event of any disasters, and thus protect human lives and support the national economy (OECD, 2021a, , and 2021b,).

Infrastructure plans and spatial planning frameworks tend to be established nationally, but subnational authorities might issue their own regulatory requirements. For example, the Danish parliament passed a law enabling municipalities to account directly for adaptation in local city planning decisions. The new law allows municipalities to ban construction in certain areas solely due to reasons relating to climate change adaptation (OECD, 2013). Regions and municipalities also have a key role in implementing the national recovery packages, which includes many infrastructure investments. For example, in July 2020, Korea adopted the New Deal to combat the economic setbacks caused by COVID-19, with a distinctive territorial approach. The government will assign major projects, such as installing green technology in outdated government-leased apartments, or installing artificial intelligence technology in traffic systems, after categorising the 299 local governments according to their development status. Some of the planned projects will be led by local governments rather than by the central government (OECD, 2021a, and 2021b).

\subsection{The role of regulation for asset performance and resilience}

\subsubsection{Promote good governance of economic regulators}

Economic regulators are part of an effective infrastructure governance framework. They ensure that a lack of competition for infrastructure services (usually where services are delivered by monopolies) does not result in excessive prices and poor service quality. Economic regulators set tariffs and ensure access to both public and private infrastructure in a number of industries such as water, electricity and gas, telecommunications and transport. Where economic regulators are involved in infrastructure industries, they have an ongoing relationship with the operators of regulated infrastructure throughout the infrastructure's life-cycle - from the identification of infrastructure needs, through construction and maintenance to its eventual decommissioning.

Economic regulators can give confidence to the market in regulated sectors such as water or energy and contribute to resilient and quality infrastructure. As highlighted by the OECD Recommendation on the Governance of Infrastructure, life-cycle costs and asset quality can be optimised through sustainable tariff settings, supporting market efficiency, quality, reliability and affordability of services.

Regulators can use the information collected for setting tariffs to inform decision-makers about capital costs, asset depreciation and consumers' preferences. Investment decisions can also benefit from effective price and quality regimes, as tariffs can cover the costs of infrastructure maintenance and upgrade, and thus reduce fiscal stress on governments (OECD, 2021a, , and 2021b,). For example, the Bundesnetzagentur (BNetzA) - the German Federal multisector economic regulator - introduced in 2009 the incentive regulation in the energy sector to ensure efficient grid operation investment. The incentive regulation includes all costs, i.e. capital expenditure (CAPEX) and operational expenditure (OPEX), thus following a total expenditure or TOTEX approach. Based on an efficiency benchmark, BNetzA calculates with the revenue cap formula for each operator a revenue cap setting the efficiency target (relative to the 
most efficient operator and factoring in a general productivity factor X-gen) to be reached during the regulatory period ("individual revenue path") (G20, 2021).

Cost-effective resilience measures can be prioritised across the infrastructure life-cycle through incentives. For example in Finland, the Energy Authority sets the requirements for business continuity and reliability standards in the electricity sector, while the National Emergency Supply Agency provides tools, guidance and methods for operators to comply with these regulations. In France, critical infrastructure operators and local authorities have agreed on a mix of measures to increase critical infrastructure resilience for the risk of a major flood in Paris, including information-sharing tools, emergency preparedness and vulnerability reduction policies for existing and future infrastructure (OECD, 2019c).

In the UK, the water sector regulator Ofwat includes resilience as a key theme for setting tariffs. As such, private sector participants submit business plans to Ofwat, and these are mapped onto government priorities (including resilience and maintenance). Ofwat then outlines expectations and findings in relation to companies' plans on long-term resilience. This can include the quality of their resilience frameworks or maintaining stable asset health. The determinations for 2019 have pledged $£ 12 b n$ extra funding to increase resilience and protect the environment $(\mathrm{G} 20,2021)$. Also in Scotland tariffs take into account climate objectives beyond financial sustainability (See Box below).

Economic regulations can also lead to more resilient infrastructure by removing barriers to investment in climate adaptation measures (OECD, 2018). In the UK, there is a focus to review price control mechanisms in energy and water sectors to reflect long-term asset life in a changing climate context, aligning incentives with long-term investors, resulting in better management over the life-cycle (see Chapter 5). Germany is considering incentive regulations to allow additional climate adaptation-relevant investments for power generation, transmission and distribution to be accredited or reimbursed (Vallejo and Mullan, 2017).

\section{Box 2.3. Strategic Review of Charges by the Water Industry Commission of Scotland}

The Water Industry Commission for Scotland (WICS) is the economic regulator of the water industry in Scotland. The regulator engages in a price setting process every six years within overarching principles and objectives set by the Scottish government. The Strategic Review of Charges for 2021-27 (SRC21) began in 2017 and sought to base SRC21 on a transparent and collaborative price review, in a context of the emerging evidence of the long-term challenges faced by the industry in respect of the need to transition to net zero by 2040 and replace ageing infrastructure in a financially sustainable way.

SRC21 introduced a new regulatory framework designed to address these challenges. This approach included promoting open dialogue of the issues and seeking to establish an evidence base that underpinned the requirements. The regulator believed that the previous focus on establishing a hard budget constraint as a way of ensuring efficient resource use over a defined regulatory period - while effective in the shorter term - had not created sufficient focus on the asset needs over the long-term. Underinvestment in replacement of utility assets inevitably raises issues of intergenerational equity when current consumers are not paying the true cost of services. In addition, the traditional regulatory approach tended to result in investment decision-making on the basis of lowest immediate cash use, rather than investment in solutions that created the best value for customers, with payback occurring beyond the regulatory period. At the same time, given the long asset lives associated with a large proportion of the asset base, there is inherent uncertainty about the timing of investment need placing an undue reliance on the ability of the regulated company to forecast five to six years out. Infrastructure investment can be "lumpy", marked by large one-off expenditures, and this can be incompatible with a focus on fixed regulatory periods.

Faced with these challenges, SRC21 resulted in shifts to the regulatory framework that encouraged a long-term perspective and allowed for flexibility to respond to emerging needs and analysis. To 
encourage a long-term perspective, the regulator asked the regulated company to create a long-term strategic plan. The new regulatory framework represents a shift away from the rigid approach of previous periods when the company and regulators would agree ex-ante on a list of necessary investment requirements. The new process, supported by an Investment Planning and Prioritisation Framework, supports decision-making based on highest priority and highest value, rather than setting ex-ante defined outputs and then seeking to deliver these at lowest short-term cost. The result is a framework that allows for rolling investment decisions based on evidenced priority and value. To incentivise the move to whole-life cost solutions with wider benefits (such as Natural and Social capital benefits), WICS has also allowed for an additional element of ring-fenced funding that only becomes available when the company has identified and evidenced investment expenditure with higher cost, but higher whole-life value.

As part of the new regulatory framework for SRC21, the regulator worked jointly with water industry stakeholders throughout the process to ensure joint ownership of the approach, which focused on establishing the best outcomes for customers, communities and the environment.

In particular, stakeholders were committed to adopting the principles of Ethical Based Regulation (EBR). EBR requires open and honest conversations about the future challenges for the Scottish water industry, and how best to tackle them. This approach necessitates candour and transparency in all interactions between the regulator, Scottish Water and other stakeholders. EBR will be supported by the adoption and implementation by Scottish Water and other market participants of Ethical Business Practice (EBP) which seeks to build trust and confidence through a combination of candour and evidenced analysis.

\subsubsection{Resilience standards and regulations}

Regulations can either prescribe detailed technical regulations and standards for quality infrastructure and resilience, or specify contractual outcomes linked to the duration of service disruption or minimum service requirements (OECD, 2021a and 2021b).

Asset and maintenance standards allow to hold contractors accountable for project and professional specifications and can be embedded in contractual provisions improving maintenance delivery. Among major international standards for quality infrastructure are the British Standards Institution's (BSI) Publicly Available Specification (PAS 55), the International Standards Organisation 55000 (ISO 55000), and two major international standardisation organisations: the European Committee for Standardisation (CEN, Centre Européen de Normalisation) and the International Standards Organisation (ISO) (WEF 2014 and OECD, 2018). For example, standards for pavements, road barriers, and street lighting developed in Australia support decision making measuring the value of road maintenance and renewal work, maintenance and performance outcomes (Opus International Consultants 2016; Austroads 2018).

Regulations can also focus on resilience, such as in the case of Fiji where climate risk reporting became mandatory or in Norway, where municipalities are required to prioritise the conservation or restoration of ecosystems to manage natural hazards and need to provide a rationale if they chose a different measure (OECD, 2020e, 2021a, and 2021b). However, the uncertainty of the nature and intensity of hazards and vulnerabilities, from climate to cyberattacks to pandemics, poses challenges in setting realistic standards with a high degree of confidence. Academia and scientific evidence data and analysis should be reflected in the design of resilience standards.

Standards and technical specifications also require government action to ensure that they are implemented. For example, the United Kingdom's National Infrastructure Commission, through its resilience strategy, recommends that regulators not only develop resilience standards and cost them, but carry out regular monitoring of their implementation by operators (OECD, 2021a, and 2021b). The purpose 
of monitoring is to evaluate the compliance of infrastructure operators with resilience standards as well as with the conduct of stress tests. It also seeks to track the implementation of resilience measures that address the vulnerabilities revealed through stress tests. To further strengthen enforcement of resilience standards, regulators can issue fines, such as in the case of the water and digital infrastructure sectors (National Infrastructure Commission, 2020).

Regulation can unleash considerable opportunities for Nature-based Solutions (NbS). Spatial planning determines how housing, infrastructure development and land preservation are envisaged, and hence the role $\mathrm{NbS}$ can, and has to, play in that. Given the important role of local governments in spatial planning, countries have issued national guidance and developed tools to help promote the integration of NbS into local land-use plans. Another key regulatory lever that can foster the use of NbS is building codes. Countries are working to integrate NbS into building codes, such as requiring a minimum for green space areas on and around new buildings and permeable material in driveways to increase water absorption and retention capacities. Public procurement can influence which specific construction materials or plant species to be integrated into infrastructure investments. One challenge country practitioners seem to face is the difficulty of demonstrating the full range of the costs and benefits of $\mathrm{NbS}$, which makes it difficult for procurement agencies to follow value-for-money principles (OECD, 2021f) (see also Chapter 3).

\section{References}

ASCE. (2017), "Sustainability at ASCE." American Society of Civil Engineers, http://www.asce.org/sustainability-at-asce/ (Jan. 1, 2017). American Society of Civil Engineers.

Basu D., Misra A., Puppala A. J. (2015), Sustainability and geotechnical engineering: perspectives and review.

Bocchini, P. \& others (2014), Resilience and Sustainability of Civil Infrastructure: Toward a Unified Approach. Journal of Infrastructure Systems.

Bruneau M. and Reinhorn A. (2006), Overview of the Resilience Concept, Proceedings of the 8th U.S. National Conference on Earthquake Engineering April 18-22, 2006, San Francisco, California, USA Paper 2040.

Chittoori, B. \& others (2018), Unified Approach to Sustainability, Resiliency and Risk Assessments, Civil Engineering Department Boise State University.

Colker R., (2019), optimizing community infrastructure, resilience in the face of shocks and stresses.

Fisher and Gamper, (2017), Policy Evaluation Framework on The Governance of Critical Infrastructure Resilience in Latin America.

G20 (2021) Policy Agenda on Infrastructure Maintenance - Annex - Infrastructure Maintenance Case Studies.

G20/OECD (2020), Report on the Collaboration with Institutional Investors and Asset Managers on Infrastructure: Investor Proposals and the Way Forward.

Haeri, S. M. (2016), "The role of geotechnical engineering in sustainable and resilient cities." 23, 16581675.

Lee, M. (2016), "Resilience Assessment in Geotechnical Engineering." University of Waterloo.

National Infrastructure Commission (2020), Anticipate, React, Recover: Resilient Infrastructure Systems. IEA (2020), Energy Security, OECD publishing, Paris, France.

ITF (2021 forthcoming), Developing Strategic Approaches to Infrastructure Planning.

OECD (2021a) Governments at a Glance. 
OECD (2021b) Implementation Handbook on Quality Infrastructure: Chapter 4: Subnational governance and investment in infrastructure.

OECD (2021c), Recommendation of the Council on the Governance of Infrastructure, OECD/LEGAL/0460, [https://legalinstruments.oecd.org/en/instruments/OECD-LEGAL-0460].

OECD (2021d), Recommendation of the Council on Public Procurement, OECD/LEGAL/0411, [https://legalinstruments.oecd.org/en/instruments/OECD-LEGAL-0411].

OECD (2021e), The territorial impact of COVID-19: Managing the crisis across levels of government, [https://www.oecd.org/coronavirus/policy-responses/the-territorial-impact-of-covid-19-managing-thecrisis-across-levels-of-government-d3e314e1/].

OECD (2021f), Scaling up Nature-based Solutions to Tackle Water-related Climate Risks: Insights from Mexico and the United Kingdom, OECD Publishing, Paris, [https://doi.org/10.1787/736638c8-en].

OECD (2020a), Digital Economy Outlook 2020.

OECD (2020b), Public Procurement and Infrastructure Governance: Initial policy responses to the Coronavirus (COVID-19) crisis, [https://read.oecd-ilibrary.org/view/?ref=135 135391eb6wiwbrmn\&title=Public-Procurement-And-Infrastructure-Governance].

OECD (2020c), Best Practices for Managing Fiscal Risks: Lessons from case studies of selected OECD countries and next steps post COVID-19.

OECD (2020d), Subnational Government in OECD Countries: Key data 2018.

OECD (2020e), When the going gets tough, the tough gets going: how economic regulators bolster the resilience of network sectors in response to the COVID-19 crisis.

OECD (2020f), Regulatory Quality and COVID-19: Managing the Risks and Supporting the Recovery.

OECD (2020g), Nature-based solutions for adapting to water-related climate risks.

OECD/UCLG (2019), World Observatory on Subnational Government Finance and Investment, [https://www.sng-wofi.org/].

OECD (2019a), "Financing climate objectives in cities and regions to deliver sustainable and inclusive growth", OECD Environment Policy Papers, No. 17, OECD Publishing, Paris, [https://doi.org/10.1787/ee3ce00b-en].

OECD (2019b), Effective Public Investment across Levels of Government: Implementing the OECD Principles, [https://www.oecd.org/effective-public-investment-toolkit/].

OECD (2019c), Good Governance for Critical Infrastructure Resilience.

OECD/The World Bank (2019), Fiscal Resilience to Natural Disasters: Lessons from Country Experiences.

OECD (2019d), The Governance of Regulators, Driving Performance at Peru's Telecommunications Regulator.

OECD (2018), Climate Resilient Infrastructure, OECD Environment Policy Paper Nb 14.

OECD (2017a), Getting Infrastructure Right: A framework for better governance, OECD Publishing, Paris, [https://doi.org/10.1787/9789264272453-en].

OECD (2017b), Gaps and Governance Standards of Public Infrastructure in Chile.

OECD (2017c), The Role of Economic Regulators in the Governance of Infrastructure, The Governance of Regulators, OECD Publishing, Paris, [https://doi.org/10.1787/9789264272804-en].

OECD (2015), Recommendation of the Council on Budgetary Governance.

OECD (2014), Boosting Resilience through Innovative Risk Governance.

UNEP (2017), Mine Tailings Storage: Safety Is No Accident. 
UNIDSR (2009), "Terminology on Disaster Risk Reduction". United Nations Office for Disaster Risk Reduction Available from [https://www.unisdr.org/we/inform/terminology\#letter-c].

Vallejo and Mullan (2017), Climate-resilient infrastructure: getting the policies right.

WEF (2014), Strategic Infrastructure, Steps to Operate and Maintain Infrastructure Efficiently and Effectively.

World Bank (2014), Operations and Maintenance of Rural Infrastructure in Community-Driven Development and Community-Based Projects - Lessons Learned and Case Studies of Good Practice. 


\section{Innovation in maintenance and asset management strategies of existing infrastructure}

To meet increasing demand, rather than expanding capacity through new infrastructure, governments can maximise asset use and enhance its quality for users through demand management techniques and smart infrastructure or alternative sustainable options. New technologies and data science encompassing earth observation, remote sensing, big data, Internet of things (loT), cloud technologies and machine learning are transforming how infrastructure is operated and maintained. Nature-based solutions (NbS) offer innovative, cost-effective opportunities in support of infrastructure sustainability and resilience.

This chapter covers innovations in maintenance and asset management strategies - such as infra-tech and nature-based solutions - during the operations \& maintenance and renewal phases, hence the focus is on existing assets. 


\section{Introduction ${ }^{16}$}

Infrastructure assets are subject to value depreciation due to gradual wear or aging. Efficient monitoring and maintenance can avoid faster asset deterioration, loss of asset value and higher costs. In addition, maintenance is essential for infrastructure resilience to shock events: the impacts of floods, extreme temperatures, geological hazards, security threats or other risks depend upon assets' vulnerabilities, Pressure is growing to reduce costs with the fiscal limitations of local authorities translating into a lack of inspections and monitoring of infrastructure assets. At the same time, consumers' service quality expectations are rising with users of infrastructure expecting better information and management.

Monitoring asset performance during the operation phase measures the asset's condition, use and functionality, and can help inform operators on maintenance requirements for effective, safe and accessible public services. Without a clear view of the age profile and quality of the asset base, a country is unable to budget appropriately for maintenance funding. However, infrastructure monitoring through the asset life-cycle faces many challenges. Making use of new opportunities such as Infratech and investment in $\mathrm{NbS}$, also brings with it a host of governance challenges.

To meet increasing demand, rather than expand infrastructure capacity, governments can maximise asset utilisation and enhance its quality for users through demand management techniques and smart infrastructure. New technologies allow to reduce maintenance costs while improving operational efficiency. Automation and smartphones allow to reduce monitoring and maintenance costs, offering alternatives to traditional infrastructure design, construction and maintenance, while predictive maintenance can extend the life of the asset, ensuring also an efficient allocation of the available budget. Information technology systems such as digital twins can facilitate gathering and analysing data, undertaking a holistic approach through the life-cycle. Technology development plays a critical role in responding to the COVID-19 crisis enabling infrastructure to become more resilient to future disasters and pandemics, ensuring the continued operations of critical networks such as utilities, transport and telecommunications.

Nature-based solutions (NbS) offer innovative, cost-effective opportunities in support of infrastructure sustainability and resilience. The concept of $\mathrm{NbS}$ is fundamentally based on the understanding that natural and managed ecosystems produce a diverse range of services, on which sustainable infrastructure and resilience depend. NbS can range from minimal or no interventions to significant changes in ecosystem management. Minimal measures can be to protect or conserve ecosystem functions. NbS can increase the effectiveness and operable life of grey infrastructure. For example, integrating NbS into grey flood control measures can increase water absorption capacity, reduce velocity, and regulate peak flows. In the Odra basin in Poland, natural flood retention areas (dry polders) were combined with traditional flood embankments to protect against the recurrence of a very severe (1,000-year) flood (Browder et al., 2019).

\subsection{Monitoring and evaluation of public investments throughout the delivery, operation and decommissioning}

Monitoring the whole-of-life performance of an asset is crucial to optimise life-cycle costs and ensure asset quality. To ensure the asset performs throughout its life, the OECD Recommendation on the Governance

\footnotetext{
${ }^{16}$ This chapter covers implementation and delivery of asset management strategies during Operations \& Maintenance and Renewal phase hence the focus is on existing assets. It is based on OECD new material and case studies and examples from G20 members' survey, GIH, WBG and WEF. It includes work from OECD public governance work on infrastructure in earlier phases, in O\&M and decommissioning (OECD Recommendation on the Governance of Infrastructure, 2020).
} 
of Infrastructure highlights the relevance of monitoring asset performance against predefined service delivery targets and expected outcomes. An asset's value and depreciation should be reviewed regularly during operations, while managing the end of infrastructure contracts through audit and ex post value for money evaluations.

Major challenges for asset maintenance activities include limited visibility of asset conditions and manual data analysis processes. Traditional monitoring (condition assessment) of structures relies heavily on periodic visual inspections which results in significant cost and disruptions to users and subject to errors. The manual, time-consuming evaluation which leads to inefficiency, long maintenance periods and high costs. For example, the water sector or civil infrastructure (i.e. bridges) are commonly monitored through periodic site inspections with implications on significant cost and disruptions to users and difficult assessment of an asset's underlying deterioration.

\subsubsection{Monitoring asset performance}

Monitoring of infrastructure implies the regular observation and recording of the performance of the asset. It is a process of systematically and routinely gathering information on all aspects relevant to the delivery of the infrastructure service to the public and users in a timely and proportional manner. This includes the state of each infrastructure asset, piece of equipment and component, and how each of them performs, both over time and relative to others. The monitoring during the operational phase includes regular observation and recording of the performance data of the asset on all aspects relevant to the procurement of the infrastructure service to the public and users.

Knowledge of the condition of existing assets has budget implications. Identification of spending needs to maintain and upgrade infrastructure assets allows to include budget allocations for maintenance in longterm strategic plans. For example, the result of this analysis helped the German government to determine that EUR 141.6 bn of the Federal Transport Infrastructure Plan (EUR 269.6 bn) should be invested in the structural maintenance of existing networks, while only EUR 98.3 bn was allocated to upgrading and new construction projects (OECD, 2020a, 2021a, and 2021b).

Performance assessments are not regularly undertaken at government level. According to the OECD survey, in 2017 performance assessment was only mandated in half of the countries, and ex post audits by the Supreme Audit Institution (SAI) regarding infrastructure assets are mainly conducted on a case-bycase basis. The Supreme Audit Institution should audit and assess individual projects as well as the infrastructure programme in general with regards to its finance, performance, value for money and compliance over the life-cycle. This ex-post evaluation demands enough human and financial resources and dedicated tools. Systematic audits are also common for financial audits but less used with respect to value for money.

Maintenance of infrastructure suffers from insufficient measurement. Data on assessments of past and current conditions are often not available. This includes data on past construction and repairs and an asset's usage and performance. Keeping records on public assets up to date is a technically demanding task, involving valuation and revaluation of nonfinancial assets. The majority of countries do not reflect nonfinancial assets in the government's financial statements, with only a few countries producing comprehensive asset registers - such as Estonia and Ireland (Blazey, Gonguet and Stokoe, 2020). An analysis of accrual basis financial data showing cumulated amortisation and depreciation of assets and technical assessments of existing infrastructure has also been explored as an option for governments to plan for the maintenance of the most appropriate assets in order to meet current and likely future demands, and the disposal of assets that are no longer required.

Few countries produce exhaustive maintenance expenditure data on a regular basis. Most empirical studies focus on specific sectors such as transport thanks to better data availability, including at a crosscountry level, available for example at the OECD database. In Canada, information is gathered through 
the Annual Capital and Repair Expenditures Survey, and in the United Kingdom through the Annual Report on the Government Major Projects Portfolio.

Monitoring is paramount to ensure resilience of critical infrastructure. Continuous monitoring increases accountability and early adoption of resilience measures. Beyond regular performance assessments to prioritise investment in resilience, other tools include fines for noncompliance and positive incentives such as recognition or awards for implementation good practices, open access evaluations or rankings. In Korea, the Ministry of Interior and Safety makes public the annual evaluation ranking of disaster response capacities amongst critical infrastructure operators. The resulting peer pressure creates additional incentives for operators to keep up their public image (OECD, 2021a, and 2021b,).

\section{Box 3.1. Smartphone data for monitoring}

Gul M., Mei Q. (2018) presents a novel crowdsourcing-based framework for indirect bridge health monitoring by utilising smartphones in vehicles as sensors of infrastructure quality. In their proposed framework, smartphone data from a large number of vehicles could be used to detect damage. When people drive across bridges, for example, their smartphones would automatically collect the vibration data and extract features which would be transmitted to a remote database where it would be analysed systematically to assess the condition of bridges.

Batista A. J., Giusti, R. Souza V.M. (2018) propose a conceptual framework which also uses smartphones as an automated pothole detection system using vibration data. A mobile phone application would collect vibration signals and location information. After processing the data, the app would identify potential pothole-related road segments and report them, together with their GPS location which would allow the identification of real potholes using pre-trained machine-learning. This information would be saved to a custom database that can be used by a road maintenance department. This data could also be used to warn drivers of approaching potholes, reminding them to slow down and be careful.

Sources: Gul M., Mei Q. (2018), "A crowdsourcing-based methodology using smartphones for bridge health monitoring", Struct. Health Monit., vol. 18, pp. 1602-1619, 2018., Batista A. J., Giusti, R. Souza V.M. (2018), "Asfault: A low-cost system to evaluate pavement conditions in real-time using smartphones and machine learning", Pervasive Mobile Comput., vol. 51, pp. 121-137, 2018.

\subsection{Maximising asset utilisation in operations and maintenance}

Major challenges for existing infrastructure include congestion and excessive demand impacting the quality of physical assets. Demand has risen beyond forecasted levels due to societal and demographic trends such as global population growth and urbanisation.

To meet increasing demand, rather than expanding infrastructure capacity, governments can maximise existing assets by enhancing their quality for users and therefore reducing investment in new capacity. New financing models and vehicles could also help countries facing the current economic downturn by increasing private sector investment in resilient infrastructure, widening the range of investors, and increasing transparency and stakeholder participation (See Chapter 5). 


\subsubsection{Demand management techniques and smart infrastructure}

Beyond building new assets, it is essential for governments to make the most of existing assets.

By 2050, according to the UN Department of Economic and Social Affairs, 68 percent of the world population is expected to live in cities compared to 55 percent of the population today. This results in higher pressure on transport networks and consequent growing congestion. At the same time, consumers' expectations of infrastructure service quality are rising, for example demand for information to avoid traffic in real time.

Demand-side measures improve resilience, reducing failures and disruptions in service provision. Demand management techniques aiming to influence behaviour and investments of infrastructure users include time-based user charges; self-regulation through improved information; increased operations control redistributing demand in time, space or mode (for instance, reducing peak-period car travel in urban areas) WEF (2014).

\section{Box 3.2. Innovation in Public Transport}

Lincoln Autonomous Shuttle Project: The City of Lincoln, Nebraska, USA, successfully tested a demand-responsive autonomous microtransit vehicle on the University of Nebraska's Innovation Campus. This project showed how new transportation technologies can be integrated into an existing public transit system to ensure safe, efficient, affordable and equitable access to transport services.

Local Government - Dk Plus de Mobilité: The Dunkirk Urban District Council in France, has established "DK Plus de Mobilité" to increase the share of public transit (currently less than 7 percent) in the Dunkirk area (200 000 inhabitants). The project - developed in consultation with the local population - combines free public transport for all, with the upgrading and modernisation of transport infrastructures.

Singapore Fusion Analytics for Public Transport Emergency Response: The Singaporean government has launched the Fusion Analytics for Public Transport Emergency Response (FASTER) initiative, a pilot which uses big data to improve the country's public transport system by more quickly responding to train breakdowns, delays and other unexpected incidents. With FASTER, the transit authority collects anonymised location-based information from StarHub and combines it with fare card transactions and video feeds from stations to identify stations that have become overcrowded. When it detects heightened crowding, Singapore deploys bus services and issues alerts on social media to inform commuters of expected delays to give them an opportunity to plan accordingly. These data also provide the opportunity to develop detailed models of how users move through the city, helping government understand traffic patterns, how citizens use the urban transport system and key problems with existing routes. This information helps the authorities decide where more buses and trains are needed, or what incentives to provide to users to take different routes (in the form of travel credits).

Source: OECD (Fostering Innovation in the Public Sector (2017), OECD Observatory of Public Sector Innovation Observatory of Public Sector Innovation (oecd-opsi.org), and Land Transport Authority (2014), "LTA, SMRT, StarHub and IBM collaborate to improve transport with data for Singapore commuters", www.Ita.gov.sg/apps/news/page.aspx?c=2\&id=407a5053- 0345-40f5-8d64-51fb31bfb2a0; Weizhen (2014), "Big data to help ease transport woes", www.todayonline.com/singapore/big-data-help-ease-transport

Technological progress and big data have increased the opportunities for applying demand management. Internet of Things (IoT) and Artificial Intelligence-based cloud computing have allowed the digitalisation of assets, systems, and processes applicable also to infrastructure (Mabkhot et al., 2018). Availability of mass data and rapid advances in processing power, storage density and connection speed, have made big data applications increasingly economical. 
An increasing number of examples are showing how ICT-based innovations can strengthen infrastructure resilience:

- Distributing capacity in the energy sector: Smart meters and improvements in battery storage, hold the potential to increase domestic users' contribution to grid reliability. In the Netherlands, the Eneco Crowdnett is aggregating home batteries to provide a "virtual power station" and research is showing that the batteries of electric vehicles can be aggregated in a similar manner (OECD/The World Bank/UN Environment (2018).

Improving using real-time data: traffic management systems in Stockholm or Barcelona allow to evaluate current traffic situation and predict future congestion. Based on the demand level the Urban Lab Dynamic Traffic Forecasting in Barcelona increases and decreases the number of green lights and available parking spaces

- Managing demand in the water sector: Smart meters collect and transmit real time residential and industrial water usage data reducing water loss, demand forecasting and optimising network operations, as well as increasing community water efficiency. Evidence has shown a decrease of water consumption after the installation of metering technologies.

\subsection{Leveraging Infratech for better asset maintenance}

Maintaining high-quality infrastructure is challenging for numerous reasons, including harsh weather, unexpected utilisation, and inconsistent wear and tear. Effective infrastructure maintenance is based on structural health monitoring reducing the cost for maintenance and extending the service life.

Operational inefficiencies translate into higher costs and loss of asset value. Pressure is growing to reduce costs due to constraints to public budgets and customer demand for lower prices. In particular fiscal limitations of local authorities often translate into lack of inspections and monitoring of infrastructure assets.

There is a lack of information at the level of public infrastructure entities. Governments and infrastructure agencies do not have the necessary information for a holistic view of the network, in order to make shortterm decisions to adapt to events and incidents. Furthermore, the lack of data granularity makes it difficult to do meaningful data analysis to inform policy makers.

\subsubsection{Automation to reduce maintenance costs}

Automation allows to reduce maintenance costs offering alternatives to traditional infrastructure maintenance and monitoring. For example, drones represent a cost-effective alternative to time consuming and high-risk tasks typically performed by humans. 3D printing can ensure rapid and cost-effective formulation of parts with on-site 3D printing estimated to reduce manufacturing time of spare parts by up to 95 percent ${ }^{17}$. Miniature robots also have huge potential for deployment in pipes to identify leaks ${ }^{18}$. (See Box below). Increased automation has an impact on jobs market which needs to be taken into account by policymakers.

\footnotetext{
17 3D Printers, GIH (2020).

${ }^{18}$ Fiber-optic cable can be used to detect very small leaks by measuring variations in the signal in an external fiber, before the leaks develop into larger leaks and burst a pipe, WB (2020).
} 


\section{Box 3.3. Drones, 3D printing for maintenance}

Robotic technologies hugely improve inspection and maintenance of infrastructure reducing costs of manual inspection and large-scale equipment and allowing access to disaster sites (Asama $\mathrm{H}$., Nagatani K. 2016). For this reason, research and development on maintenance technologies is focusing on the use of flying and mobile robots and technologies for unmanned operation of construction equipment for emergency disaster restoration. However regular use faces also some challenges given the inability to conduct inspection work in strong winds and flight time limitations.

Drones in the transport and energy sectors allow monitoring and maintenance works and operational networks for compliance to contract service level agreements. "Drone technologies can enhance the process to inspect assets as the photos they take have a very high resolution, sharper than the human eye, and provide an opportunity for review multiple times. These photos can be used to gain a highquality perception of the condition of assets. They also enable enhanced safety and security through persistent and flexible surveillance coverage of the transport network and can provide rapid-response when a security-related incident is detected." (GIH, 2020)

3D printers producing individual components on-site allow for a fast response to maintenance requirements. For example, on-site printers in railway maintenance facilities can enable the rapid production of parts (e.g. chair armrests for trains) to replace faulty parts and allow a train to re-enter service. This on-demand 3D printing style is increasingly being adopted in public transport maintenance facilities, such as those operated by Bombardier, Siemens Mobility and Deutsche Bahn. $(\mathrm{GlH}, 2020)$

Sources: GIH (2020) Case Study DRONES FOR MONITORING SURVEILLANCE AND INSPECTION, GIH (2020) Case Study DRONES FOR MONITORING SURVEILLANCE AND INSPECTION, GIH (2020) Case Study 3D PRINTING FOR MAINTENANCE.

\subsubsection{Predictive maintenance to extend the life of the asset}

Optimising maintenance scheduling ahead of asset failure or breakdowns extends the life of the asset and limits its deterioration. In fact, maintenance is cost-effective and efficient when performed on a regular and pro-active basis. Predictive maintenance (PdM) leverages available data and new computing methods to send warnings in case of near failure.

An infrastructure asset's vulnerability and criticality determine the appropriate maintenance strategy with a major challenge the optimal time (before/after failure) to maintain an asset. Among the primary policies for maintenance of infrastructure, condition-based maintenance (CBM) has been one of the most preferred policies for the past few decades (Arrizabalaga S. Beltran S. Errandonea I. 2020). In fact, preventive maintenance leads to over-maintaining the asset regardless of actual need - a poor allocation of scarce maintenance funding - , whereas corrective maintenance is more expensive than directly enhancing the asset and can lead to penalties due to service interruptions.

Predictive maintenance defines the optimal timing for the maintenance of an asset, where early action leads to undue extra cost, and late activity represents a safety risk (Bukhsh Z., Stipanovic I. 2020). The use of sensors allows continuous monitoring and reporting of remote assets and machine learning techniques alert of current conditions while predicting future interventions. 
Figure 3.1. Maintenance policies

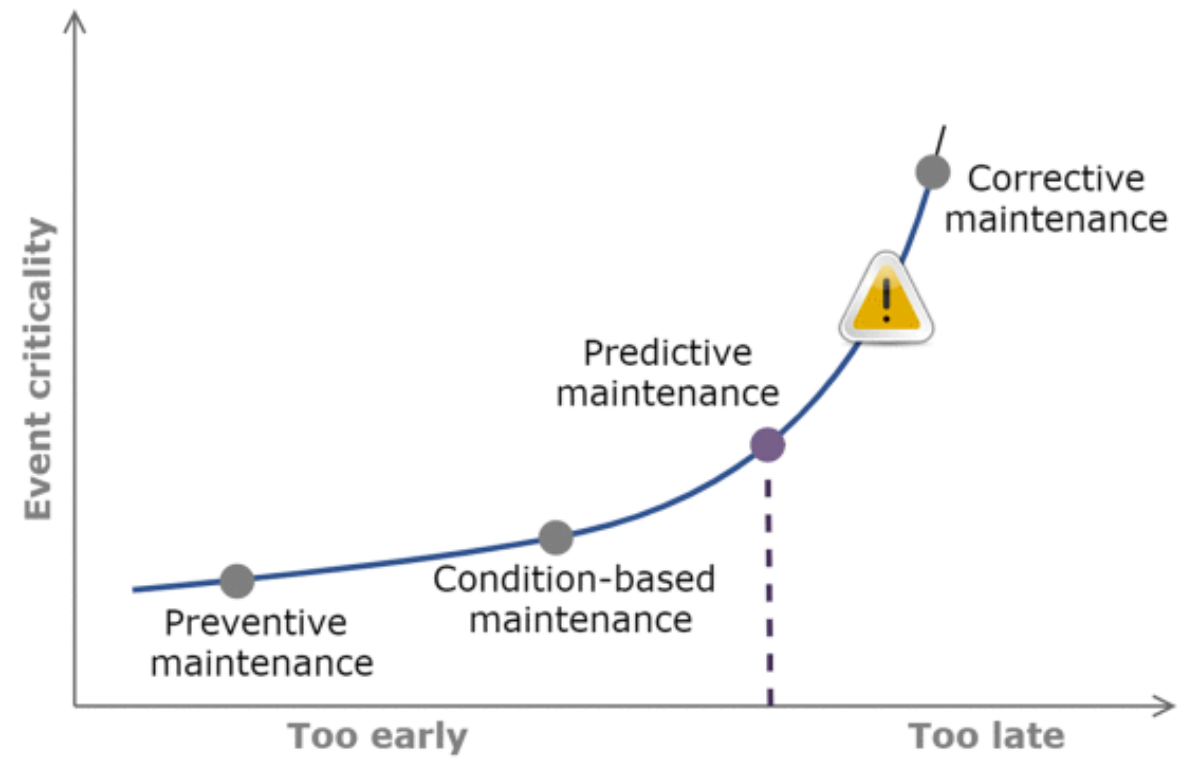

Source: Patwardhan, S. (2018)

By providing tools to better identify and target maintenance, predictive maintenance of infrastructure implies a more efficient allocation of the available budget. For example, in the province of Bolzano in Italy, the budget for the maintenance of the road infrastructure is predicted and allocated, collecting data and using machine learning algorithms to define the quality level of the roads and the level of road use (EC, 2021).

\section{Box 3.4. Infrabel: Making dumb hardware smart}

The large availability of similar assets in the rail sector allows wide application of predictive maintenance (PdM). According to a report from PWC (2017), Infrabel - the state-owned company responsible for Belgian rail infrastructure - has started large scale application of data analytics in maintenance as part of a complete transformation into a digital enterprise in which 'basic' assets are replaced by smart assets that are integrated in an Internet of Things.

In particular, Infrabel has developed new tools to automate maintenance. For example, it uses measurement trains for inspecting tracks, railway ties and overhead lines; cameras mounted on overpasses to monitor the pantographs of passing trains; sensors for detecting overheating in shaft sleeves on passing trains; semiautomatic vehicles to check whether sign-post visibility meets the regulatory requirements; and meters to detect drifts in power consumption.

New smart condition monitoring tools imply organisational changes. Major innovations include merging of smaller units and recruitment of data scientists, the creation of a centralised Data Centre functioning as a single tool where data from various systems is integrated and standardised.

Source: Predictive Maintenance 4.0 Predict the unpredictable June 2017 PWC 


\subsubsection{Information management systems: digital twins}

Information management systems allow to integrate different datasets, including multi-sensing systems, ICT, computer vision technologies, cloud data management, statistics and big data analytics (WEF, 2014). Building on this data, prediction models can support governments in better planning interventions, based on the underlying deterioration and evaluate overall performance of infrastructure assets. For example, the Cambridge Centre for Smart Infrastructure and Construction (CSIC), Highways England and Kier are testing emerging sensing technologies - acoustic emission - for the structural assessment and deterioration detection of static highways assets such as concrete bridges (CSIC, 2020).

A digital twin (DT) is a virtual replica of an asset including real-time data acquired during the operation of that asset (Coleman, 2020). According to Glaessgen and Stargel, a DT consists of three parts: the physical product, virtual product and the communication between them. By drawing on the best available data, the DT provides an integrated, multi-scale simulation of its real-world infrastructure counterpart, allowing operators to predict and test probabilities, including maintenance needs. (Glaessgen and Stargel, 2012 Arrizabalaga S. Beltran S. Errandonea I., 2020).

The UK and Germany are among the most active administrations testing digital twins for built environment and digitalisation strategies. The National Infrastructure Commission (NIC) report on Public Good, published in in 2017, suggests that through collecting the right data, setting standards and sharing data securely for the public good, the UK could release an additional $£ 7 b n$ in benefits per year across the infrastructure sector (equivalent to 25percent of the total UK infrastructure spend). In 2018, the UK Government Digital Framework Task Group (DFTG) published the Gemini Principles to guide the creation of a National Digital Twin (NDT) - an ecosystem of digital twins connected by securely shared data with the aim to improve the performance, service and value of the UK's infrastructure (CSIC, 2020).

InfraX in Germany, is a cloud-based digital platform for predictive maintenance of transport infrastructure, creating digital twins (as virtual replicas of physical assets) of infrastructure structures. InfraX supports local or national authorities consolidating data from input data (such as building inspection reports, photos, sensor or laser data). Building on this data, automated prediction and evaluation of remaining lifetimes of infrastructure provide support to policy decision makers. Predictive digital tunnel twins have also been used in the recent renovation of the 'Koningstunnel' in The Hague, the current renovation of the "Heijnenoord tunnel" near Rotterdam, and in the development of suites of bespoke digital tunnel twins developed by the municipality of Amsterdam and the Belgium region of Flanders (G20, 2021).

The concept of digital federation enables secure and sovereign data exchange within and between countries. Digital federation allows collaboration across the silos within the infrastructure sector and between the infrastructure sector and other industries. The potential integration of processes and value chains can help make the infrastructure sector more resilient, efficient and aligned with the realization of ambitious decarbonization and environmental protection targets. Governments have already developed architectures for sovereign and trusted data exchange such as the US NIST Cloud Federation and the EU Gaia-X Federation Services19 (Nübel K., Bühler M., Jelenik T. and others, 2021 forthcoming).

\footnotetext{
19 US: The NIST Cloud Federation Reference Architecture: https://www.nist.gov/publications/nist-cloud-federationreference-architecture ; EU: Gaia-X Federation Services: https://www.gaia-x.eu/sites/default/files/2021-05/Gaia$\underline{X \text { Architecture Document 2103.pdf }}$
} 


\subsection{Nature based solutions to strengthen infrastructure resilience}

Nature-based solutions ${ }^{20}(\mathrm{NbS})$ offer innovative - and in many cases, cost-effective - opportunities to support infrastructure sustainability and resilience. The concept of NbS is fundamentally based on the understanding that natural and managed ecosystems produce a diverse range of services, on which sustainable infrastructure and resilience depends. For example, urban green space expansion can contribute to strengthening urban infrastructure resilience against risks of flooding, while at the same time reducing the impacts of climate extreme events (e.g. heatwaves) by lowering the urban heat island effect as well as improving air quality. The later in turn makes an important contribution to human health and wellbeing. Similarly, complementing urban grey infrastructure (e.g. the built environment) with green measures (e.g. green roofs) increases water retention and carbon sequestration thus lowering carbon emissions from urban infrastructure and increasing resilience against water-related climate risks. Indeed, $\mathrm{NbS}$ have been recognised for their potential to reduce the sources of climate change (e.g. greenhouse gas emissions), while strengthening resilience to its harmful impacts (OECD, 2021c and 2021e).

$\mathrm{NbS}$ can range from minimal or no interventions to significant changes in ecosystem management. NbS may be a "no-regrets" measure, as they can yield benefits even in the absence of the underlying risk materialising, such as climate change (Hallegatte, 2009). At the same time, they can help manage uncertainty by avoiding or delaying lock-in to capital-intensive grey infrastructure, allowing for flexibility to adapt to changing circumstances, especially in terms of risks driven by a changing climate (OECD, 2013). For example, a floodplain may attenuate larger flood volumes than can be held within a levee-lined river channel, (World Bank, 2017), while mangroves can keep pace with moderately high rates of sea-level rise (Woodroffe et al., 2016).

$\mathrm{NbS}$ can increase the effectiveness and operable life of grey infrastructure. For example, integrating $\mathrm{NbS}$ into grey flood control measures can increase water absorption capacity, reduce velocity, and regulate peak flows. In the Odra basin in Poland, natural flood retention areas (dry polders) were combined with traditional flood embankments to protect against the recurrence of a very severe (1000-year) flood (Browder et al., 2019). Another example is the use of pervious concrete, porous asphalt for permeable pavements, infiltrating rainwater where it falls. This is particularly cost effective where land values are high and there are problems with flooding and icing (EPA, 2021). There is growing evidence of the economic benefits of $\mathrm{NbS}$. For example, in the Northeast of the United States, protected coastal wetlands are estimated to have helped prevent over USD 600 million of direct property damages during Hurricane Sandy (The Nature Conservancy Business Council, 2019). Globally, it is estimated that without mangroves, 15 million more people would suffer from flooding annually (Menéndez et al., 2020). Research has shown that in some cases, NbS can be more cost-effective than grey alternatives, and in particular for less extreme hazards. For example, across 52 coastal defence projects in the United States, NbS were estimated to be 2-5 times more cost-effective than grey infrastructure, and most effective to defend against waves up to half a metre high and at increased water depths (Narayan et al., 2016).

Studies which compare the value of $\mathrm{NbS}$ to alternative approaches are rare, and economic appraisals often do not properly capture or value the full suite of co-benefits of an NbS. In addition to reducing losses and damages, the multiple co-benefits of $\mathrm{NbS}$ can have significant economic value. For example, in Europe, it was found that restored rivers, in addition to increasing flood protection, enhanced agricultural production, carbon sequestration and recreation, yielded an estimated net societal economic benefit over unrestored rivers of an estimated EUR 1400 per hectare per year (Vermaat et al., 2015). Finally,

\footnotetext{
20 Definition of Nature-based Solutions: NbS are measures that protect, sustainably manage or restore nature, with the goal of maintaining or enhancing ecosystem services to address a variety of social, environmental and economic challenges $\mathrm{NbS}$ can be considered as an 'umbrella concept' for other approaches such as ecosystem-based adaptation (EbA), eco-disaster risk reduction (eco-DRR), green infrastructure (GI) and natural climate solutions (NCS) (OECD, 2020b).
} 
investments in NbS can stimulate the economy by creating jobs, much the same way as investments in grey infrastructure. For example, the American Recovery and Reinvestment Act of 2009 financed coastal habitat restoration projects that yielded 17 jobs per million dollars invested (Edwards, Sutton-Grier and Coyle, 2013). In the European Union, it is estimated that restoring 15percent of degraded ecosystems would result in between 20000 and 70000 full-time jobs (OECD, 2019b).

\subsection{Promoting public sector take-up of Infra-tech and Nature-based solutions}

While many of the Infratech and NbS strategies for building infrastructure resilience are not new, in practice they are still often applied as one-off interventions, at relatively modest scale, and on an ad-hoc basis. In order for governments, investors and users to benefit from these innovative approaches, governments first need to understand their uses and limitations, and more importantly, modernise decision-making, monitoring, and accountability systems to allow for more agile, outcome- and data-based approaches to infrastructure management over its life-cycle. New technologies and NbS often lack the policy and financial framework to be applied more systematically, more frequently and at larger scale.

In the context of developing countries, innovation in general has been an engine for the growth, driving technological advances, productivity enhancement and stronger competitiveness through transformational revolutions in products, services, processes, and delivery modalities, as well as governance and financing. While conventional technology/innovation transfer from advanced economies has played a significant role in developing countries, the context- and location-specific nature of development challenges calls for demand-oriented and bottom-up local innovation to address social and environmental challenges associated with infrastructure management. Promotion of and engagement in such innovation should be well targeted and time-bound, building locally specific capabilities for problem solving - while also recognising many potential flow-on benefits of locally-driven innovation. Despite the evident benefits that developing countries can draw from innovation, remarkably low levels of innovation-related investment, a lack of the necessary complementarities like physical and human capital, and other challenges like the cost of doing business or intellectual property rights, impede both innovation itself, and the returns that any innovation does produce. In this context, building and streamlining innovation ecosystems - both institutional and entrepreneurial, and multidisciplinary collaborative ecosystems - that support collective efforts for spurring innovation is essential.

\subsubsection{Public governance challenges for the take-up of InfraTech}

Given the many actors and jurisdictions involved in the planning and delivery of infrastructure, the broader take-up of digital technologies is hampered by a lack of national standards and approaches that would enable standardised approaches, interoperability and benefits of scale. In addition, as some innovative solutions rely on new technologies that are still relatively un-tested or un-proven, technological uncertainty may reduce the willingness of some actors to invest in their use. At a deeper level, new technologies for monitoring, delivering and predicting infrastructure maintenance needs call for the continued shift of public sector decision-making processes to focus on outcomes, to be more open to external stakeholders, and to work in real-time on the basis of data and analysis, thereby requiring fundamental changes in regulatory, audit and decision-making processes. (See also Chapter 4).

- Agile governance and regulatory frameworks: in response to the challenges and opportunities brought by new (digital) technologies, the OECD is developing draft principles on Agile Regulatory Governance to Harness Innovation. The Principles would support governments in using and adapting regulatory policy and governance in the face of disruptions and capitalise on the opportunities brought by new technologies to establish agile, resilient and data-driven policy 
approaches ${ }^{21}$. For example, the emergence of new data sources presents new opportunities to help monitor and enforce regulations, including remote and real-time monitoring of compliance.

- Digital Maturity: Beyond digitising analogue public sector processes, adopting InfraTech will require an underlying re-design of government processes that takes into account the nature and strategic role of digital tools and technologies. The OECD 2019 Digital Government Index maps and assesses six dimensions characterising a fully digital government: Digital by design, Datadriven public sector, Government as a platform, Open by default, User-driven and Proactiveness ${ }^{22}$.

- Data-driven public sector: Countries such as Ireland, the Netherlands, United Kingdom and the United States have moved or are moving towards the definition of overarching data strategies as means to strengthen data governance in the public sector, build greater public sector cohesion and promote the integration and application of data for decision-making, performance, foresight and service design and delivery ${ }^{23}$.

- Budget planning processes and criteria: In order to adopt more cost-effective interventions, for example through the use of predictive maintenance, public budgeting processes will have to develop more outcome-based decision-making criteria. Currently budgeting follows the "preventive maintenance" process, where maintenance intervention is planned manually by experts in the field, based on information such as date of the last intervention, available budget, manually determined quality of the road, characteristics of the road (geometry, height, gradient) (EC, 2021).

- Procurement of ICT: Improved dialogue between project and programme-level developers of ICT solutions and Central Purchasing Bodies can enable public procurement solutions that better tap into private sector innovation, to decide what to develop themselves and what to purchase from markets and to manage the risk of stranded technologies and datasets linked to outdated technologies. Such an approach can also support testing, experimentation and piloting of new technologies that helps better tailor digital tools to final user needs, minimising risks linked to the dynamic nature of digital tools.

\subsubsection{Governance challenges for the take-up of $\mathrm{NbS}$}

A set of underlying characteristics of $\mathrm{NbS}$ differentiates them from traditional infrastructure, making them a "poor fit" for decision making within existing institutional, regulatory and financial processes developed with traditional infrastructure solutions in mind (OECD, 2020b).

The characteristics of $\mathrm{NbS}$ can limit their consideration by governments, local authorities or the private sector in different phases of the infrastructure life-cycle:

- Timeframe, planning and prioritisation: While grey infrastructure reaches its desired protective benefit immediately upon finalisation of construction, the growth rate of the living components, such as forests, takes much longer to fully reap their full protective benefit. (Kabisch et al., 2016). Some $\mathrm{NbS}$, especially those involving the restoration of badly degraded ecosystems, can be slow to develop their benefits or deliver potential co-benefits in full. At the same time, the adaptability of $\mathrm{NbS}$ over time make them appreciate in value as opposed to the high depreciation costs associated with grey infrastructure. The challenge though is that $\mathrm{NbS}$ may not yield the resilience effects in the time frame policy makers would hope for (World Bank, 2017). The dynamism of NbS can lead to policy makers, regulators and/or permitting agencies prioritising grey infrastructure over $\mathrm{NbS}$

21 OECD Effective and innovation-friendly rulemaking in the Fourth Industrial Revolution; Concept Note [GOV/RPC(2020c)25].

${ }^{22}$ OECD (2020d), "The OECD Digital Government Policy Framework: Six dimensions of a Digital Government", OECD Public Governance Policy Papers, No. 02, OECD Publishing, Paris, [https://doi.org/10.1787/f64fed2a-en].

${ }^{23}$ OECD (2019b), The Path to Becoming a Data-Driven Public Sector [https://doi.org/10.1787/059814a7-en]. 
because it is familiar and easily understood with respect to compliance and permitting. Assessing technical performance of an $\mathrm{NbS}$, as well as its interaction with grey infrastructure, can be imprecise due to the inherent dynamism and complexity of natural systems.

- Cost-benefit assessments: Delays to the accrual of benefits due to time scales mean that benefitcost ratios are variable over time, oftentimes resulting in traditional cost-benefit assessments leading to skewed results for NbS. In addition, NbS generate a host of ancillary social, economic and environmental co-benefits related to human health and livelihoods, food and energy security, recreation/tourism, ecosystem rehabilitation and maintenance, climate change mitigation and adaptation or biodiversity protection. These benefits are often not reflected in the benefits assessment of traditional infrastructure investments. The existing methods for assessing, valuing and monitoring these co-benefits are often underdeveloped or challenging to apply (Trémolet S. et al, 2019). There is additionally a wide variation in the hydrological and other services delivered by different ecosystem types (WWAP, 2018), and specific costs and benefits of different solutions are dependent on local circumstances (Brown and Mijic, 2019).

- Implementation: The spatial scale considered for planning NbS substantially affects their ability to deliver expected outcomes. Often, NbS cannot be sustained by managing individual sites in isolation, as the delivery of associated ecosystem services might depend on processes taking place on a larger scale (World Bank, 2017). In some cases, a certain size of ecosystem may be needed for it to be resilient to various pressures and therefore continue to provide services in future. Finally, there are inherent trade-offs in the use of $\mathrm{NbS}$ as the space dedicated to $\mathrm{NbS}$ often implies the land cannot be used for another productive use.

- Operation and maintenance: On the one hand, NbS cross jurisdictions as well as sectors, causing confusion over ownership and responsibility for maintenance. NbS often require the active support of local citizens and landowners, for example through tasks such as replanting trees or maintaining water retention structures. This is in contrast to the long-term operations and maintenance of grey infrastructure, which is typically the direct responsibility of the service provider or infrastructure operator. A reliance on a multitude of stakeholders can create uncertainties about performance over time. On the other hand, ecosystems are not static, as they are made of living components that change over time. This can be a benefit, as it means NbS can adapt to changing environmental and risk conditions, thereby potentially exceeding the design lifetime of grey infrastructure (World Bank, 2017). However, it can also introduce new sources of uncertainty, increasing the difficulty in developing solid predictions about service levels. NbS implemented for climate adaptation purposes may themselves be climate-sensitive. For example, peatlands provide valuable ecosystem services through flood management and carbon sequestration (Shuttleworth et al., 2019), but are highly sensitive to climate change (Bonn et al., 2016).

- Securing financing: Diffuse benefits can render NbS challenging for private investment to create suitable revenue streams when many of the potential co-benefits are not traded in the market. The combination of inherent ecological dynamism and long timescales can create challenges with setting a payment schedule among beneficiaries, which can pose challenges to investors seeking short- or medium-term returns. Finally, most existing funding models do not match well to the need for continuous low-level investment over long time frames that characterise $\mathrm{NbS}$.

- Stakeholder engagement: Large spatial scales often require interventions that involve multiple stakeholders. The cost of engaging and negotiating with multiple stakeholders, working across regulatory jurisdictions and collaborating with dispersed landowners can be time consuming and costly. In addition, those responsible for providing the adaptation service (such as a flood management authority) may not have the capacity or legal legitimacy to engage with landowners.

- Monitoring and evaluation: Monitoring green infrastructure that covers large spatial areas may require data collection and analysis across sectors as well as co-ordinated processing 
communication among agencies at different governance levels. Monitoring ecological trends may require a different set of expertise and metrics than would be used for conventional infrastructure.

National governments play a key role in fostering the take-up and scaling of new technologies and NbS. As discussed in the next chapter, building capabilities for resilience and maintenance in strategy and planning will help to align and bridge planning objectives and timeframes, focus monitoring and performance criteria on risk and outcomes, and co-ordinate infrastructure actors both horizontally and vertically within government as well as with stakeholders who deliver and use infrastructure. Governments need to design an institutional, policy, regulatory and financial enabling environment that facilitates the take up of innovative solutions by both public agencies across levels of government as well as private actors. It is important for national governments to ensure that governance arrangements, regulations and technical capacity do not inadvertently discourage their use.

\section{References}

Arrizabalaga S. Beltran S. Errandonea I. (2020), Digital Twin for maintenance: A literature review Computers in Industry, Volume 123, December 2020, 103316.

Asama H., Nagatani K. (2016), Robotics in infrastructure maintenance, Cross-ministerial Strategic Innovation Promotion Program (SIP) (Translation of Feature Article of JSCE Magazine, Vol. 102, No. 10).

Batista A. J., Giusti, R. Souza V.M. (2018), "Asfault: A low-cost system to evaluate pavement conditions in real-time using smartphones and machine learning", Pervasive Mobile Comput., vol. 51, pp. 121-137, 2018.

Blazey, Gonguet and Stokoe, (2020), Maintaining and Managing Public Infrastructure Assets, Well Spent: How strong infrastructure governance can end waste in public investment, IMF Washington.

Bonn, A. et al. (2016), Peatland restoration and ecosystem services: Nature-based solutions for societal goals, in Peatland Restoration and Ecosystem Services: Science, Policy and Practice, Cambridge University Press, [http://dx.doi.org/10.1017/CBO9781139177788.021].

Browder, G. et al. (2019), Integrating Green and Gray, https://openknowledge.worldbank.org/ handle/10986/31430.

Brown, K. and A. Mijic (2019), Integrating green and blue spaces into our cities: Making it happen, Imperial College London, Grantham Institute Briefing paper.

Bukhsh Z.; Stipanovic I.Bukhsh Z.; Stipanovic I.Bukhsh Z.; Stipanovic I. (2020), Predictive Maintenance for Infrastructure Asset Management, IT Professional (Volume: 22, Issue: 5, Sept.-Oct. IT Professional ( Volume: 22, Issue: 5, Sept.-Oct. IT Professional ( Volume: 22, Issue: 5, Sept.-Oct. 12020 ).

Coleman T. (2020), Digital Twins Contribute to Infrastructure Resilience, Insights [https://www.wsp.com/en-GL/insights/digital-twins-contribute-to-infrastructure-resilience].

CSIC (2020), Systems integration for resilient infrastructure, Cambridge Centre for Smart Infrastructure and Construction [https://www-smartinfrastructure.eng.cam.ac.uk/projects-and-case-studies/systemsintegration-resilient-infrastructure].

EC (2021), GAIA X [https://www.data-infrastructure.eu/GAIAX/Navigation/EN/Home/home.html].

Edwards, P., A. Sutton-Grier and G. Coyle (2013), Investing in nature: Restoring coastal habitat blue infrastructure and green job creation, Marine Policy, [http://dx.doi.org/10.1016/j.marpol.2012.05.020].

Eggermont, $\mathrm{H}$. et al. (2015), Nature-based solutions: New influence for environmental management and research in Europe, Oekom Verlag, [http://dx.doi.org/10.14512/gaia.24.4.9]. 
EPA (2021), What is Green Infrastructure? United States Environmental Protection Agency Website. GAIA $X$ - A Federated Data Infrastructure for Europe [https://www.datainfrastructure.eu/GAIAX/Navigation/EN/Home/home.html].

Gartner (2020), "Prepare for the Impact of Digital Twins".

G20 (2021) Policy Agenda on Infrastructure Maintenance - Annex - Infrastructure Maintenance Case Studies.

GIH (2020), InfraTech Stock Take of Use Cases, Global Infrastructure Hub, G20 Infrastructure Working Group Reference Note July 2020.

GIH (2020), Case Study drones for monitoring surveillance and inspection.

GIH (2020), Case Study 3D printing for maintenance.

Glaessgen E. and Stargel D. (2012) The Digital Twin Paradigm for Future NASA and U.S. Air Force Vehicles

Gul M., Mei Q. (2018), "A crowdsourcing-based methodology using smartphones for bridge health monitoring", Struct. Health Monit., vol. 18, pp. 1602-1619, 2018.

Hallegatte, S. (2009), Strategies to adapt to an uncertain climate change, Global Environmental Change, [http://dx.doi.org/10.1016/i.gloenvcha.2008.12.003].

IET (2020), Digital twins for the built environment - An introduction to the opportunities, benefits, challenges and risks, Institution of Engineering and Technology (IET) \& Atkins.

Kabisch, N. et al. (2016), Nature-based solutions to climate change mitigation and adaptation in urban areas: perspectives on indicators, knowledge gaps, barriers, and opportunities for action, Ecology and Society, [http://dx.doi.org/10.5751/ES-08373-210239].

Land Transport Authority (2014), "LTA, SMRT, StarHub and IBM collaborate to improve transport with data for Singapore commuters".

Mabkhot et al., (2018) Requirements of the smart factory system: a survey and perspective, Machines (2018), p. 23

Menéndez, P., et al. (2020) The Global Flood Protection Benefits of Mangroves. Sci Rep 10, 4404 (2020). https://doi.org/10.1038/s41598-020-61136-6

Narayan, S. et al. (2016), The Effectiveness, Costs and Coastal Protection Benefits of Natural and NatureBased Defences, PLOS ONE, [http://dx.doi.org/10.1371/journal.pone.0154735].

Nübel K., Bühler M., Jelenik T. and others (2021 forthcoming) Infrastructure 4.0 - Value Chain Integration through Federated Digital Platforms, T20 Policy Brief, Italy.

OECD (2021a) Implementation Handbook on Quality Infrastructure: Chapter 4: Subnational governance and investment in infrastructure.

OECD (2021b), Government at a Glance.

OECD (2021c) "Strengthening adaptation-mitigation linkages for a low-carbon, climate-resilient future", OECD Environment Policy Papers, No. 23, OECD Publishing, Paris, [https://doi.org/10.1787/6d79ff6aen].OECD (2021d), Recommendation of the Council on the Governance of Infrastructure, OECD/LEGAL/0460, [https://legalinstruments.oecd.org/en/instruments/OECD-LEGAL-0460].

OECD (2021e), Scaling up Nature-based Solutions to Tackle Water-related Climate Risks: Insights from Mexico and the United Kingdom, OECD Publishing, Paris, [https://doi.org/10.1787/736638c8-en]. 
OECD (2020a), Infrastructure governance review of Spain: supporting better decision-making in transport investment.

OECD (2020b), "Nature-based solutions for adapting to water-related climate risks", OECD Environment Policy Papers, No. 21, OECD Publishing, Paris, [https://doi.org/10.1787/2257873d-en].

OECD (2020c), Effective and innovation-friendly rulemaking in the Fourth Industrial Revolution; Concept Note [GOV/RPC(2020)25].

OECD (2020d), "The OECD Digital Government Policy Framework: Six dimensions of a Digital Government", OECD Public Governance Policy Papers, No. 02, OECD Publishing, Paris, [https://doi.org/10.1787/f64fed2a-en].

OECD (2019a), The Path to Becoming a Data-Driven Public Sector, OECD Digital Government Studies, OECD Publishing, Paris, [https://doi.org/10.1787/059814a7-en].

OECD (2019b), Biodiversity: Finance and the Economic and Business Case for Action, OECD Publishing, Paris, [https://doi.org/10.1787/a3147942-en].

OECD/The World Bank/UN Environment (2018), Financing Climate Futures: Rethinking Infrastructure, OECD Publishing, [https://doi.org/10.1787/9789264308114enhttps://doi.org/10.1787/9789264308114-en].

OECD (2017), Getting Infrastructure Right: A framework for better governance, OECD Publishing, Paris, [https://doi.org/10.1787/9789264272453-en].

OECD (2013), Water and Climate Change Adaptation: Policies to Navigate Uncharted Waters, OECD Studies on Water, OECD Publishing, Paris, [https://dx.doi.org/10.1787/9789264200449-en].

Patwardhan, S. (2018), "Predictive maintenance \& asset management with advanced data analytics", Feb. 13,2018

PWC (2017), Predictive Maintenance 4.0 Predict the unpredictable; June 2017, PWC.

Shuttleworth, E. et al. (2019), Restoration of blanket peat moorland delays stormflow from hillslopes and reduces peak discharge, Journal of Hydrology X, [http://dx.doi.org/10.1016/j.hydroa.2018.100006].

The Nature Conservancy Business Council (2019), Strategies for Operationalizing Nature-Based Solutions in the Private Sector.

Trémolet S. et al (2019), Investing in Nature for Europe Water Security., The Nature Conservancy, Ecologic Institute and ICLEI.

Vermaat, J. et al. (2015), Assessing the societal benefits of river restoration using the ecosystem services approach, Hydrobiologia, [http://dx.doi.org/10.1007/s10750-015-2482-z].

WB (2020), Value Drivers of InfraTech World Bank Washington.

Weizhen (2014), "Big data to help ease transport woes", [www.todayonline.com/singapore/big-data-helpease-transport].

WEF (2014), Strategic Infrastructure, Steps to Operate and Maintain Infrastructure Efficiently and Effectively.

Woodroffe, C. et al. (2016), Mangrove Sedimentation and Response to Relative Sea-Level Rise, Annual Review of Marine Science, [http://dx.doi.org/10.1146/annurevmarine-122414-034025].

World Bank (2017), Implementing nature-based flood protection: Principles and implementation guidance.

WWAP (2018), The United Nations world water development report 2018: nature-based solutions for water - UNESCO Digital Library, [https://unesdoc.unesco.org/ark:/48223/pf0000261424]. 


\section{Building capabilities for resilience and maintenance in strategy and planning}

At a macro level, developing a long-term strategic vision for infrastructure helps governments identify and address infrastructure service needs in a timely and coherent manner. At a micro level, resilience and maintenance criteria need to be taken into account for project design, budgeting, selection and prioritisation, including downstream costs. Climate resilience needs to be integrated into the design pipeline of projects to ensure that they are consistent with national plans and future climate change scenarios. Ensuring that infrastructure systems can cope with highly uncertain future operating conditions requires a dynamic approach to infrastructure planning and decision-making that can accommodate uncertainty and facilitate acceptability among stakeholders.

This chapter covers resilience in planning and strategy at a macro and micro level looking at a dynamic approach to accommodate for uncertainty and focusing on inclusion to ensure participation and engagement 


\section{Introduction ${ }^{24}$}

The estimated needs to cover resilient and maintenance costs are significant. Rozenberg and Fay (2019) estimate that between 1 and 3 percentage points of GDP of annual maintenance spending will be needed to reach the Sustainable Development Goals in key infrastructure sectors by 2030 . However, maintenance is not systematically incorporated as an element to consider while deciding on an investment strategy.

As seen in chapter 1, lack of information and capacity is seen as a major bottleneck for proper asset management. Decision-making is often hampered by poor asset management processes and frameworks, and sub-standard systems, tools and data. Climate change is complex and additional capacity may be needed to support decision-making under uncertainty.

At a macro level, developing a long-term strategic vision for infrastructure helps governments identify and address infrastructure service needs in a timely and coherent manner. The full cost of an infrastructure asset over its life-cycle (including maintenance and upgrade costs) should be taken into account by countries during the budgeting, project appraisal and selection processes, ensuring that the projects that are ultimately selected take into account these costs and benefits. Existing multi-stakeholder processes such as national climate adaptation planning and critical infrastructure programmes can help identify entry points for mainstreaming, and promote cross-sectoral co-ordination.

At a micro level, resilience and maintenance criteria need to be taken into account for project design, budgeting, selection and prioritisation, including downstream costs. Resilience needs to be integrated in the design of pipeline of projects to ensure that they are consistent with national plans and future climate change scenarios. The procurement process should enable decision-makers to deliver projects in a way that maximises the value generated for society as a whole.

Ensuring that infrastructure systems can cope with highly uncertain future operating conditions requires a dynamic approach to infrastructure planning and decision-making that can accommodate uncertainty, allow for a greater degree of flexibility, and enable adjustments over time to reflect changing conditions or new information. Public sector decision making and resource allocation can ensure resilience and value for money by better integrating performance and risk considerations, drawing on intelligent monitoring and modelling technologies which have created opportunities to plan investments better, monitor at a lower cost and tailor responses to extend asset life. Utilising futures and foresight methods, anticipatory innovation aims to build a concrete value chain from imagining future scenarios to concrete innovation pathways.

Ultimately stakeholder engagement is essential for legitimacy, transparency and the identification of infrastructure needs and can thus enhance the performance of projects, increasing trust in infrastructure programmes (OECD, 2017c). Public participation and digitalisation allow to proactively inform, consult and engage with stakeholders at all stages of the policy-making cycle.

\footnotetext{
${ }^{24}$ This chapter draws from the OECD Recommendations on the Governance of Infrastructure, on the Governance of Critical Risks, and on Effective Public Investment Across Levels of Government, as well as OECD work on Climate Resilient Infrastructure. It builds on the OECD Implementation Handbook on Quality Infrastructure, in particular Chapter 2, Effective governance as a foundation for implementing quality infrastructure in a COVID-19 context.
} 


\subsection{Long-term planning: mainstreaming resiliency and maintenance in infrastructure}

Developing a long-term strategic vision for infrastructure helps governments identify and address infrastructure service needs in a timely and coherent manner. As highlighted by the OECD Recommendation on the Governance of Infrastructure, a long-term strategic vision should be aligned with long-term policy objectives, including commitments on environmental protection, climate change mitigation, human rights, social inclusion, gender equality, regional development, among others.

\subsubsection{Long-Term Strategic Vision for Sustainable and Resilient Infrastructure}

Infrastructure development impacts the landscape, permanently affecting population growth patterns, economic growth, and the mobility of people and firms for a long time.

Most surveyed OECD countries have become aware of the importance to ensure policy coherence between long-term infrastructure plans and broader sustainable development objectives, in light of the commitments made under the Sustainable Development Goals of Agenda 2030. The majority of OECD countries (73 percent) have aligned their long-term infrastructure plan with environmental and climate action policies (OECD 2020a). In the vast majority of these countries, the recurrent policy objective is to invest in projects that are key enablers for the implementation of broader government sustainability initiatives (67 percent), closely followed by the adaptation of existing infrastructure to improve environmental performance (57 percent) and identification of cross-sector synergies to diminish negative environmental impacts (57 percent). Fewer OECD countries have adopted targets on resource efficiency in the construction and operation of infrastructure (40 percent) and on research and development to promote environmentally friendly infrastructure (33 percent).

Governments can maximise the benefits from economic stimulus interventions through quality infrastructure spending. For example, developing effective strategies and policies to support environmental objectives and decarbonisation efforts is one of the main priorities for the Irish Government. After declaring a Climate and Biodiversity Emergency in 2019, the country set a Climate Action Plan defining a roadmap to achieving a net zero carbon energy system. This comes at a time of increasing public investments in infrastructure. Ireland's National Development Plan 2018-2027 (NDP) and Ireland's National Planning Framework are the two branches of a substantial investment program named "Project Ireland 2040", which will encompass over 116bn EUR going to infrastructural investments by 2040 . Flood relief schemes, public buildings, education and health facilities, water infrastructure, roads, ports and sustainable transport programs are examples of areas of investment.

Several countries are modernising their infrastructure networks. In Korea, the 2020- 2025 Master Plan is a nation-wide policy planning on systematic maintenance and management of infrastructure and improvement of infrastructure performance. ${ }^{25}$ China has launched in 2021 a nationwide drive to retrofit ageing highway bridges to improve safety and durability, through improving and expanding traffic and flood resistance capacity. Germany is retro-fitting and modernising its network of bridges containing about 5200 structures largely corresponding to the European TEN-T core network (G20, 2021).

\footnotetext{
${ }^{25}$ Main tasks of the Plan consist of four pillars as follows: (1) establish comprehensive and pre-emptive maintenance and management governance system, (2) increase level of infrastructure maintenance overseeing and decrease blind spots, (3) establish foundation for 'smart maintenance and management of infrastructure' and promote related industries, (4) invest in preventive safety measures for aged infrastructure and diversify investment sources (G20, 2021).
} 


\subsubsection{National infrastructure plans and national adaptation policies (Ecosystems)}

To implement this long-term vision, countries should develop an integrated national infrastructure plan, prioritising all projects according to the highest cost-benefit ratio based on economic, environmental and social factors. This plan should integrate maintenance and resilience, including national climate adaptation planning, critical infrastructure protection programmes, spatial planning. Such a framework should cover all aspects of a sound asset management system, ranging from asset management policy and strategy to key enablers and opportunities such as natural based solutions and technological innovations.

Guidelines are useful policy tools to plan and mainstream maintenance. Italy Ministry for Infrastructure issued Bridge safety guidelines - adopted by a decree in December $2020^{26}$ - to mainstream a systematic and co-ordinated analysis and management of risk for bridges and viaduct in the country. The German Federal Ministry of Transport and Digital Infrastructure (BMVI) published a guideline for the recalculation of existing road bridges (structural assessment guideline) to ensure that the load-bearing capacity of many of the existing bridge structures, which are already between 40 and 60 years old, is assessed as realistically as possible. In China, the Operation Guideline for Performance Management of PPP Projects issued by the Ministry of Finance regulate the full life-cycle performance management of PPP projects, including the management of performance targets and indicators, monitoring, evaluation and result application carried out throughout the full life-cycle of PPP projects (G20, 2021). In Brazil PROSEFER the National Railway Safety Program in Urban Areas is a management tool for planning improvements to existing Brazilian railways; categorise and rank priority investments; increase the transport capacity of the Brazilian railways; improve urban mobility and quality of life in urban areas of municipalities that live daily with the railway activity $(G 20,2021)$.

Integrating climate risk into decision-making at this early stage of planning can help to minimise downstream costs associated with adaptation measures and maintenance costs (OECD, 2018c). It can also facilitate $\mathrm{NbS}$ and ecosystem-based approaches to adaptation, by maintaining restrictions or creating incentives that protect ecosystems (e.g. wetlands and forests) and ensure the ongoing provision of ecosystem services such as flood defence and erosion control (OECD, 2018c).

Countries should integrate maintenance and rehabilitation projects into the national infrastructure programme and plans, alongside greenfield projects, and prioritise all projects according to the highest cost-benefit ratio based on economic, environmental and social factors. A national long-term strategic vision addresses infrastructure service needs, how they should be met and who is responsible for making this happen. The strategy should be politically sanctioned, co-ordinated across levels of government, take stakeholder views into account and be based on clear quantitative and qualitative assumptions. Infrastructure plans should also have a proper link with the annual budget formulation process, since it is at this time that resources are allocated to government projects and programmes.

National adaptation planning and critical infrastructure programmes can help identify entry points for mainstreaming, and promote cross-sectoral co-ordination. Infrastructure adaptation to climate change (National adaptation planning) can be facilitated by incorporating climate risk into broader infrastructure planning frameworks, as well as the critical infrastructure protection programmes that are in place in over 20 OECD countries (OECD, 2018d). As pointed out in GCA (2019), this helps to identify critical assets and prioritize investments in new or retrofit infrastructure like in the example provided of Curaçao, which has developed a long-term infrastructure plan designed to provide benefits for people and the environment, while also preparing for long-term adaptation to sea-level rise.

In the Netherlands, following national climate adaptation policy the aim is to have climate-proof networks by 2050. An implementation agenda is planned in 2021 building on the Rijkswaterstaat climate resilient

\footnotetext{
26 "Linee guida per la classificazione e gestione del rischio, la valutazione della sicurezza ed il monitoraggio dei ponti esistenti" - approved in April 2020 by the Consiglio Superiore dei Lavori Pubblici.
} 
networks project started in 2018 and including analysis of stress tests and risk assessment, discussed with stakeholders through so called risk dialogues. (G20, 2021). In Turkey, through the Istanbul Seismic Risk Mitigation and Emergency Preparedness (ISMEP) Project, nearly 1500 public buildings (healthcare facilities, educational buildings, public buildings etc.) have been retrofitted or reconstructed and became resilient to the disasters. The Government of Spain has developed a plan for the adaptation of the Spanish Port System to climate change, in line with its National Plan for Adaptation to Climate Change 2021 - 2030. (G20, 2021).

\subsubsection{Total costs needs assessment to support decision making and investment}

The full cost of the infrastructure asset's life-cycle (including maintenance and upgrade costs) should be taken into account by countries during the budgeting, project appraisal and selection processes, ensuring that the projects that are ultimately selected take into account these costs and benefits. A transparent allocation of risks and the adoption of a plan to manage, monitor and mitigate risks throughout the asset's life-cycle is an additional tool that can ensure the availability of resources for unexpected maintenance or upgrade costs.

Infrastructure contributes to addressing social needs economic activity. The OECD Recommendation on the Governance of Infrastructure shows how a long-term strategic vision for infrastructure is grounded upon shared ambitions for national and subnational development, enhancing the economic, natural, social and human capital which underpins wellbeing, sustainable and inclusive growth, competitiveness and public service delivery. The plans are informed by rigorous assessment of current and future infrastructure needs at the national and subnational levels, and present how these needs should be prioritised and addressed.

Infrastructure investment requirements relate not just to new structures, but also to maintenance, upgrade and management of existing infrastructure. Maintenance often makes up a substantial proportion of the cost of an infrastructure investment over its operational life span.

Investment needs should be based on an analysis of total costs including beyond construction also O\&M, adaptation and decommissioning. Around 90 percent of OECD countries estimate construction and operation costs when assessing the affordability of new infrastructure projects. However, the assessment of maintenance ( 83 percent), adaptation ( 57 percent) and decommissioning ( 43 percent) costs are less frequent in OECD countries (Figure 4.1). Especially in a COVID-19 context, more efforts are needed to adopt mechanisms that effectively consider the affordability of new projects at all stages of the asset's lifecycle , with careful consideration of assumptions made about the cost of capital, discount rate, and future ability to cover O\&M costs.

\section{Figure 4.1. Costs generally estimated to assess affordability of new infrastructure projects, 2020}

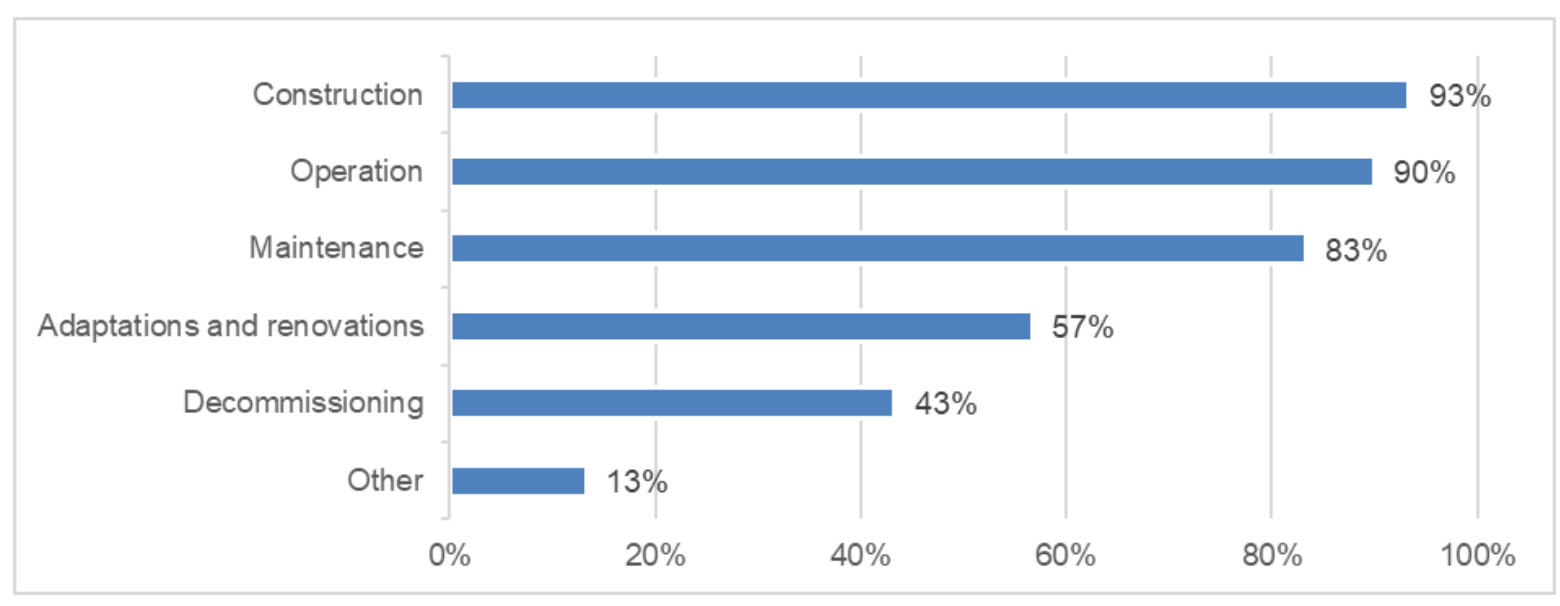

Source: OECD (2020a), Survey on the Governance of Infrastructure. 


\subsection{Integrating resilience \& maintenance at the project level}

\subsubsection{Evidence-based project selection and prioritisation processes: aligning incentives}

Maintenance needs of existing assets can end up being neglected if the political incentives are skewed towards displaying tangible results to a certain constituency (OECD, 2021d). Political capture can undermine sound decision making on infrastructure when processes for identifying priority projects and choosing delivery modes are not sufficiently robust and transparent (OECD, 2017c). According to OECD work, only 19 OECD countries report that they have a shortlist of priority projects, with most driven by some combination of cost-benefit analysis results, infrastructure plans and strong political backing (OECD, 2020a)

The OECD Recommendation on the Governance of Infrastructure highlights the importance for governments to understand the expected returns of infrastructure projects in terms of value for money, and social and economic efficiency. Most OECD countries already support infrastructure prioritisation and decision-making processes which give significant weight to the results of cost-benefit analysis, as well as the presence of the project in a long-term strategic plan (OECD, 2018a).

In order to form the basis for sound decision-making processes, CBA needs to be anchored in a robust methodology The strength of CBA lies in its logical simplicity and the fact that it generates clear quantitative values (e.g. Net Present Values, Benefit/Cost ratios) that can be used to compare and rank projects, even across sectors. Strengthening cost-benefit analysis practices can become an effective tool to ensure that a portfolio of infrastructure projects maximises value for money.

To ensure evidence-based project selection and prioritisation, cost benefits analysis need to be integrated into the political decision-making process. Key conditions for a sound technical appraisal process include a robust methodology, the institutional arrangements (e.g. whether CBA results are independently vetted), and the type of information included in the assessment and the right timing to undertake the analysis.

While CBA is an important component of the evidence-based decision-making process, there are relevant elements outside its scope that should be considered alongside the CBA, such as a project's contribution to strategic policy goals, and impacts that are difficult or even impossible to quantify (e.g. gender equality, inclusiveness, resilience). Supplementing CBA with other methodological tools can help accommodating multiple objectives and uses. Some countries have adopted complementary methods to analyse both monetary and non-monetary costs and benefits, such as multi-criteria analysis (OECD, 2017c).

The United Kingdom has adopted general guidelines for the incorporation of multi-criteria analysis in decision-making processes (Department for Communities and Local Government, 2009). The guidelines provide an explanation of techniques that do not necessarily rely on monetary valuations as a way to complement the use of monetary methodologies such as financial analysis, cost-effectiveness analysis, and cost-benefit analysis. While CBA is at the core of the five case model appraisal process, it is effectively integrated with other relevant decision criteria. Although decisions are based on the results of all five case studies, CBA and value for money are used in the economic case following guidance issued by HM Treasury (the Green Book) and are given substantial overall weight. The Green Book sets out the required overall methodology and list the inputs and parameters to guide the socio-economic assessment of proposed projects and programmes (HM Treasury, 2018).

\subsubsection{Public procurement and life-cycle perspective in infrastructure}

Delivering sustainable infrastructure involves retuning procurement processes to take into account multiple policy dimensions. Procurement processes that place an exclusive focus on costs, or fail to consider the whole of the projects' lifetime, may not support delivery of an optimal combination of quality, technical features (e.g. resilience, environmental sustainability) and price. A vast majority of OECD countries 
(93 percent) employ a combination of financial and qualitative criteria to select and award proposals. However, there is room for improvement in terms of adopting an assessment of life-cycle costs for contract award, as this practice is only conducted in 40 percent of OECD countries and can directly impact countries' ability to reduce inefficiencies and costs over the long-term (Figure 4.2).

\section{Figure 4.2. Mechanisms to help identify proposals offering the best value for money, 2020}

\section{Number of Countries}

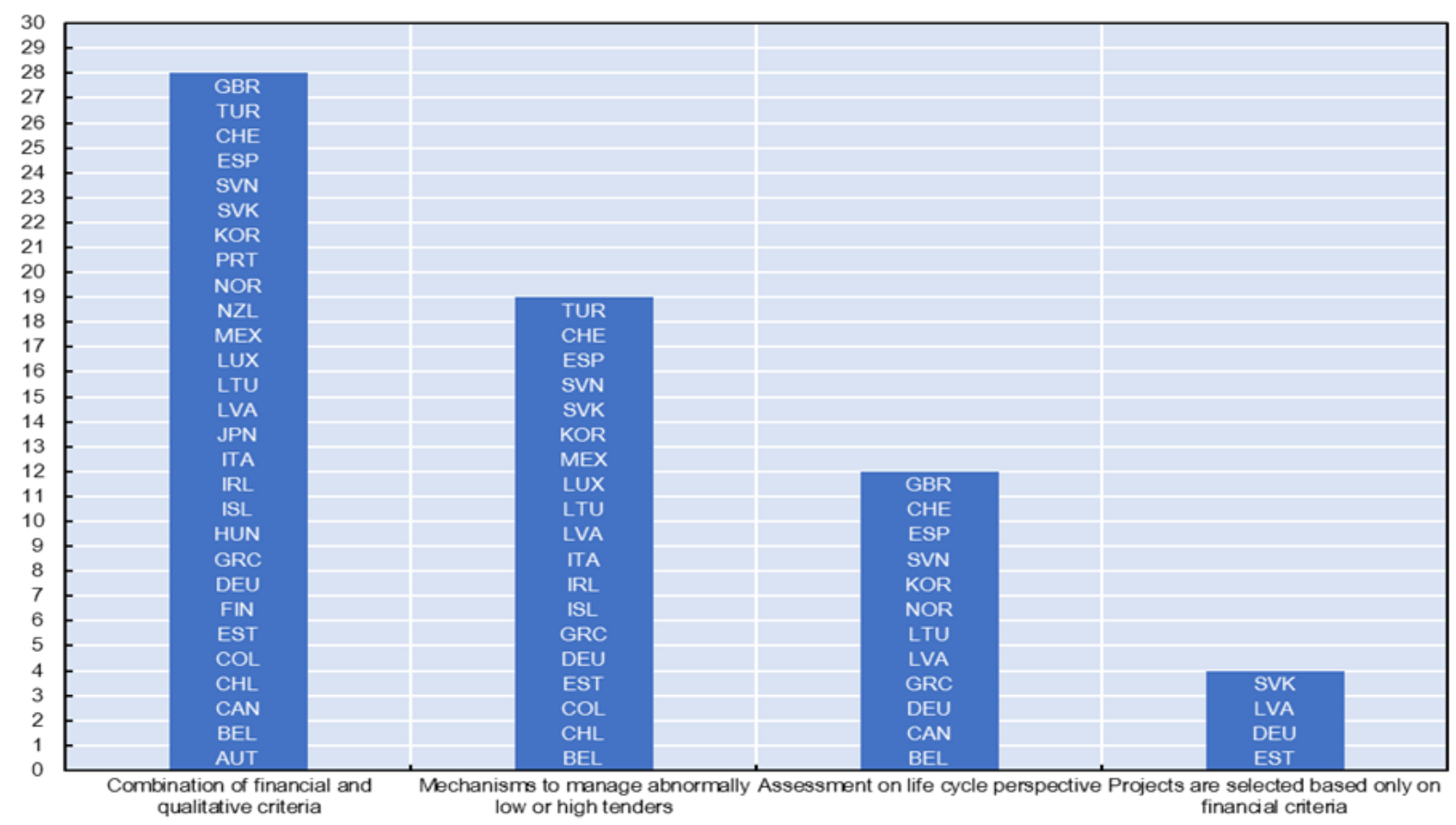

Source: OECD (2020a), Survey on the Governance of Infrastructure

Infrastructure assets have a long life and are particularly prone to risks such as inefficiency, lack of quality, cost overruns, economic and financial uncertainty and integrity breaches. These risks can threaten the assets' value for money and capacity to deliver the intended services. When procuring major infrastructure projects, the majority of OECD countries already identify, allocate and mitigate risks at each stage of the investment life-cycle. According to the OECD Governance of Infrastructure survey, 60 percent of OECD countries conduct risk management activities covering the entire infrastructure procurement life-cycle , which is aligned with previous findings from the OECD Recommendation of Public Procurement implementation report (2019). Nevertheless, more efforts are needed to promote a life-cycle perspective to risk in order to maximise benefits and prolong the life of infrastructure investments.

Contracting authorities play a key role in overseeing compliance with technical specifications and can develop a system of effective and enforceable sanctions if contractors are in breach. OECD countries have in place a wide range of mechanisms aiming to hold contractors accountable for project specifications and professional standards. Most OECD countries (80percent) employ tools to enforce contractual clauses, closely followed by dedicated on-site supervision that is also practiced by 70 percent of OECD countries. While half of OECD countries (53 percent) already conduct periodical assessments of contractors' performance against key performance indicators, this practice could become more widely adopted.

Infrastructure projects' complexity, scale, time-span and risks call for specialised delivery and procurement strategies that enable decision-makers to deliver projects in a way that maximises the value generated for 
society throughout the entire asset's life-cycle . The OECD Recommendation on the Governance of Infrastructure highlights: 1) selecting contractors based on criteria combining qualitative and financial elements and including an assessment of costs, benefits and impacts incurred throughout the life-cycle of the asset; 2) carefully evaluating optimal risks allocation and the use of value for money analytical tools to compare assessment of service delivery options; and 3) implementing balanced contractual relationships, holding contractors accountable for project specification and professional standards.

Resilience should be taken into account in public procurement. When comparing competing bids at the design stage, governments should require to take into account potential costs for example of climate impact over the asset lifetime, in particular towards the end of the concession (OECD 2018c) For long-term contracts such as PPPs, two important factors are the choice of discount rate affecting the weight placed on potential future impacts relative to those in the near-term and the allocation of responsibilities regarding risks planning, management and response. The Netherlands Rijkswaterstaat (Ministry of Infrastructure and Water Management) in order to reduce $\mathrm{CO} 2$ emissions and become fully circular and climate neutral by 2030 is looking at solutions for circular infrastructure. Initial focus in on viaducts for roads and motorways that can be repeatedly procured and applied in other projects (replacement as well as new construction) by Rijkswaterstaat, as well as in projects by other public and semi-public organizations and/or private parties (inter)nationally (G20, 2021).

\subsection{Supporting policy makers under uncertainty}

\subsubsection{Adaptive infrastructure planning approaches that can accommodate uncertainty}

To prioritise resilient infrastructure, governments need first to develop an understanding of the complex (inter-)dependencies and vulnerabilities across critical infrastructure systems. For example, for many infrastructure systems exposed to or dependent on the environment such as, for example, water supply, flood protection, nuclear power plants and ports, climate change is generating deep uncertainty over future operating conditions in terms of temperatures, rainfall, extreme weather events, and sea level rise (OECD, 2021d).

Increased uncertainty makes data on past conditions no longer useful as a guide for the future. This is due in the case of climate to the existence of multiple possible scenarios (contingent on mitigation pathways) and, to the inaccuracy of climate models and long-term projections of climate impacts. Facing these complexities, traditional decision-making tools for infrastructure planning are inadequate.

Beyond alternative cost-benefit analysis, which depend on being able to assign probabilistic values to different outcomes, a number of alternative decision-making approaches have been developed, using scenario planning as their basis, that offer greater flexibility (e.g. real options analysis, robust-decision making, and adaptive planning). However, the use more flexible approaches has yet to gain wide application in infrastructure planning.

In adaptive planning approaches, planners envisage multiple actions and a range of alternative policy or investment pathways (OECD, 2021d). The Netherlands, for example, has adopted adaptive water management as the basis for its long-term planning for its water resources (Box below). 


\section{Box 4.1. Adaptive water management in the Netherlands}

The Netherlands has a long and robust tradition of living with water. Located in a delta, more than half of the country's territory and population and two-thirds of its economic activity are flood-prone. Safety against flooding and the management of excess rain have long been the foundation of water management in the Netherlands. Centuries of concerted action and investment helped build and maintain the country's extensive system of primary and regional flood defences.

A new paradigm towards adaptive water management has put thinking about the future and long-term sustainability at the heart of Dutch water policy. This shift began with the programme "Room for the River" and culminated with the adoption of the Delta Act in 2012. The act established the Delta Programme, the Delta Commissioner and the Delta Fund to advance an adaptive water management approach that places primacy on a long-term perspective (up to 2100) and flexible strategies to cope with future challenges related to water safety and freshwater supplies.

Adaptive management is seen as a structured, iterative, learning-based process involving the fundamental features of learning and adaptation leading to both improved understanding of the (resource) system and to improved management based on that understanding. This entails integrating a long-term perspective into water management planning with iterative decision making, considering how decisions in the short term potentially enable or foreclose future options, and the use of naturebased solutions, which can avoid or delay lock-in to capital-intensive, conventional "grey" infrastructure.

Source: (OECD, 2018c; Rijkeb and van Herkb, 2015 and OECD 2021d)

\subsubsection{Anticipatory innovation governance methods}

Anticipatory innovation governance methods contribute to the broad-based capacity to actively explore possibilities, experiment, and continuously learn as part of a broader governance system (Tõnurist and Hanson, 2020). Utilising futures and foresight methods, anticipatory innovation aims to build a concrete value chain from imagining future scenarios to concrete innovation pathways. Not all events can be anticipated, but having more concrete guideposts and visions towards which to develop infrastructure can help structure adaptive processes (discussed above) and avoid technology-centric, smart solutions that do not serve the large public needs or broader public values. Adaptive resilience is suited for the unexpected in the world as we know it, while anticipatory innovation focuses on preparing for and shaping the unexpected world (for example, imagining car free cities and then searching for workable technological and social arrangements that could make this change possible).

Anticipatory innovation starts with an outline of the parameters around which policymakers wish to make changes: preferable futures or futures to avoid. Policymakers would then experiment in a real-world environment in order to determine effective policy - ideally with a subset of the individuals or groups that would be affected by government intervention, technologies or large-scale changes. As organisations gain knowledge, they continuously reassess those preferable futures, and whether or not they are tracking towards them. This process of intentionally and systematically entering and interviewing problem spaces and unknowable terrains can help governments steer towards preferable futures, and help governments and society be more equipped for the crises and changes that await. By using an action-oriented approach to frame policy development, governments will be able to dynamically shape the future in the making.

For example, the city of Helsingborg, Sweden, has adopted an anticipatory innovation governance approach with a dedicated budget and capability-building with 500+ managers. It has developed a portfolio of hundreds of small-scale innovation projects designed to test radically different approaches to public 
transit, social care, liveability, and environmental stewardship. Prioritising quick action over long planning cycles, their goal is to create a continuous and rich source of insights and data about possible futures, while building capacity for a range of governance approaches that could be applied in shifting, unknowable circumstances.

Another example is the multi-level research programmes centred around the simulation and virtual prototyping of solutions to future challenges in urban mobility at the University of Leeds, inspired by the evidence emerging from the Government Office for Science report (2019) on the 'Future of Mobility'. In line with the initial report, the work tackles issues surrounding an ageing population, the emergence of connected autonomous vehicles, "mobility as a service" and sustainability as central considerations in the response to future transportation needs. This led to the development of Virtuocity, an interactive centre for city simulation, enabling research participants to interact with the platform in a 'multi-player' fashion. To develop Virtuocity, researchers looked at integrating population growth projections (PGP) and AgentBased Modelling (ABM) with existing transport design methodologies (Eggert et al., 2019).

\subsection{Building smart-intelligent infrastructure for resilience and maintenance}

As discussed in Chapter 3, the development of intelligent monitoring and modelling technologies - new processes and analytics - have created opportunities to plan investments better and to extend asset life. Predictive maintenance (or knowledge-based maintenance) aims at optimising maintenance based on predictions. By accessing monitoring data using sensors, digital technologies, and artificial intelligence techniques, smart/intelligent infrastructure can develop self-diagnostic systems that alert in case of deteriorating condition, expected failures, and intervention needs.

In order to ensure a pro-active and intelligent maintenance plan, the following diagram describes the knowledge and information that needs to be collected. The asset monitoring collects the data, which is further assessed to determine the performance level of assets. The future performance level and remaining useful lifetime are modelled using machine learning. Given the possible failure details, the optimal maintenance plans are developed (Arrizabalaga S., Beltrána S., Errandonea I., 2020).

Figure 4.3. Building Intelligent Infrastructure for Resiliency and Maintenance

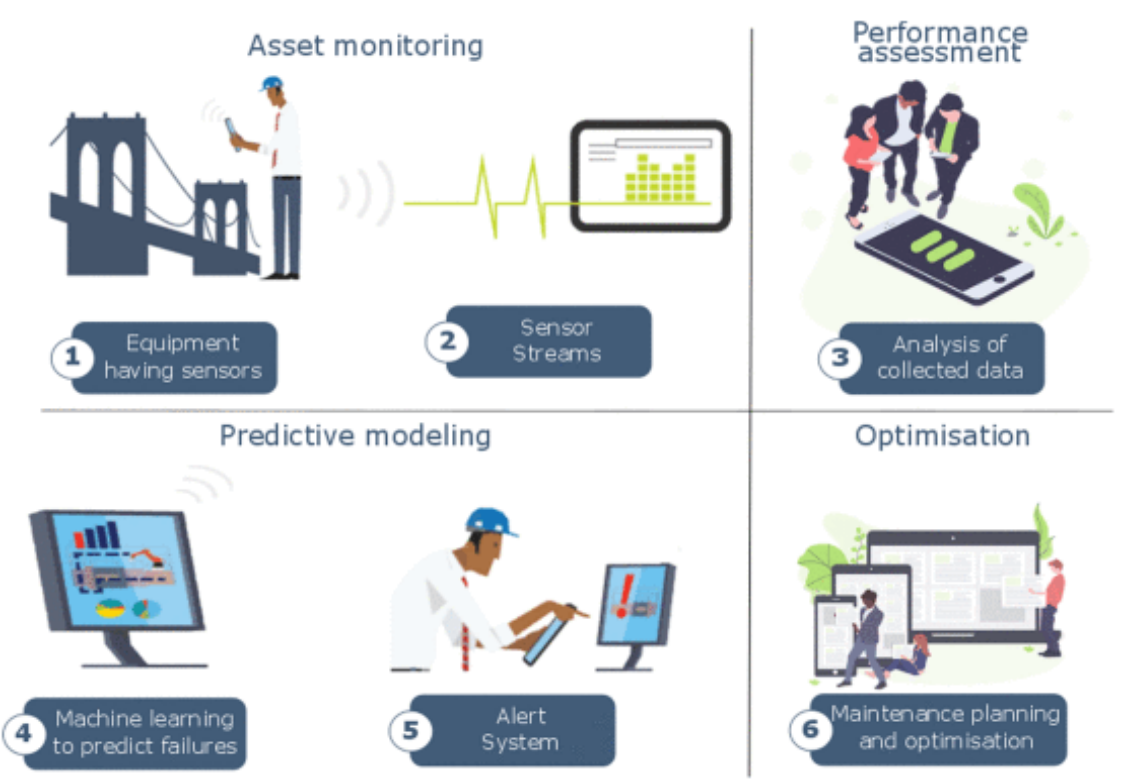

Source: Bukhsh Z.; Stipanovic I. (2020) Predictive Maintenance for Infrastructure Asset Management, IT Professional (Volume: 22, Issue: 5, Sept.-Oct. 1 2020) 
To meet the growing needs of maintenance, Tokyo Metropolitan Expressway (TME) developed a special data collection vehicle named 'InfraDoctor' equipped with a camera and laser scanner. It generates high precision 3D point data of the structures as well as surrounding facilities with GIS based MMS (Mobile Mapping System) instantaneously and stored in the cloud server while driving on the road. A special AI system has been deployed to analyse structures' deformation by time series location differentials of 3D point data. Ultimately to sustain the timely maintenance cycle, the asset information management system integrates information on structural designs, inspections, diagnoses, and repair plans and update them in real-time $(G 20,2021)$.

In the Netherlands, the "Vital Assets" program was set up to optimize timing of maintenance, by using simple energy sensors, deviations from normal electricity consumption can be detected. Combining this data with other types of data (e.g. temperature, wind or usage) allows Rijkswaterstaat to investigate whether the deviations are normal or not. Abnormal deviations are reported to the asset manager and contractor, who check what kind of maintenance is required (G20, 2021).

Reliable data is essential in developing a life-cycle plan for current and future operations that incorporates sustainability and resiliency considerations. Several monitoring instruments can record diverse parameters from an asset/structure. However, acquisition of the quality data and converting it into useful information is a substantial challenge.

Big data analytics is transforming the availability and use of information. There has been an exponential increase in data sources helpful to the design process, including from satellite imagery, mobility records, social media, logistics and transaction records. The cost of gathering data for example through crowd sourcing techniques allow drastic cost reductions and high returns. (See Chapter 3). New (digital) technologies enable smarter oversight activities such as risk-based targeting by providing better information and knowledge through the use of more granular, and high-quality data (e.g. timely) that would allow for proactive actions and response. Yet, this implies establishing solid data governance arrangements and data management practices to i) enable data access and sharing among relevant actors, ii) reduce the risks of informing decision-making technologies such as Al systems with inaccurate data inputs (OECD, 2019c), and iii) make sure that data access and sharing practices are trustworthy ${ }^{27}$.

Also, big data analytics can assist regulators in allocating resources efficiently and obtaining results that demonstrate meaningful outcomes. They can also help regulated parties demonstrate compliance thus lowering costs of regulatory burden on businesses. The use of big data analytics raises however a series of challenges that should be properly addressed (OECD, 2021c forthcoming), including legal barriers (e.g. quality and adequacy of regulatory frameworks), institutional barriers (e.g. structures governing the operation of regulators) or technology risks (e.g. privacy, data protection and security).

In Korea, the Seoul Infrastructure Next 100-Year Project' aims to change the traditional management technique which has focused on 'short-term maintenance and post management' to 'preemptive mid- to long-term response in preparation for the future'. The maintenance system will be integrated, and it will be established a big data management database to predict the best time for maintenance and reinforcement for each facility based on this data. This future-predicting model is expected; (1) to save KRW 193.9 bn every year (KRW 5.8 tn during 30 years), (2) to increase an average life span of infrastructure facilities up to 15 years. (3) to increase on average safety performance by 5.6 percent $(G 20,2021)$.

\footnotetext{
27 SOURCE platform integrating flexibility at each stage (preparation, operations, maintenance), can be connected to other databases and platforms at the country and regional level, SOURCE allows to make adjustments as issues arise (e.g. modifying entries; adding due diligence documents; updating risk assessments/ratings). Such function contributes to increasing local capacities, incentivizing project developers to undertake continuous reviews of external conditions and factors (e.g. climate projections; climate and biodiversity risks in identified sites) and to incorporate more precise and/or new information affecting the resilience of their projects or portfolio - Sustainable Infrastructure Foundation 24 May 2021.
} 


\section{Box 4.2. Making infrastructure resilient - Modelling Flooding macro impact}

Flooding is a frequent occurrence particularly in coastal regions, and near rivers and lakes. Flooding events can cause damage and destruction to property and infrastructure. Flooding is becoming increasingly frequent with climate change and rising sea levels. As urban expansion continues, flooding in these areas can become more frequent due to insufficient drainage. This requires action to lessen the risk of urban flooding for infrastructure.

In France, the OECD calculated the economic impact of a major flood of the Seine River affecting the Paris metropolitan area. For this purpose, a hybrid approach was developed, combining modelling of direct losses, assessment of the impacts connected with the interruption of critical networks and macroeconomic modelling. Three scenarios were built around the historic centennial flood of 1910, and direct damages were estimated between USD 3 and 30 bn, with 10000 to 400000 job losses and an impact on the national GDP between 0.1 percent and 3 percent cumulated over a 5-year period.

Water height and flood management modelling as described in (GIH, 2020) builds on sensors (GPS, water level, radar for thermal images) to collect data on the water level, resources, quality and waterrelated hazards, for a set geographical area. The data then is transmitted and analysed to a central system in real-time tracking patterns to identify areas likely to be flooded, looking at the probability that flooding will occur. This allows flood protection and better water management, better mitigation (e.g. dams and water management systems) or identification of alternative areas with lower risk of flooding. For example (GIH, 2020):

- Maeslant Storm Surge Barrier, the Netherlands. The operation of the barrier is fully automatic via a connection to a computer system that links to weather and sea level data.

- WaterNSW Water Monitoring Network, Australia. Over 5000 monitoring stations measure the quality and quantity of New South Wales (NSW)'s rivers, streams, groundwater bores and dams. Over 1300 of these stations deliver real-time data through NSW's telemetry and remote data capture networks.

- Oxford Flood Network. A project built in partnership with Nominet UK and Thinglnnovations, comprising of 30 wireless water level sensors to detect levels of water around the city to visualise flooding and river conditions.

Source: OECD (2018d) Critical Infrastructure Framework and GIH (2020) Case Study WATER HEIGHT AND FLOOD MANAGEMENT MODELLING

\subsection{Engaging citizens and stakeholders for better planning: inclusiveness, public participation, transparency}

The OECD Recommendation on Open Government defines stakeholder participation as all the ways in which stakeholders (here all the interested and/or affected parties) can be involved in the project cycle and in service design and delivery. The Recommendation defines the inclusion of stakeholders in the design and planning phase of an infrastructure project through participatory mechanisms such as consultations or deliberative processes, thereby strengthening public support and increasing the legitimacy of public spending. In addition, stakeholder engagement opportunities can improve the linkages between public investment management and service delivery by ensuring that investments are planned, selected, and designed in a manner that responds to particular challenges in service provision and outcomes, including those in critical social sectors such as health and education. Building upon this, current OECD work 
involves exploring how a robust civic space environment can better enable stakeholders to engage in the planning, design, delivery, and evaluation stages of various government services.

Engaging with those concerned and affected by regulation is fundamental to improve the design of regulations, enhance compliance with regulations and increase public trust in government. Following the OECD Recommendation on Open Government, stakeholders include individuals as citizens, consumers and employees (including their representative organisations and associations) and institutions and organisations whether governmental or non-governmental, from civil society, academia, the media or the private sector. Economic regulators that play a significant role in the operations and maintenance of infrastructure assets may or may not be required by law to carry out engagement processes on their regulatory decisions and actions; in practice, most regulators have in place formal engagement mechanisms. Stakeholder engagement should aim to be regular, genuine and fit for purpose, proportional to the matter at hand. (OECD, 2014)

\section{Box 4.3. Stakeholder Engagement}

FixMyStreet, citizen monitoring of public infrastructure: This open-source online platform, originally developed in the United Kingdom and currently implemented in many other countries such as Sweden, Switzerland or Malaysia, allows citizens to report problems related to public infrastructure such as potholes or broken streetlights. In addition to a collaborative monitoring of public infrastructure, FixMyStreet enhances the accountability of public authorities in the delivery of maintenance, as the reports are open to scrutiny by the community.

BA Obras (Open Urban Works): Online and interactive platform that allows citizens to access information on more than 1000 public projects of the Buenos Aires City Government (hereinafter, "GCBA"). Providing data visualisations and geo-referenced maps, BA Obras facilitates citizen control. The initiative seeks to increase transparency in public management based on real-time monitoring with up-to-date and structured data.

The government of Buenos Aires City published BA Obras code in Github, so other governments can replicate this platform and developed manuals with general guidelines on how to implement an open public works site using BA Obras code. There is a help desk for technical support to governments that wish to replicate it.

SIGAB - Information System for New Waste Management Model in Bogotá: A new waste management system, driven by information. Bogota has evolved its cleaning and recycling scheme, generating a profound transformation in the way in which citizens' needs are met and garbage collection is managed. This model is based on the effective use of data and information. This initiative has allowed greater transparency in the actions of involved public and private organisations, an intense collaboration to provide the best service and enabling citizens' active participation.

Source: OECD, Observatory of Public Sector Innovation Observatory of Public Sector Innovation (oecd-opsi.org), OECD 2018, https://sigab.gov.co.

The OECD Recommendation on the Governance of Infrastructure provides guidance on how governments can facilitate the participation of users and impacted communities during the relevant phases of the project life-cycle, ensuring debate and oversight on the main economic, fiscal, environmental and social impacts of the project. For example, representative deliberative processes can help policy makers to better understand public priorities, identify where consensus is and is not feasible, and make legitimate decisions that involve trade-offs (OECD, 2020). Regarding resilience in particular, understanding levels of 
acceptance of service disruption by customers can constitute a good starting point to define resilience requirements.

Another mechanism available to public authorities is to build partnerships with operators as an effective way to improve decision-making and build support for implementing resilient approaches, in adding additional costs of investing. In Switzerland, for example, the Critical Infrastructure Protection strategy setting resilience objectives for critical infrastructure operators is based on partnerships and platforms for critical infrastructure operators, federal and subnational authorities (OECD, 2021c forthcoming). As highlighted in OECD (2018), local and indigenous knowledge and community engagement can help identify climate vulnerabilities and facilitate local level participation in national adaptation planning.

Data-driven approaches are particularly effective for meeting citizen expectations and rethinking the way governments and citizens interact (OECD 2019). Data can play a key role in creating conditions that improve public services, increase the effectiveness of public spending and inform ethical and privacy considerations.

The OECD Recommendation on Open Government and the OECD Recommendation on Digital Government Strategies promote innovative ways to effectively engage with stakeholders to source ideas and co-create solutions, including digital technologies and technology-driven approaches. Digital tools are becoming a key mechanism for informing citizens and stakeholders and enabling their participation and engagement in a meaningful way. The use of high-quality open governments data and accessible tools can also play a crucial role in ensuring information is timely and available to the public and that stakeholders are able to provide inputs. The use of digital tools can also support the accountability of governments and an effective maintenance of public infrastructure through continuous feedback loops, citizen monitoring platforms, service satisfaction cards, or citizen-generated data. In addition, open government data and citizen monitoring mechanisms, can support the accountability of the public procurement cycle when it comes to infrastructure projects, from its design to its maintenance.

\section{References}

Arrizabalaga S. Beltran S. Errandonea I. (2020), Digital Twin for maintenance: A literature review Computers in Industry, Volume 123, December 2020, 103316.

Burton, I. et al. (2012), "Managing the Risks: International Level and Integration across Scales", in Managing the Risks of Extreme Events and Disasters to Advance Climate Change Adaptation, Cambridge University Press, [https://www. ipcc.ch/pdf/special-reports/srex/SREX-Chap7 FINAL.pdf]

Bukhsh Z.; Stipanovic I. (2020), Predictive Maintenance for Infrastructure Asset Management, IT Professional (Volume: 22, Issue: 5, Sept.-Oct. 1 2020).

Burger, P. and Hawkesworth, I., (2013), Capital budgeting and procurement practices, OECD Journal on Budgeting.

Consiglio Superiore dei Lavori Pubblici, Ministero delle Infrastrutture e dei Trasporti (2020), "Linee guida per la classificazione e gestione del rischio, la valutazione della sicurezza ed il monitoraggio dei ponti esistenti", [Microsoft Word - Frontesp-IndiceLLGG17-04-2020 STC.doc (mit.gov.it), 2 APPENDICI.pdf (mit.gov.it)].

Eggert, E.; Pipiou,G.; Fouad, N. and N.Tang (2019), Tools and Methods for Anticipatory Innovation Governance: Enabling a Proactive Public Sector. LSE Capstone and Research Project.

G20 (2021) Policy Agenda on Infrastructure Maintenance - Annex - Infrastructure Maintenance Case Studies. 
GCA (2019) Adapt now: a global call for leadership on climate resilience - Global Center on Adaptation (gca.org) Global Commission on Adaptation report

GIH (2020), Case Study WATER HEIGHT AND FLOOD MANAGEMENT MODELLING.

HM Treasury (2018), Guide to Developing the Project Business Case.

OECD (2021a), Recommendation of the Council on the Governance of Infrastructure, OECD/LEGAL/0460, [https://legalinstruments.oecd.org/en/instruments/OECD-LEGAL-0460].

OECD (2021b), Recommendation of the Council on Public Procurement, OECD/LEGAL/0411, [https://legalinstruments.oecd.org/en/instruments/OECD-LEGAL-0411].

OECD (2021c forthcoming), Digitalising Regulatory Delivery using Emerging Technologies - A Review of Current Practices.

OECD (2021d) OECD Implementation Handbook on Quality Infrastructure: Chapter 4: Subnational governance and investment in infrastructure.

OECD (2020a), Survey on the Governance of Infrastructure.

OECD (2020b), Infrastructure governance review of Spain: supporting better decision-making in transport investment.

OECD (2020c), Executive summary of the Webinar on Strategic planning of infrastructure for the recovery phase, Series of webinars on infrastructure and public procurement experiences and responses to the coronavirus (COVID-19) crisis.

OECD (2020d), Public Procurement and Infrastructure Governance: Initial policy responses to the Coronavirus (COVID-19) crisis, [https://read.oecd-ilibrary.org/view/?ref=135 135391eb6wiwbrmn\&title=Public-Procurement-And-Infrastructure-Governance].

OECD (2019a) Financing Climate Futures.

OECD (2019b), Budgeting and Public Expenditures in OECD Countries 2019.

OECD (2019c), The Path to Becoming a Data-Driven Public Sector, OECD Digital Government Studies, OECD Publishing, Paris, [https://doi.org/10.1787/059814a7-en].

OECD (2018a), Governance of Capital Budgeting and Infrastructure.

OECD (2018b), Developing Robust Project Pipelines for Low-Carbon Infrastructure.

OECD (2018c), Climate Resilient Infrastructure, OECD Environment Policy Paper Nb 14.

OECD (2018d), Critical Infrastructure Framework.

OECD (2017a), Boosting Disaster Prevention through Innovative Risk Governance: Insights from Austria, France and Switzerland, OECD Reviews of Risk Management Policies.

OECD (2017b), Gaps and Governance Standards of Public Infrastructure in Chile.

OECD (2017c), Getting Infrastructure Right: A framework for better governance, OECD Publishing, Paris, [https://doi.org/10.1787/9789264272453-en].

OECD (2015), Climate Change Risks and Adaptation: Linking Policy and Economics.

OECD (2014), Boosting Resilience through Innovative Risk Governance.

Reid, H. and S. Huq (2014), "Mainstreaming community-based adaptation into national and local planning", Climate and Development, Vol. 6/4, pp. 291-292, [http://dx.doi.org/10.1080/17565529.2014.973720]. 
Rijkeb and van Herkb, (2015), Room for the River: a stepping stone in Adaptive Delta Management, International Journal of Water Governance.

Rozenberg, J; Fay, M.. (2019). Beyond the Gap : How Countries Can Afford the Infrastructure They Need while Protecting the Planet. Sustainable Infrastructure;. Washington, DC: World Bank. () World Bank. https://openknowledge.worldbank.org/handle/10986/31291 License: CC BY 3.0 IGO

Tõnurist, P. and A. Hanson (2020), "Anticipatory innovation governance: Shaping the future through proactive policy making", OECD Working Papers on Public Governance, No. 44, OECD Publishing, Paris, [https://doi.org/10.1787/cce14d80-en].

UN Environment, How digital finance favours infrastructure investments, decarbonisation and energy access to all.

WEF (2019), Innovative technologies about to transform our infrastructure. 


\section{Ensuring funding and financing for maintenance and resilient infrastructure}

Delivering systemic change for sustainable and resilient infrastructure requires gaining community support and the social licence to operate infrastructure assets. Given current constraints and future stimulus impact on public budgets, alternative and diversified funding sources are needed with budgetary treatment playing a key role in planning and securing stable funding for infrastructure. Public interventions should also focus on creating incentive schemes to better mobilise private financing.

This chapter looks at funding and financing models for maintenance and resilient infrastructure covering traditional public sources, new alternative options and the involvement of private sector, in particular long term investors as insurers and pension funds. 


\section{Introduction ${ }^{28}$}

Funding to maintain public infrastructure typically relies on government spending. It may involve full or partial subsidy, providing services to users for free or at prices below cost (WEF, 2014). Public sector funding is particularly crucial in accelerating action in difficult to reach areas like adaptation and resilience ${ }^{29}$. However as seen in chapter 1 , lack of reliable and stable funding due to short time horizons, political priorities and pressured public budgets are major barriers to maintenance spending and building resilient infrastructure. Ultimately funding for infrastructure maintenance is both insufficient and insufficiently targeted.

Governments tend to under-estimate and under-plan maintenance expenditure, leading to a shortening of an infrastructure assets' useful life (Halland, 2021). Deferring maintenance can also increase funding gaps as costs increase over time. However, given current constraints and future stimulus impact on public budget, alternative and diversified funding sources are needed with budgetary treatment playing a key role in planning and securing stable funding for infrastructure.

Public interventions should also focus on creating incentives schemes to better mobilise private financing as well as harness private sector expertise or innovations. Different delivery models (feed-in and availability tariffs, premium tariffs, quotas, tenders) and quality of support schemes define the role of the private sector in providing maintenance and operations services. An emphasis on a life-cycle approach could be beneficial in order to attract long-term investors such as institutional investors with an interest in maintaining the value of their assets over time. Ultimately this will drive down the overall costs of projects including operations, maintenance and eventual replacement.

Delivering the systemic change for sustainable and resilient infrastructure, requires gaining community support and the social licence to operate infrastructure assets. A new narrative on infrastructure investing must reconcile the nature of infrastructure as a service with the development of infrastructure as an asset class, with relevant information for infrastructure investors on the sustainability and resilience characteristics of assets in terms of the long-term horizon and of environmental, social and governance (ESG) impacts and risks. To reflect this narrative, alternative models and products need to be developed involving all stakeholders through new forms of collaboration between private, public sectors and communities. The financial sector, applying long-term thinking, has the potential to be a driver of change for the future.

\subsection{Maintenance funding and incentives for optimal operations and management}

Maintenance-related public budget funding ${ }^{30}$ is subject to several challenges. The first one being political capture in case of budget cuts. In addition there is little incentive to make provision for operations and maintenance $(\mathrm{O} \& \mathrm{M})$ relative to new projects and construction outlays. Achieving the lowest-possible initial costs can create inefficiencies on the best option available for resilience.

\footnotetext{
28 This chapter leverages past OECD contributions to the G20, plus recent analysis such as the OECD Business and Finance Outlook, the OECD Implementation Handbook on Quality Infrastructure, and OECD work on capital budgeting.

29 In the United Kingdom, for example the "Decarbonising Transport: Better, greener Britain” published in July 2021, sets the policy options and budget for net zero transport by 2050 , while the National Adaptation Programme focuses on adaptation to climate change challenges over a period of 5 years.

${ }^{30}$ In this section we use the term "financing" for how you meet the upfront costs of infrastructure (equity or debt financing) and "funding" for how you pay the asset over its life-cycle.
} 
Maintenance can be routine in nature, existing as part of operating expenses and drawing on operating budgets, or require more significant capital expenditures which may call for additional capital injections in the form of equity or debt financing.

As discussed in Chapter 4, long-term strategy and vision is needed to build and maintain resilient infrastructure. This is also a requisite to ensure stable expenditure on maintenance across multiple government levels and political cycles. Governments can employ different funding modalities and incentive mechanisms to ensure sufficient and stable funding for maintenance. In particular here below are the main options, following analysis of the Urban Institute (2011), IMF (2020) and WEF (2014):

Earmarking a proportion of user taxes: ad hoc dedicated funds have been used to ensure stable funding to maintain networks. Road funds, for example, are independent entities, usually established through legislation, with a board of directors and obligations associated with planning, reporting, and audits. In the USA, the Highway Trust Fund is a transportation fund receiving money from a federal fuel tax and established in 1956 for highway construction and maintenance ${ }^{31}$. Earmarking limits flexibility in budgetmaking, however, and may limit accountability in the use of funds.

User charges: concessionaires are usually responsible for maintenance and management, primarily financed though revenues collected from users. Long-term concessions as Public Private Partnerships (PPPs), typically includes the construction and maintenance of the asset over the long term. The private sector through revenues generated by tolls (or availability-based systems) is responsible for spending to keep the quality and performance to a certain contracted level. Contractual provisions should ensure that the infrastructure is returned to its original condition, providing an incentive for adequate maintenance.

Land value-capture tools (tax increment financing): infrastructure development that increases the value of nearby properties also increases revenues generated through property taxes which can be diverted to infrastructure projects and used for maintenance spending. For example, transit-oriented development, in which the government owns land, captures the increase in land values (e.g., tax increment financing), or participates as a co-investor, has been adopted as a measure of controlling both land use and transportation as well as participating in the investment (Urban Institute 2011).

Strategic Investment Funds and National wealth funds: several countries have established or are establishing strategic investment funds (SIFs) and national wealth funds to mobilise private capital for infrastructure investment ${ }^{32}$ Investing through a SIF as opposed to channelling investments through the government budget can provide benefits in terms of asset maintenance, as SIFs have an interest in maintaining the value of their assets over time as commercial investors (Halland 2021).

Auxiliary business activities and corporate finance: infrastructure assets such as airports, railways and ports often provide business activities increasing the overall returns from the asset and the available funding for maintenance (WEF 2014). Some entities may also set aside reserves which help to improve long-term financial health, support credit ratings, and ensure the ability to meet maintenance requirements.

Dynamically priced managed lanes or congestion zone pricing: use of the Internet of Things and real time data has opened new sources of revenues for maintenance, allowing also to manage transport demand. For example Stockholm, Singapore and London have implemented congestion pricing with fees varying depending on the time of day and automatic collection using license plate scanning technology. Also, Electronic Toll Collection (ETC systems) are an effective way of applying user and polluter-pay

\footnotetext{
${ }^{31}$ The fund receives money from a federal fuel tax on gasoline and of diesel fuel and related excise taxes. However, it is currently facing difficulties in increasing federal fuel taxes to keep sustaining the adequacy of the fund.

32 The definition of strategic investment fund used here is drawn from Halland et al. (2016) and refers to funds that are fully or partially funded by governments, invest to achieve policy objectives as well as commercial financial returns according to a "double bottom line"; and seek to mobilise additional capital from private investors.
} 
principles. They allow to capture rate of vehicles using the network potentially resulting in an increase in toll revenue, which can be used for the financing of infrastructure (GIH 2020).

Natural disaster funds can be established as financial resources for future climate adaptation and hazard management needs. For example the Mexican government has set up a natural disaster fund to be applied to all sectors but in practice used to repair/rebuild public infrastructure for 80 percent of total resources of which 28percent are highways (Evans and others 2020, FONDEN 2020).

\section{Box 5.1. Maintenance funding}

The growing deficit in maintenance infrastructure push for alternative and diversified mode of funding. Case studies supporting the G20 Policy Agenda on Maintenance provide some examples.

In Switzerland, the law defines earmarked funds through the National Roads and Agglomeration Transport Fund (NAF) and the Railway Infrastructure Fund (BIF) for the benefit of transportation infrastructure, with a clear prioritisation of maintenance and preservation of infrastructure assets. These funds are financed through federal and state budgets, mineral oil and automobile taxes as well as user charges.

In Indonesia, the first two PPP projects are reaching or have reached financial closing in the non-toll road sector namely the Eastern Sumatera Highway Preservation in South Sumatera Province and Eastern Sumatera Highway Preservation in Riau Province. The projects are concession agreements between the Directorate General of Highways and private sector companies, to design, build, finance, operate and maintain (DBFOM) the roads.

In India, the Ministry of Road Transport \& Highways (MoRTH) has encouraged long term road (development), operations, and maintenance contracts through various innovative PPP modes such as Hybrid Annuity Mode (HAM) where the contractor is required not only to build the project, but also to maintain the same for a period of 15 years. In case of already developed roads, the private sector is involved in renovation or other road improvement works through the Toll Operate Transfer (TOT) mode where concessionaires are given responsibility for long term maintenance (15 to 30 years) of the road.

In Mexico, the National Infrastructure Fund FONADIN (the largest concessioner of tollroads network in the country including 57 tollroads with a total length of nearly $5,000 \mathrm{~km}$ ) through a competitive bidding process can hire private firms to operate, maintain and rehabilitate tollroads. The Supervisory Administrator Agent and the Maintainer, Rehabilitator, Operator (MRO) are in charge of operating and maintaining tollroads with defined levels of service.

In Russia, additional income for the development and maintenance of port and coastal infrastructure as public-private partnership could include: port charges or provision of services resulting from the increased (formation of a new) cargo turnover or dimensions of design vessels; additional lease payments received as a result of the improvement qualitative characteristics of the investment.

In South Africa, it exists a Provincial Roads Maintenance Grant to supplement provincial investments for road infrastructure maintenance (routine, periodic and special maintenance). Grant allocations are determined using a formula based on provincial road networks, road traffic and weather conditions. The grant requires provinces to follow best practices for planning, and to use and regularly update road asset management systems. The incentive portion of the grant is based on performance indicators relating to traffic loads, safety engineering and visual condition indicators.

Traffic management revenue through price-based parking is used in municipalities in Ghana to charge motorists based on their usage of a parking facility. Pricing changes based on geographical location of 
the parking space, the time of the day and the demand that exists at a particular point in time. Revenue generated can be used to maintain the facility as well as support other transport-related investments.

Source: G20 (2021) and Obeng D., Tuffour Y. A. (2020), Prospects of alternative funding sourcing for maintenance of road networks in developing countries.

\subsection{Budgetary treatment of infrastructure spending}

In government budgets, infrastructure investment is part of the capital budget, while maintenance expenses are classified as operating expenditure. This prevents several local administrations to finance maintenance through borrowing according to the "Golden Rule". In Europe, also a major issue is that EU Structural and Investment Funds can be used only for construction and upgrade, not for maintenance (OECD 2021 and European Court of Auditors, 2020).

The budgetary treatment of maintenance can integrate capital expenditure with current expenditure or keep them separate. This has different implications with full integration improving planning, facilitating coordination and increasing flexibility, and separate budgets ensuring that mandatory items such as entitlements do not crowd out discretionary items such as capital investment (Posner, 2009).

Governments need to be aware of the inherent challenges of their system in order to ensure that proper mechanisms are in place to address them (OECD 2021), If a government decides to submit capital and current budgets separately, it will need to strengthen the selection mechanisms for capital projects to make certain that line ministries better integrate their capital and current expenditure decisions. If it decides on a unified budget, it should ensure that it is accompanied by guidelines or fiscal rules as well as the political will to limit government borrowing that finances current expenditure (Burger, P. and I. Hawkesworth, 2013). Such an approach requires a medium-term expenditure framework to allow multi-year planning of annual maintenance expenditures.

For example, in Germany, the Federal Transport infrastructure Plan (FTIP) sets out at the federal level an overall strategy plan including for each type of investment (new projects, maintenance, replacement and upgrade) a detailed description of the funds allocated (OECD 2021 and Box below).

\section{Box 5.2. Budget allocations and clear prioritisation: Germany's 2030 Federal Transport Infrastructure Plan (FTIP)}

The Federal Transport Infrastructure Plan (FTIP) is an overall strategy for the development of the Federal Government's transport infrastructure to 2030 with total investment totalling EUR 269.6 bn and a major focus on structural maintenance.

Of the funds from the new FTIP, EUR 141.6 bn will be invested in structural maintenance and replacement representing 69 per ent of the total envelope. This is around EUR 60 bn (EUR 58.9 bn) and thus approximately 71 percent more than the funds which were available under the FTIP 2003 (EUR 82.7 bn for structural maintenance and replacement).

Source: (OECD 2021)

Another challenge for funding maintenance is that responsibilities for building and maintaining assets is usually divided among different levels of government i.e. municipal, departmental, and national. Subnational governments might not have direct funding sources for maintenance nor the capability to 
collect fees. In France for example, the maintenance of national roads is financed by the general national budget, with each department and municipality required to include expenditures for the maintenance of its roads in its annual budget. Department and municipalities have budgetary powers, including the ability to incur debts and the power to impose departmental taxes (see box below).

\section{Box 5.3. Maintenance Funding of roads in Australia and France}

In Australia, of the nation's 810,000 kilometres of public roads, almost 650,000 kilometres ( 80 per cent) are local roads. The Australian Government's Roads to Recovery Program provides funds to local governments for maintenance of the nation's local road infrastructure asset. Funds can be spent according to local council priorities, empowering local government to undertake road maintenance relevant to their communities $(G 20,2021)$.

In France, responsibilities for building and maintaining roads are divided among the three levels of government: national (including motorways), departmental and municipal. Here below we look more in detail to France's experience.

\section{National Roads}

According to Boring (2014), France had about 21,157 kilometres of roads in the national road system as of 2011 , including 11,412 kilometres of highways and 9,745 kilometres of other national roads. The state maintains and manages existing national roads through local agencies called directions interdépartementales des routes (interdepartmental directorates for roads), or DIR. These agencies, of which there are currently eleven, and which fall under the authority of the Ministry of the Environment, Sustainable Development and Energy, are tasked with the maintenance and management of the national road system. The maintenance of national roads is financed by the general national budget, by co-financing from local authorities (municipal, departmental, or regional governments), and by the Agence de financement des infrastructures de transports de France (AFITF).

\section{Departmental Roads}

Each département is responsible for funding the layout, construction, and maintenance of the departmental roads $(377,857$ kilometres) within it. The general councils of the départements are then required to include expenditures for the construction and maintenance of the departmental roads in their yearly budgets. The general councils have fairly extensive budgetary powers, including the ability to incur debts and the power to impose departmental taxes. These may include taxes on motor vehicles, but the proceeds of such taxes are not necessarily tied to expenditures on road infrastructure.

\section{Municipal Roads}

France has 654,201 kilometres of municipal roads. Each municipality is required to include expenditures for the maintenance of its municipal roads in its yearly budget. Municipalities can generate revenue from various local taxes, or from nontax revenue sources, such as fines and revenue income from investments. Spending on municipal roads does not appear to normally be tied to any specific type of revenue.

Source: G20 (2021) and Boring N. (2014) National Funding of Road Infrastructure: France, Library of the Congress:

https://www.loc.gov/law/help/infrastructure-funding/france.php

Private sector financing can create contingent liabilities for governments, that are triggered - as in the case of the COVID-19 pandemic - when demand for the asset diminishes. Discretionary funding of infrastructure maintenance leads to a pro-cyclical expenditure subject to budget pressure, rather than a counter-cyclical 
funding strategy to promote economic activity at times when infrastructure assets are underutilised (and thus easier to maintain).

In addition to assuring public funding of maintenance, governments can better incentivise the management of infrastructure assets through their accounting treatment, for example by reducing depreciation on wellmaintained assets.

\subsection{Delivery models and life-cycle approach for the private sector}

Demand for infrastructure investment by the private sector is influenced by the potential revenues that investors can earn from the project and the associated risks. Profitable projects with well-defined revenue streams (e.g. renewable energy) and network effect have a strong potential for private financing, while those where a revenue stream is not available (e.g. financing climate proofing of existing infrastructure, or certain climate-resiliency assets such as flood protection), or predictable (e.g. financing of basic infrastructure projects in developing countries with weak regulatory frameworks), may not be attractive for private investors.

Investment and financing activity for low carbon infrastructure can be analysed from a private sector point of view, at different levels (OECD 2020c, OECD 2017):

- Financial structures: private capital is provided in two main forms, corporate finance (financed on 'balance sheet') and project finance (external finance).

- Delivery models: including different forms of regulation from SOEs to fully privatised companies to PPPs and concessions.

- Financing phase: investment activity can be split across the value chain into primary financing associated with new activity in mature assets (e.g. greenfield projects, asset finance); secondary market finance relating to existing assets, including refinancing and $M \& A$.

Figure 5.1. Dimensions of Infrastructure Financing

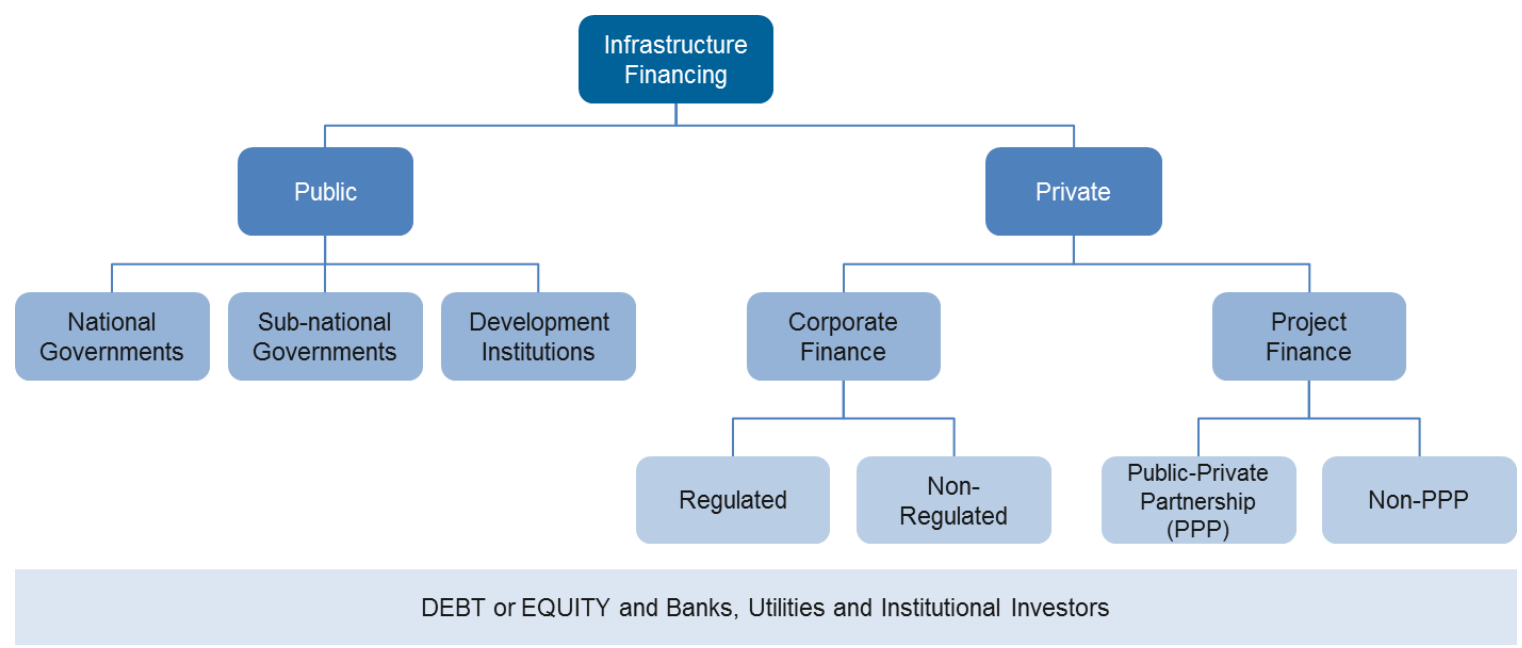

The delivery model and contractual scheme influence the risks the private sector will face and the responsibility for provision of services and financing among different stakeholders. There are a number of delivery models which have different roles for the public and/or private sector over the infrastructure asset including (i) public ownership and procurement; (ii) concessions and public private partnerships; and (iii) state owned enterprises (SOEs); and fully privately-owned companies. 
For example, Saudi Arabia has been introducing delivery models for Private Sector Participation (PSP) in the electricity sector. Privatisation and market liberalisation models include principal buyer independence and increased unbundling of the generation/distribution/retail business. Aim of these measures is to ensure: clear arm's length commercial agreements for critical value chain interfaces, equal third-party access to the transmission network, impartial procurement of new generation capacity and energy (G20, 2021).

For concessions and PPPs, different contractual schemes will determine the allocation of risks, responsibilities and financing from private sector institutions including for maintenance. As described by Gatti (OECD, 2014) on the one hand, there are O\&M services (the O\&M, Design \& Build and Turn-Key schemes) provided by the private sector where the ownership of the facility remains with the public sector. The only risk shifted to the private sector is the operational risk, as the construction/investment and commercial risks are retained by the public sector. On the other hand, is the full exit of the public sector from the businesses through asset sales/divestitures or privatisation processes. The private sector gains full control of the assets and assumes all risks involved in the deal.

In the Regulated Asset Base (RAB) model, the investment is guaranteed through the assets' revenue stream and the regulatory framework, while risks are passed to the users. Makovšek (2018) and Buckberg (2016) look at whether the Regulated Asset Base model, used for example in the water and electricity sectors, could be applied to other type of infrastructure financing models, such as concessions. According to Newbery, D. \& others (2019) in the case of the Thames Tideway Tunnel in the UK, the application of a hybrid RAB mode ${ }^{33}$ allowed to reduce risk lower than the cost of capital by accessing infrastructure funds with limited project expertise and capabilities. Helm (2009), as well as Helm and Tindall (2009), consider how the RABs can be developed to provide credible long-term contracts over a wide range of activities, suggesting three solutions to the exhausted balance sheets are considered to finance future investment: rate-of-return regulation; the split cost of capital; and a not-for-dividend, mutual or state ownership (Welsh Water and Network Rail).

\subsection{ESG risk disclosure for institutional investor's investment in resilient infrastructure}

A growing number of investors are integrating environmental, social, and governance (ESG) considerations in their investments as a tool for managing ESG-related risks and opportunities (OECD, $2020)^{34}$. As investors with a typically long-term horizon, institutional investors have a particular incentive to consider ESG factors in unlisted infrastructure, as sustainability consideration would be more important to take into account. Asset allocation decisions increasingly reflect an interest for active investing and a variety of ESG integration approaches for infrastructure.

Corporate engagement and shareholder action is a popular and growing strategy among infrastructure investors in private markets. Relevant for infrastructure, the range of active strategies focused on sustainability as an investment outcome includes thematic and impact investing. In some cases, institutional investors are evolving their investment frameworks to align their investment strategies with broader environmental or development objectives such as the United Nations Sustainable Development

\footnotetext{
33 with excess cost sharing and a cost cap.

${ }^{34}$ Environmental, social and governance (ESG) investment, sustainable investment, socially responsible investment, impact investment, moral investment and other terms are being used more or less synonymously to define the practice of incorporating ESG factors in investment decisions. For more on this see Chapter 4 and 7 of the OECD 2020 Business and Finance Outlook.
} 
Goals (SDGs), or environmental issues more broadly as part of their investment framework and/or thematic investment ${ }^{35}$.

Despite broad recognition of the importance of ESG criteria and interest in incorporating these factors into infrastructure investment decision-making, the implementation of these criteria in asset valuation remains at an early stage. Several international standards and tools have been developed to integrate sustainability and resilience aspects into infrastructure development and support ESG infrastructure asset analysis. Current methods for ESG measurement and ESG-related analysis vary among stakeholders at different phases in the infrastructure process.

The availability of clear and timely data helps investors assess the expected risk-return profile. Using InfraTech solutions to better gather and analyse data will help to mobilise private sector investment and potentially lower financing costs. Furthermore, providing more standardised information would allow governments to better understand and respond to investor interest. As highlighted in the G20 Principles for Quality Infrastructure developed in 2019, both positive and negative impacts of infrastructure projects on ecosystems, biodiversity, climate, weather and the use of resources should be internalised by incorporating these environmental considerations over the entire process of infrastructure investment, including by improving disclosure of these environment related information, and thereby enabling the use of green finance instruments.

\subsection{Leveraging capital markets and private sector resources}

New financing models and vehicles could help countries facing the current economic downturn by increasing private sector investment in resilient infrastructure, widening the range of investors and increasing transparency and stakeholder participation. Innovative partnerships have been launched to invest in resilient infrastructure and financing models are emerging.

Major challenges for private sector investors in resilient infrastructure are related to accessing the investment opportunities given the small scale of investment for maintenance spending and the lack of revenues for projects such as flood defences making it difficult to monetise benefits.

Access to, and transparency of, infrastructure investment could be widened by pooling assets though financial vehicles such as securitisation, yieldcos and listed fund structures. Aggregating portfolios of loans from the balance sheet of banks, securitisation products are well suited to refinance small scale assets such as distributed solar PV or efficiency projects. Aggregation allows to attract institutional investor while diversifying risk and lowering the cost of capital. In the USA, by bundling the replacement of over 500 bridges in a single availability-based P3 procurement and by applying asset management best practices throughout the 25-year concession period, the Pennsylvania Department of Transport created efficiencies through economies of scale while minimising environmental impacts and public inconvenience during construction (G20 2021).

Social impact bonds (SIBs) or Sustainability bond with impact-linked return (SBIR) are innovative financial instruments to unlock social impact investing, which advances the potential to drive public sector change and to attract a broader range of investors, while also financing social infrastructure. The overall goal is to expand investor base for impact investing and build public sector capacity to tackle various social challenges (OECD, Observatory of Public Sector Innovation Observatory of Public Sector Innovation (oecd-opsi.org)). SIBs first launched in the UK, have been replicated in other countries such as the United States, Canada, Israel, and Australia. Similar to social impact bonds, development impact bonds (DIBs) also finance development initiatives, but in lower income countries. Both SIBs and DIBs are performancebased instruments and pay back based on the achievement of agreed development goals (OECD, 2015).

\footnotetext{
35 in June 2020, the European Union adopted a Regulation on the establishment of a framework to facilitate sustainable investment, usually referred to as "the EU taxonomy".
} 


\section{References}

Bhattacharya A., Meltzer P., Oppenheim J, Qureshi Z, and Stern N, (2016), Delivering on sustainable infrastructure for better development and better climate December 23, 2016.

Boring N. (2014), National Funding of Road Infrastructure: France, Library of the Congress: https://www.loc.gov/law/help/infrastructure-funding/france.php .

Buckberg; E. (2016), Expanding the market for infrastructure private partnerships - Alternative risk and profit sharing approaches to align sponsor and investor interest US Treasury.

Burger, P. and Hawkesworth, I., (2013), Capital budgeting and procurement practices, OECD Journal on Budgeting.

Della Croce, R and Sharma, R. (2014), "Pooling of Institutional Investors Capital, Selected Case studies in Unlisted Equity Infrastructure", OECD Working Papers on Finance, Insurance and Private Pensions, No.38, OECD.

Della Croce, R. (2014), I.6. Are institutional investors the answer for longterm development financing?, OECD Publishing , Paris, [http://dx.doi.org/10.1787/888933121601].

Evans, C., Godart, B., Kovarik, J.B., Mendoza, J.F. and Palhol, F. (2020). Evaluating Resilient Infrastructure Systems, T20 Policy Brief, Saudi Arabia.

European Court of Auditors (2020), The EU core road network: shorter travel times but network not yet fully functional.

FONDEN (2020), General Directorate for Risk Management. 2020. Resources Authorized by Disaster Declaration. FONDEN.

G20 (2021) Policy Agenda on Infrastructure Maintenance - Annex - Infrastructure Maintenance Case Studies.

G20 (2019), Principles for Quality Infrastructure Investment.

G20 (2018), Roadmap to Infrastructure as an Asset Class.

Gallego-Lopez, C., and Essex, J. (2016a), Understanding Risk and Resilient Infrastructure Investment. Evidence on Demand, UK. 33 pp.

Gallego-Lopez, C., and Essex, J., (2016b), Designing for Infrastructure Resilience. Evidence on Demand, UK. 26 pp. [DOI:

Gatti, S (2014), "Government and Market Based Instruments and Incentives to stimulate Long Term Investment Finance in Infrastructure, OECD Working Papers on Finance, Insurance and Private Pensions, No. 37, OECD publishing.

Garcia S. and Whittaker T. (2019), ESG Reporting and Financial Performance: the Case of Infrastructure, EDHEC Infrastructure.

Gelb A., Tordo S., Halland H., Arfaa N., Smith G. (2014), "Sovereign Wealth Funds and Long-Term Development Finance: Risks and Opportunities, February 2014. World Bank Policy paper.

Gottschalg, O. and Phalippou L. (2009), The Performance of Private Equity Funds. In Review of Financial Studies, 2009, 22: 1747-1776.

Haldane A., May R. (2011), Systemic Risk in Banking Ecosystems, Nature 469 (7330):351-5.

Halland H (2021), The Fiscal implications of Strategic Investment Funds OECD Development Centre. 
Helm D., Tindall T. (2009), The evolution of infrastructure and utility ownership and its implications, Oxford Review of Economic Policy, Volume 25, Number 3, 2009, pp.411-434.

Helm D. (2009), Infrastructure investment, the cost of capital, and regulation: an assessment, Oxford Review of Economic Policy, Volume 25, Number 3, 2009, pp.307-326.

HMTreasury(2019), 'Spending Round 2019', September 2019, p.15-19, [https://assets.publishing.service.gov.uk/government/uploads/system/uploads/attachment_data/file/8291 77/Spending_Round_2019_web.pdf.].

IMF (2020), Well Spent.

Makovšek D. (2018), The Regulatory Asset Base Model, the Project Financing Model, and the proposition for a merger of concepts OECD/International Transport Forum working paper.

Newbery, D. \& Pollitt, M. \& Reiner, D. \& Taylor, S., (2019). "Financing low-carbon generation in the UK: The hybrid RAB model," Cambridge Working Papers in Economics 1969, Faculty of Economics, University of Cambridge.

Obeng D., Tuffour Y. A. (2020), Prospects of alternative funding sourcing for maintenance of road networks in developing countries.

OECD (2021) OECD Implementation Handbook for Quality Infrastructure Investment: Supporting a Sustainable Recovery from the COVID-19 Crisis, https://www.oecd.org/finance/OECDImplementationHandbook-for-Quality-Infrastructure-Investment.htm

OECD (2020a), G20/OECD Report on the Collaboration with Institutional Investors and Asset Managers on Infrastructure: Investor Proposals and the Way Forward.

OECD (2020b), Green Infrastructure in the Decade for Delivery: Assessing Institutional Investment, Green Finance and Investment, OECD Publishing, Paris, [https://doi.org/10.1787/f51f9256-en].

OECD (2020c), Business and Finance Outlook: Sustainable and resilient finance, Chapter 7 "ESG and Institutional investment in Infrastructure".

OECD (2019a), Good Governance for Critical Infrastructure Resilience, OECD Reviews of Risk Management Policies, OECD Publishing, Paris, [https://doi.org/10.1787/02f0e5a0-en].

OECD/IMF (2019b), Reference Note on the Governance of Quality Infrastructure Investment.

OECD (2018) Climate Resilient Infrastructure, OECD Environment Policy Paper Nb 14

OECD (2017), Investing in Climate, Investing in Growth.

Posner, P., S. Ryu and A. Tkachenko (2009), "Public-private partnerships: The relevance of budgeting", OECD Journal on Budgeting, vol. 9/1, [https://doi.org/10.1787/budget-v9-art3-en].

Urban Institute (2011), Funding and Investing in Infrastructure, by Michael A. Pagano College of Urban Planning and Public Affairs University of Illinois at Chicago December 2011.

World Bank (2019), Lifeline: the resilient infrastructure opportunity.

WEF (2014), Strategic Infrastructure, Steps to Operate and Maintain Infrastructure Efficiently and Effectively. 


\section{Building resilience - \\ New Strategies for Strengthening Infrastructure Resilience and Maintenance}

Following the COVID-19 shock to economies and societies, many countries are renewing infrastructure investment as a stimulus measure. Such investments present an opportunity for govemments to address short-term infrastructure challenges through maintenance spending while building resilient and sustainable infrastructure for the future. Infrastructure resilience and maintenance requires a multidimensional approach, considering a range of factors and stakeholders at the local, regional, national and global levels to identify trade-offs among objectives and enable more robust policy choices. Drawing on examples and case studies, this report provides a framework for optimising existing infrastructure assets and building new resilient infrastructure. It also includes strategies for ensuring quality and performance over an asset's lifecycle. 